\title{
CHAMBER MUSIC EXPLORATIONS FOR MEDITATION
}

\author{
JANOS ZSOLT IMRE
}

\author{
A THESIS SUBMITTED TO \\ THE FACULTY OF GRADUATE STUDIES \\ IN PARTIAL FULFILMENT OF THE REQUIREMENTS \\ FOR THE DEGREE OF \\ MASTER OF ARTS
}

\author{
GRADUATE PROGRAM IN MUSIC \\ YORK UNIVERSITY \\ TORONTO, ONTARIO
}

APRIL 2017

(C) JANOS IMRE, 2017 


\begin{abstract}
The thesis presents and examines my compositional process and creative methodology in producing three compositions for meditation purposes. The purpose was to compose three original pieces of chamber music that created a subjective musical picture that captured a mood and a depictive sound. For each work the author describes his intention for the composition and analyses the compositional elements such as melody, harmony, and thematic construction. A brief history and an overview of meditation is included, followed by an illustration on music and its elemental effect on meditation.

This work examines the concepts of, and serves as an exercise in exploring, a variety of compositional techniques.
\end{abstract}




\section{Acknowledgements}

I would like to thank my supervisor Al Henderson for his guidance and direction while writing this thesis, as well as Mark Chambers for his additional guidance. I would also like to acknowledge the guidance and wisdom provided by Frank Falco and Bob Shields. My gratitude is also due to Terre Tilban-Rios for her expertise and commitment. Lastly, I give my special thanks to my wife, Kate, for her incredible patience and unconditional support throughout this endeavour. 


\section{Table of Contents}

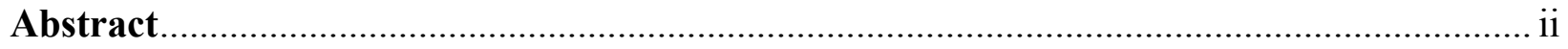

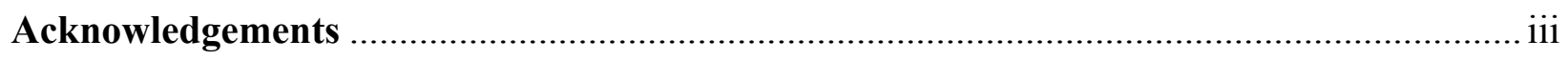

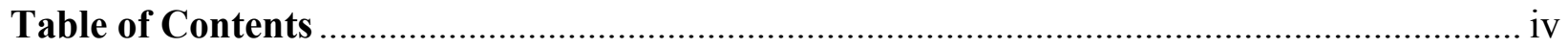

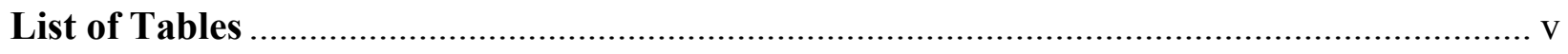

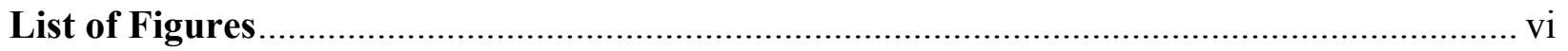

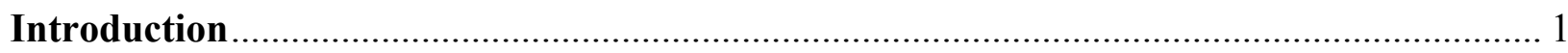

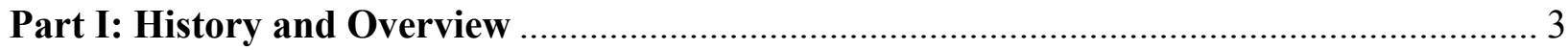

The Meaning and Benefits of Meditation ......................................................................... 3

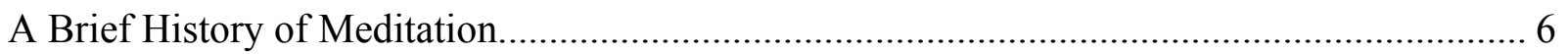

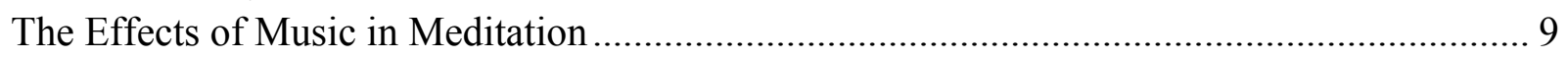

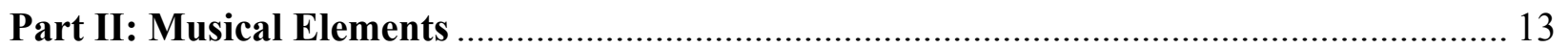

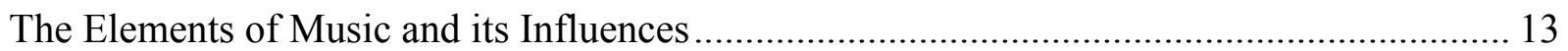

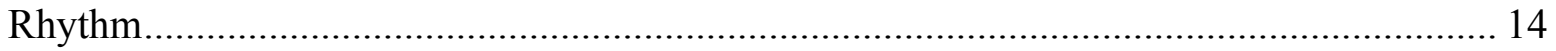

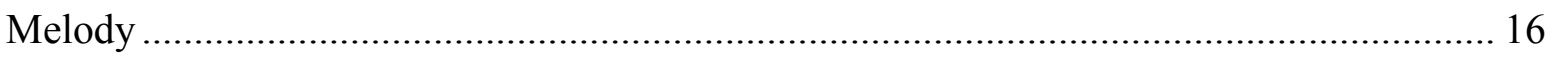

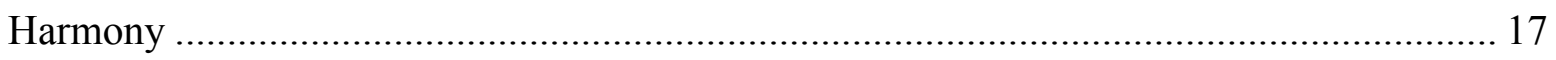

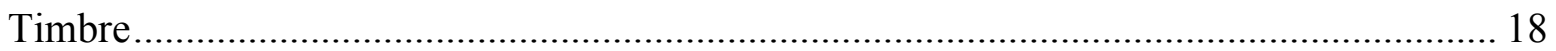

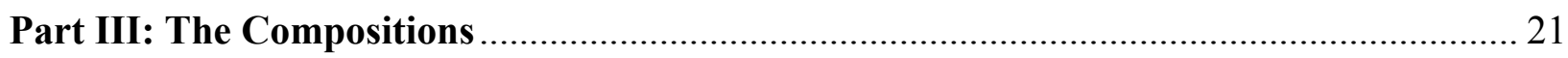

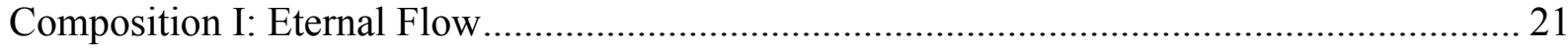

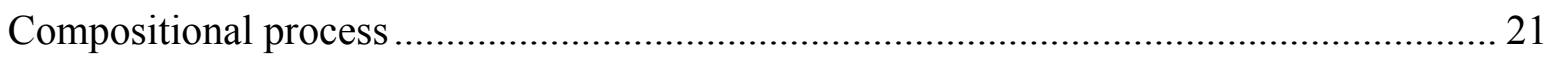

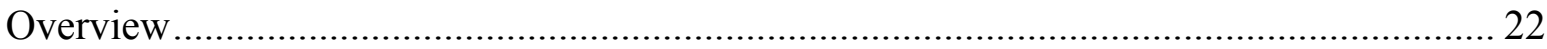

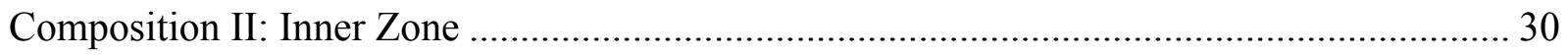

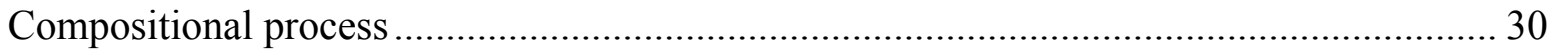

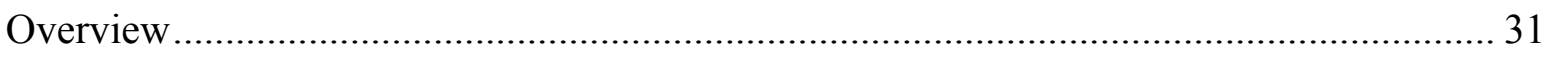

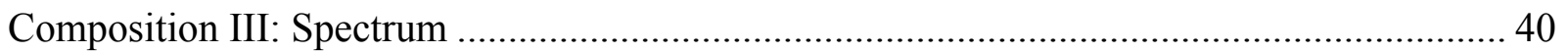

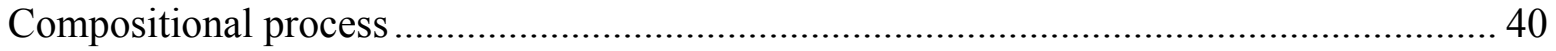

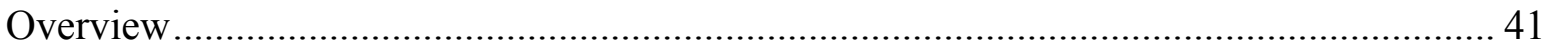

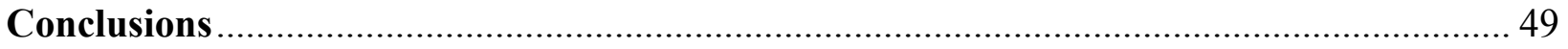

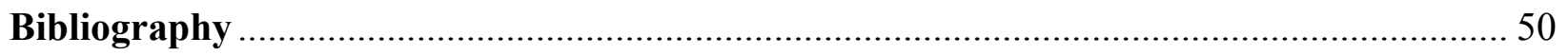

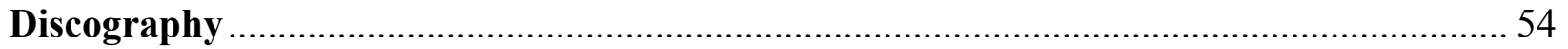

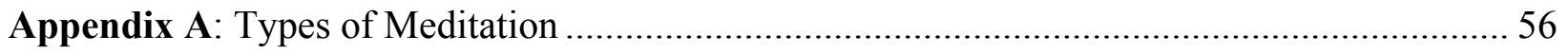

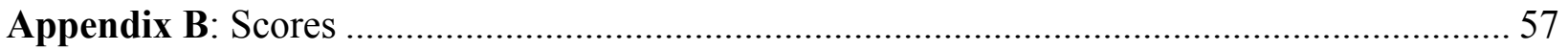




\section{List of Tables}

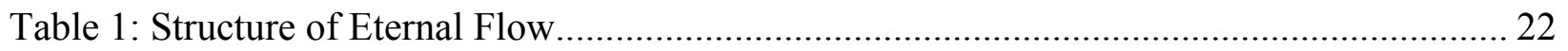

Table 2: Eternal Flow's first part sections .......................................................................... 22

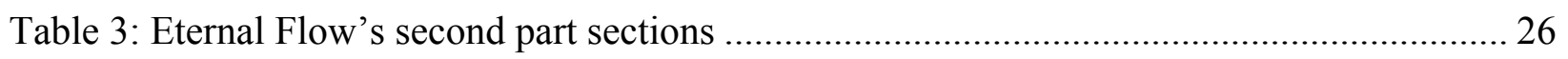

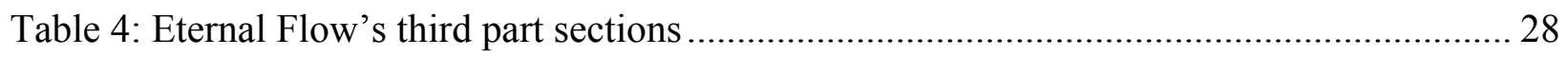

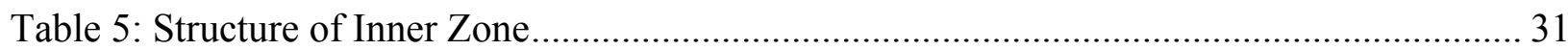

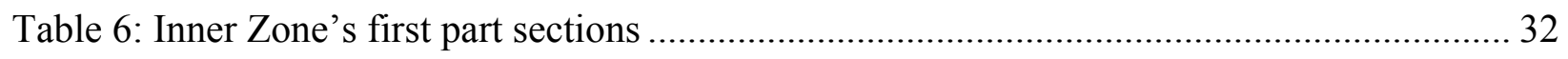

Table 7: Inner Zone's second part sections....................................................................... 35

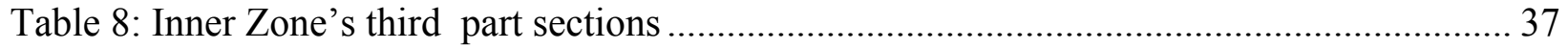

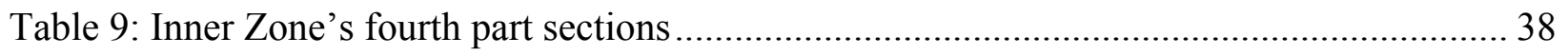

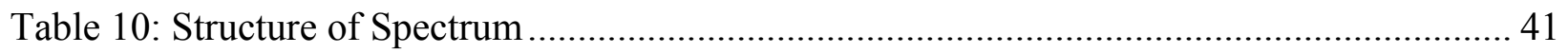




\section{List of Figures}

Figure 1: The first motivic unit --- 23

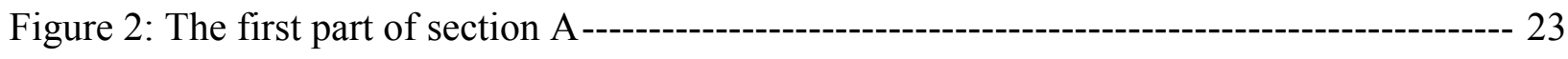

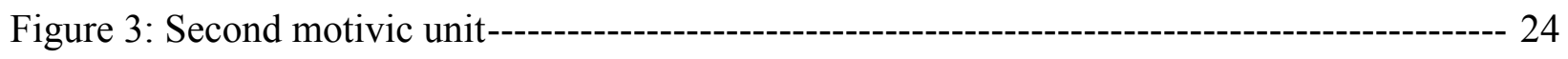

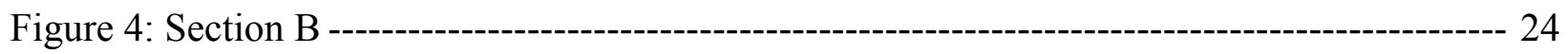

Figure 5: The first part of section $\mathrm{A}_{1}-{ }_{-}$

Figure 6: First six measures of section C -------------------------------------------------------------- 26

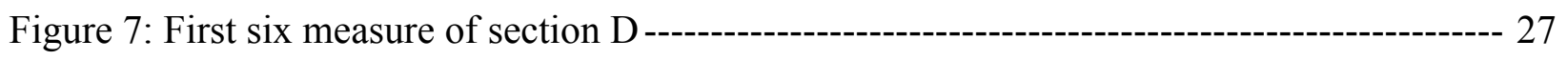

Figure 8: Last four measures of section D---------------------------------------------------- 27

Figure 9: Inner Zone's mantra motif ------------------------------------------------------------- 32

Figure 10: First melody theme --- 33

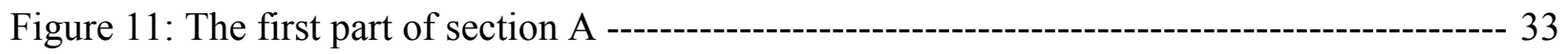

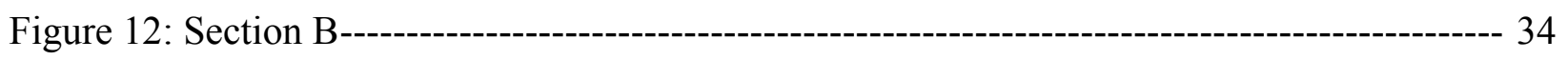

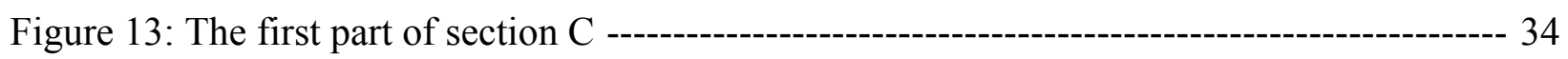

Figure 14: The first part of section $\mathrm{A}_{1}$--1 36

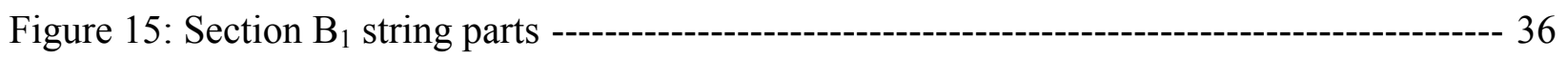

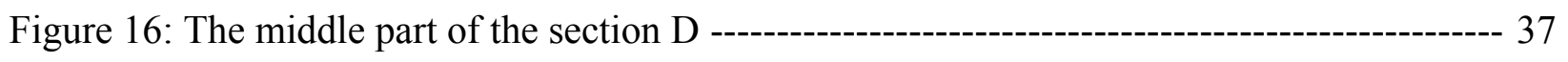

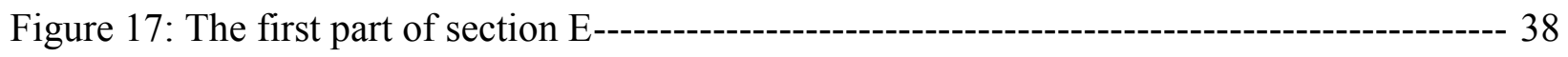

Figure 18: Spectrum's mantra pattern -------------------------------------------------------------- 42

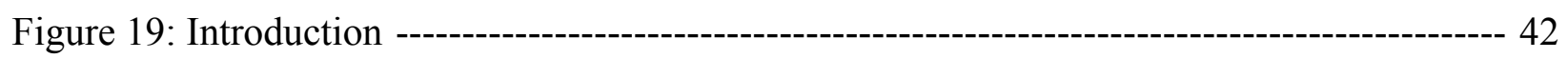

Figure 20: The first melodic theme---------------- 42

Figure 21: Second melodic theme ------------- 43

Figure 22: Harmonic motion ----------------------------------------------------------------- 43

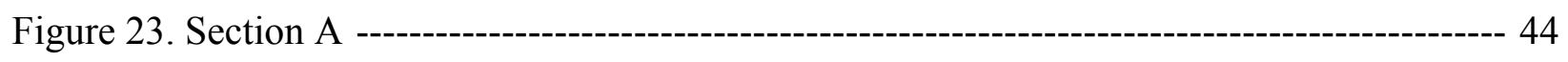

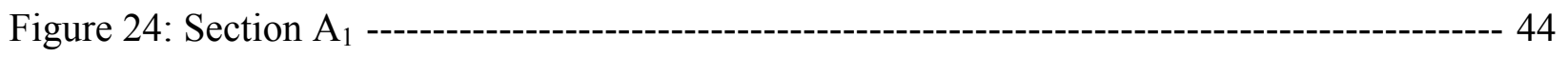

Figure 25: The first part of section B --------------------------------------------------------- 45

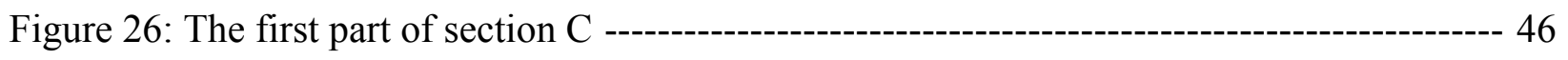

Figure 27: The second part of section C ---------------------------------------------------------- 46

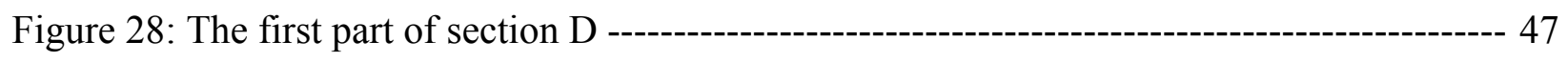

Figure 29: The second part of section D-1- 47 


\section{Introduction}

Music evokes a wide range of feelings, from excitement to relaxation, enjoyment to sadness, fear to relief, and even mixtures of these.

The following paper will present three exploratory compositions and related research prepared for the fulfillment of requirements for the degree of Master of Arts.

Over the course of the past several years, I have been engaged in meditation and I have found myself increasingly connected to this practice. As my meditation experience has evolved I became interested in writing music for meditation that would allow me to explore, experiment and grow musically, and hopefully would provide material to use in my meditation practices. These works will not only examine these ideas, but will serve as an exercise in exploring a diversity of compositional techniques and to capture moods and depictive sounds. This paper will analyze and discuss the genesis and structure of each piece, as well as the compositional elements of melody, harmony, form, thematic construction, which are used to create music for meditation.

The paper is divided into three parts. The first part will focus on background research about meditation. It includes an overview of meditation including a short history, its origins, the effects of music and its benefits in meditation. The second part briefly discusses the music elements and its influences. The third part of the paper describes and analyses the musical compositions. Each piece is deliberated in detail, to provide an understanding of the creative process and devices used in preparing, framing and composing the pieces. The pieces are written for string quartet and percussion instruments. The result of this work is the creation of new pieces that fulfill the purpose and a practical illustration of compositional processes. 
I have been inspired and influenced by the great works of composers such as Haydn, Mozart, Beethoven, Debussy, Bartók, Mahler, Ravel, Copeland, Arvo Pärt, Pauline Oliveros, Tom Scott, Steven Halpern, and many others. 


\section{Part I: History and Overview \\ The Meaning and Benefits of Meditation}

The word meditation is used to define practices that self-regulate the mind and body. It is one of the oldest and most widely practiced mind-body therapies. ${ }^{1}$ The term meditation carries different meanings in different contexts. The Cambridge Dictionary defines meditation as the act of giving your attention to only one thing, either as a religious activity or as a way of becoming calm and relaxed. ${ }^{2}$ On the other hand, Wilson and Cummings define meditation as a state of complete mindfulness, living in the 'here and now'.

Meditation is a practice of concentrated focus upon a sound, music, object, visualization, the breath, body part, movement, or attention itself in order to increase awareness of the present moment, reduce stress, promote relaxation, and enhance personal and spiritual growth. ${ }^{4}$

Meditation techniques are classified by the way in which they focus attention. These two main categories are 'focused attention' and 'open monitoring,.

With 'focused attention', the mind is directed at a single object during the meditation session. This object could be the breath, a mantra, part of the body, an external object, sound etc. Examples of meditation styles based on focused attention are: Chakra Meditation, Guided Meditation, Zen Meditation, Transcendental Meditations. ${ }^{67}$

With 'open monitoring', instead of directing the attention at any one object, the meditator

\footnotetext{
${ }^{1}$ Michael J. Baime, Meditation and Mindfulness. In Essentials of Complementary and Alternative Medicine. (New York, 1999), 522.

2 "The Cambridge Dictionary", “meditation”, accessed December 15, 2016, http://www.dictionary.cambridge.org/dictionary/english/meditation.

${ }^{3}$ Vietta E. Wilson and Mark S. Cummings. Learned Self-Regulation (Toronto, 2015).

4 "Consumers, Dorland's Medical Dictionary for Health. The Free Dictionary, accessed Nov. 7, 2016, http://medical-dictionary.thefreedictionary.com/meditation.

${ }^{5}$ Antonio Raffone and Narayanan Srinivasan, "The exploration of meditation in the neuroscience of attention and consciousness." Cognitive Processing 11 (2010): 1-7.

${ }^{6}$ Ibid.

${ }^{7}$ Appendix A.
} 
cultivates an objectless awareness, monitoring the content of ongoing experience, without judgment or attachment. All perceptions, internal (thoughts, feelings, memory, etc.) or external (sound, image, etc.), are acknowledged and seen for what they are. Examples of open monitoring meditation styles are: Mindfulness Meditation, Vipassana Meditation, Taoist Meditation. ${ }^{89} 10$

Although it is not essential to play music while meditating, several meditation styles are practiced to the accompaniment of music. Certain types of music can affect human emotions, mood, and mental perspective, and can create an ideal atmosphere for the individual to focus on the act of meditation. Examples of meditation styles that use music while meditating are: Mindfulness Meditation, Guided Meditation, Sound Meditation, Zen Meditation. ${ }^{10}$

Meditation is used to clear the mind and to achieve a state of thoughtless awareness without decreasing effectiveness and alertness. All meditation methods serve one goal to slow down and stop the continuous activity of our minds. Musical elements such as the pulse, rhythm, melody and instrumentation can aid in achieving this state.

Meditation can also incorporate a mantra. Mantras are an essential part of some meditation practices. The term mantra can be defined as a word, group of words, a syllable or a sound that is often repeated to anchor the mind in the present moment, to sustain it from wandering off, and to aid concentration during the meditation. A mantra may or may not have descriptive structure or literal meaning. The most basic and important mantra is Om, which in Hinduism is known as the source of all mantras, the sound of the universe. ${ }^{11}$ John Coltrane recorded an album based on the $\mathrm{Om}$ mantra. ${ }^{12}$ In reciting a mantra, such as $\mathrm{Om}$, the meditator tends to diminish the mental chatter, decreasing the continuous activity of the mind. The goal of

\footnotetext{
${ }^{8}$ Raffone and Srinivasan, The exploration of meditation, 1-7.

${ }^{9}$ Rael B. Cahn and John Polich. "Meditation states and traits." Psychological Bulletin 132. (2006):180-211.

${ }^{10}$ Appendix A.

${ }^{11}$ Hazrat Inayat Khan, The Mysticism of sound and music (Boston: Shambhala, 1996).

${ }^{12}$ John Coltrane, Om. Impulse! 39118. 1968. CD.
} 
the mantra is to help the mind to become more unified, less scattered, more attentive and present.

Mantras can be incorporated in music, as well. Using a repeated series of notes can provide a mantra effect. These sound or sonic mantras could help the meditator concentrate during the meditation practice. In music, a repeated melodic or rhythmic figure called an ostinato can be reflected as a mantra. Examples of music that uses mantras or music patterns as a mantra include: Steven Halpern - Om Zone VII, ${ }^{13}$ John Coltrane - A Love Supreme, ${ }^{14}$ Arvo Pärt Spiegel im Spiegel, ${ }^{15}$ Maurice Ravel - Bolero. ${ }^{16}$

The benefits of meditation could be physical, mental, emotional or spiritual. Meditation can benefit individuals with or without severe medical illness or stress. Nonetheless, meditation helps to maintain a healthier body, improves the immune system and energy level, improves breathing and heart rates, reduces blood pressure, and can diminish heart and brain problems. ${ }^{17}$ Studies show that individuals who meditate have demonstrated less depression, anxiety, and stress. Meditation can also help to calm the mind, to improve concentration, lead to a deeper level of physical relaxation, increase creativity, increase self-actualization, and enhanced personal and spiritual growth. Listening to music while meditating can help balance the emotions, and can improve concentration. Music can produces pleasant feelings and those feelings supplied by music while meditating can help to reach a deeper state of meditation.

\footnotetext{
${ }^{13}$ Steven Halpern, In the Om Zone. Halpern Inner Peace. 8030. 2007. CD.

${ }_{15}^{14}$ John Coltrane, A Love Supreme. Impulse! B001097002. 1965. CD.

${ }^{15}$ Arvo Pärt, Arvo Pärt Portrait. Angèle Dubeau \& La Pietà. Analekta. 28731. 2010

${ }^{16}$ Maurice Ravel, Ravel: Bolero. Arthur Fiedler \& The Boston Pops Orchestra. Sony M. 00004TCP7. 2000. CD.

${ }^{17}$ Yadneshwar Khobragade, Sujata Khobragade and Adinegara bin Lutfi Abbas. "Hypertension and meditation." Int. Journal of Community Medicine and Public Health 3. (2016):1685-1695.
} 


\section{A Brief History of Meditation}

Meditation has been present in human life for thousands of years. It is often found in a religious context. The earliest form of meditation dates back anywhere between $5000-3500$ BCE. Researchers suggest that it was common practice for older civilisations to use repetitive, rhythmic chants (nowadays commonly called mantras) in attempts to pacify the gods. ${ }^{18}$ The earliest written records on meditation can be found in the Hindu tradition. These records contain scriptures which describe the meditative traditions of ancient India. ${ }^{19}$

Other forms of meditation developed between the sixth to fifth centuries BCE, through Taoism in China, and Jainism and Buddhism in India and Nepal. ${ }^{20}$ All these religions practiced meditation in an attempt to achieve enlightenment and spiritual development.

When the Common Era (current era, A. D.) started, the practice of meditation would spread quickly due to its relationship with multiple religions. Meditation began to spread to other countries in East Asia mostly through Buddhism. After transmitted to China, Buddhism spread to Vietnam, Korea, and Japan, where it become known as Japanese Zen. ${ }^{21}$ While Buddhism reached other countries, each region enhanced their own interpretation, and established their own way of practicing it.

Various forms of meditation have been present for centuries in all major religions. There are indications in the Tanakh (the Hebrew Bible), that Judaism contained a central meditative tradition Hitbodedut, ${ }^{22}$ while later, in Islam, the practice of Sufism included meditative

\footnotetext{
${ }^{18} \mathrm{Jr}$. George S. Everly and Jeffrey M. Lating, A clinical guide to the treatment of human stress response (New York: Springer, 2013).

${ }^{19}$ Ibid.

20 Ibid.

${ }^{21}$ Peter Harvey, An Introduction to Buddhism. Teachings, history and Practices. (Cambridge: Univ. Press, 1995).

${ }^{22}$ Aryeh Kaplan, Jewish Meditation (New York: Schocken Books, 1985).
} 
techniques, and its followers practiced controlled breathing and the repetition of holy words. ${ }^{23}$ In Christianity, many practices are considered forms of meditation. Forms of introspective thinking can be found in counting rosary beads and the Adoration, which focuses on the Eucharist. Also, Christian monks who spent most of their lives in monastery cells contemplating God, can be considered to practice a form of meditation. ${ }^{24}$

During the 18th century, meditation (and Buddhism) became a subject of discussion for intellectuals in Europe such as the German philosopher Schopenhauer and the French writer, philosopher Voltaire. ${ }^{25}$ Meditation found its way into Britain through translations of scriptures from various Buddhist schools in different parts of east Asia. ${ }^{27}$

At the beginning of the 20th century Asian Buddhist masters and educators of the Zen, Tibetan and Theravada traditions and principles emigrated to the United States and Canada in order to promulgate their beliefs and their meditative practices. ${ }^{28}$

An enormous interest in meditation began after the Second World War. Many soldiers who served in the Pacific during the war had intimate contact with local cultures. When they returned home they brought meditation with them and the practice of meditation increased.

The number of meditation centres started to grow exponentially during the 1970s. Today, dozens of websites offer meditation practice and meditation techniques for millions of practitioners around the world. However, after decades of scientific study and research, the exact mechanism at work in meditation remains unclear. ${ }^{29}$

In the 1960s and 1970s numerous academics, scholars and scientific researchers started to

\footnotetext{
${ }^{23}$ John Bowker, The Concise Oxford Dictionary of World Religions (Oxford: Oxford University Press, 2000).

${ }^{24}$ Herbert Benson, The Relaxation Response (New York: Morrow, 1975).

${ }^{25}$ Peter Abelson, Schopenhauer and Buddhism (Honolulu: University of Hawaii Press, 1993).

${ }^{26}$ Derek Beales, Enlightenment and Reform in Eighteenth-Century Europe (London: I. B. Tauris \& Co. Ltd, 2005).

${ }^{27}$ Diana St. Ruth, BBC UK, Religions. accessed November 15, 2016 http://www.bbc.co.uk/religion/religions/buddhism/history/britishbuddhism_1.shtml

${ }^{28}$ Rick Fields, How the swans came to the lake (New York: Shambhala, 1981).

${ }^{29}$ Everly and Lating, A clinical guide to the treatment of human stress response.
} 
investigate the effects of meditation and its benefits. Spiritual and secular forms of meditation have been the subject of scientific analysis, resulting in thousands of published books and scientific articles on the subject of meditation. ${ }^{30}$

${ }^{30}$ Michael Murphy and Steven Donovan, The Physical and Psychological Effects of Meditation. (Petaluma: Inst. Of Noetic Sciences, 1997). 


\section{The Effects of Music in Meditation}

The influential effect of certain music lies in its capacity to alter moods, to evoke feelings, and to create distraction. It is connected to our emotions, and has the capacity to evoke emotional arousal. Music influences the human body, which can be measured. The mood responses created by music can be detected. Moreover, the elements of music, rhythm, harmony, melody, and timbre have a substantial effect on humans. The Indian classical musician and master of Sufism, Hazrat Inayat Khan, suggests that music can help to achieve the goal of meditation.

"There is nothing in this world that can help one spiritually more than music.

Meditation prepares, but music is the highest for touching perfection". 31

Music has been part of meditation practices for thousands of years. Its curative power date back to ancient times and it was known as an influential instrument for health, healing, and wellness.

"In ancient times, schools have taken music as a source of their meditation. Those who meditated with the help of music, they drive much more benefit from it than those who meditate without the help of music". ${ }^{32}$

Ancient cultures acknowledged that the power of sound, such as chanting, drumming and other ways of producing sound, had a deep effect on the human mind. ${ }^{33}$

In their published study about the effect of music on human behaviour, psychologists Irving A. Taylor and Frances Paperte concluded that:

"Music, because of its abstract nature, detours around the ego and intellectual controls

\footnotetext{
${ }^{31}$ Khan, The Mysticism of sound and music, 99.

32 Ibid.

${ }^{33}$ Michael J. Balick and Roberta Lee. "The power of sound: Ethnomedical tradition and modern science." Alternative Therapies 9 (2003): 63-72.
} 
and, contacting the lower centre directly, stirs up latent conflicts and emotions which may be expressed and activated through music; ... if the structural dynamics of the music impinging on the sensorium is similar to the prevalent structure the two will unite and thus fusion will allow music to affect emotions directly". ${ }^{34}$

The authors point out that a human's emotional state may be altered through music. The mood quality of music can match the mood or the emotion of the person. The expression of an emotion or mood, may be achieved by selecting the music that corresponds to that emotion or mood. As well, altering a mood or emotion, is accomplished by selecting music that effectively juxtaposes with the mood being altered.

Music is one of the most universal sensory stimuli for human beings. The American philosopher Suzanne Langer, suggests that in some cultures, music can express more specific feelings that language fails to communicate.

"The forms of human feeling are much more congruent with musical forms than with the forms of language, music can reveal the nature of feelings with a detail and truth that language cannot approach". ${ }^{35}$

In 'Emotions expressed and aroused by music', ${ }^{36}$ philosopher and ethnomusicologist Stephen Davies notes that in music we acknowledge motion, pattern and dynamic structures that can influence or stimulate us emotionally.

"We hear in music a terrain shaped by ongoing interactions between its parts, which vary in their pitch, complexity, teleological impetus, energy, texture, inertia, tension, and so on". 37

Psychoacoustics is the branch of psychology concerned with the perception of sound, and

\footnotetext{
${ }^{34}$ Irving A. Taylor and Frances Paperte. "Current Theory and Research in the Effects of Music on Behavior." Journal of Aesthetics 17, (1958): 251-258.

${ }^{35}$ Susanne K. Langer, Philosophy in a new Key (New York: New American Library, 1951), 235.

${ }^{36}$ Stephen Davies, "Emotions expressed and aroused by music" in Handbook of Music and Emotion, ed. Patrik N. Juslin, and John A. Sloboda. (Oxford: University Press, 2011).

${ }^{37}$ Stephen Davies, "Emotions expressed and aroused by music," 55.
} 
its physiological effects. ${ }^{38}$ According to Leeds, in this field the terms music, sound, frequency, and vibration are interchangeable, because they are different approximations of the same core. ${ }^{39}$ Music creates psychological effects on humans, by appealing to the limbic system, which is the centre of sensations, emotions and feelings in the brain. ${ }^{40}$ This includes how we listen, our psychological responses, and the physiological impact of music and sound on the human nervous system. However, music, sound, and vibration alters the frequency of our brainwaves, and has a direct effect on the activity of our mind and body. ${ }^{41}$ As music attracts our attention, it can support meditation practice, can help to clear our minds, and can prevent the mind from wandering.

Furthermore, music has been found to generate a relaxed mood and stress reduction, making it a plausible way to accommodate coping with pain and anxiety. ${ }^{42}$ The vibrations in music have the ability to modify muscle tension, heart rate variability, blood pressure, and the respiratory rate. Music may act directly on the autonomic nervous system when the stress response is interrupted and anxiety levels are reduced. ${ }^{43}$

Music is an effective device for altering mood, helping relaxation, promoting calmness or restoring balance to the autonomic nervous system. The psychophysical elements of music play a substantial role in human physiological and psychological functions, thus creating alterations in mood. Nevertheless, the most fundamental elements of music captures ones focus by shifting attention away from something that is unpleasant or stressful to a more positive stimulus.

In his book 'Flow' psychologist Mihaly Csikszentmihalyi concluded that keeping order

\footnotetext{
${ }^{38}$ Angus Stevenson and Maurice Waite. Oxford English Dictionary (New York: Oxford University Press, 2011).

${ }^{39}$ Joshua Leeds, The Power of Sound (Rochester: Healing Arts Press, 2010).

${ }^{40}$ Carolyn J. Murrock. "Music and Mood" in Psychology of moods, ed. Anita V. Clark. New York: Nava Science Publishers, 2005): 333-345.

${ }_{41}^{4}$ Ibid.

${ }^{42}$ Ibid.

${ }^{43}$ Ibid.
} 
in the mind from within is difficult. ${ }^{44}$ Outer stimulation is essential to keep attention directed. The distinct structure of music requires commitment to experience present moment awareness. This unique characteristic makes music a potent distractor and a cure to focus the wandering mind.

The most common and effective method of meditating starts with focusing on the breath. Listening to music while meditating, and focusing on the sound, or on the elements of music, can result in thoughts flowing away without any conscious effort. The tone of the instruments can act as a bridge from the everyday world to a calming, pleasing, and relaxed state.

The elements of music are beneficial as they can help balance the emotions, reduce the level of stress hormones, and release tension. According to Khan, while meditating, music can help to tune the mind and soul and help to accomplish a spiritual insight and altered consciousness. $^{45}$

In conclusion, music can make us to feel uplifted and energized. It can elevate or depress, and it can reduce or educe stress. It stimulates our body to lower blood pressure, decrease heart rate, to diminish stress hormones, reduce muscular tensions, and to help us achieve a state of meditation and relaxation.

\footnotetext{
${ }^{44}$ Mihaly Csikszentmihalyi, Flow: The Psychology of Optimal Experience (New York: Harper and Row, 1990).

${ }^{45}$ Khan, The Mysticism of sound and music.
} 


\section{Part II: Musical Elements}

\section{The Elements of Music and its Influences}

In the literature of music psychology, the term psychophysical has been used to refer to the physical properties of music, (tempo, range, melody, rhythm, dynamics, harmony).

Musicologist Mark Reybrouck claims that the term psychophysical, within the field of music, is the connection between acoustic level of musical stimuli and the level of meaning and their perceptual processing. ${ }^{46}$ The psychophysical elements of music have been found to have a considerable influence on listeners regarding the emotional content of music: tempo, rhythm, melody, harmony, articulation, dynamics, consonance, dissonance, range and timbre. ${ }^{47}$

The elements of music, with its set of rules for combining sounds in an infinite number of ways, plays a significant role in the psychological and physiological functions between the brain and body. ${ }^{48}$ Nonetheless, the psychophysical elements of music have notable effects on our minds and bodies during the meditation process as well.

"The Yogis regulated the rhythm of the circulation, of the heart and of every action of the breath, with the help of vibration, of music, of both tone and rhythm". 49

The power of music can change moods both consciously and subconsciously, and has a substantial effect on humans.

"Music creates order out of chaos; for rhythm imposes unanimity upon the divergent, melody imposes continuity upon the disjointed, and harmony imposes compatibility upon the incongruous". 50

Music, in general, is based on organized and repetitive patterns that create order. The

\footnotetext{
${ }^{46}$ Mark Reybrouck, The Musical Code between Nature and Nurture (Ferrara: Springer Science. 2008).

${ }^{47}$ Alf Gabrielsson and Patrik N. Juslin, "Emotional expression in music performance: Between the performer's intention and the listener's experience," Psychology of Music 24 (1996): 68-91.

${ }^{48}$ Murrock, Music and Mood.

${ }^{49}$ Khan, The Mysticism of sound and music, 50.

${ }^{50}$ Yehudi Menuhin, Theme and Variations (New York: Stein and Day, 1972).
} 
order that music brings to our experience is rhythmic, melodic and harmonic. Music tends to sculpt us, in our thoughts and our behaviour patterns, into conformity with its own inherent patterns of rhythm, melody, morality and mood.

Music is a compound blend of rhythm, harmony, melody and timbre that notably affects the human body in two ways: directly, as the effect of sound upon the cells and organs, and indirectly, by affecting the emotions, which then influences various bodily processes. ${ }^{51}$

\section{Rhythm}

"Motion is the significance of life, and the law of motion is rhythm". 52

Music involves the organization of sounds within a rhythmic framework. While listening to a melody, most often, consciously we pay attention to the notes of the melody, and subconsciously we absorb the rhythm of the melody. ${ }^{53}$ Most of the time, humans, consciously, do not pay attention to their body rhythms, but subconsciously these rhythms drive them in their every moment.
"The words thoughtful and thoughtless signify a rhythmic or unrhythmic state of mind, and balance, which is the only upholding power of life, is kept by rhythm". 54

Rhythm is the form of motion and is the most fundamental, crucial, structural, and organizational element of music. Rhythm is the pulse or the life force of music. Pulse, duration and tempo are features of rhythm that move music. ${ }^{55}$

The finest place to learn the artistry of rhythm is the human body. The human body

\footnotetext{
${ }^{51}$ David Tame, The Secret Power of Music (Rochester, Vermont: Destiny Books, 1984).

${ }^{52}$ Khan, The Mysticism of sound and music, 151.

${ }^{53}$ E. Thayer Gaston, "Dynamic music factors in mood change," Music Educators Journal 37 (1951): $42-44 .$.

${ }^{54}$ Khan, The Mysticism of sound and music, 155.

${ }^{55}$ Christine Stevens, Music medicine (Boulder: Sounds True, 2012).
} 
cannot function without rhythm. The whole construction of the human body is based on rhythm and pulsation. Our body's rhythm is so natural that it is barely noticeable. The rhythm keeps our body's mechanism together, whether the beat of the heart, of the pulse, of the head and the circulation of blood is all based upon rhythm. Rhythm affects the human mind as well.

Inhaling and exhaling is a natural, balanced pattern, a breathing beat. Breathing keeps the mind and body connected, and instrumentally keeps rhythm in every moment of our lives. ${ }^{56}$

As we know, music can change moods both consciously and subconsciously. The most subconscious element of music is the rhythm, and is the basic dynamic, and driving factor that stimulates action. $^{57}$

In her work, 'Music and Mood', Carolyn Murrock concludes that consistent rhythm gives a secure feeling while inconsistent rhythm commands attention and creates apprehension. ${ }^{58}$ Entrainment accounts for changes in brain waves, heart rhythms, respirations, emotional tones, timing, pacing, and other organic rhythms of the human body according to musical rhythm. ${ }^{59}$ Within the study of chronobiology, entrainment occurs when rhythmic physiological or behavioural events match their period to that of an environmental oscillation. As the natural rhythm of the human body is inherent (natural), the human brain can be entrained to match the rhythm of the music. A constant entrainment can bring an individual from one emotional state into another emotional state, through a gradual change in the rhythm of the music. ${ }^{60}$

The human heart typically beats at approximately $65-80$ beats per minute. When individuals are exposed to music at a higher tempo than their own intrinsic heartbeats, that music will have a stimulating, arousing effect to intensify the general mood. Conversely, when

\footnotetext{
${ }^{56}$ Stevens, Music medicine.

${ }^{57}$ Gaston, Dynamic music factors in mood change.

${ }^{58}$ Murrock, Music and Mood.

59 Ibid.

${ }^{60}$ Ibid.
} 
individuals are exposed to music at a slower tempo, one that is less than an individual's intrinsic heartbeat, it will have a relieving or calming effect. ${ }^{61}$

Entrainment involves synchronizing the rhythm, or pulse, of the music resulting in both psychological and physiological effects on the human body. ${ }^{62}$

\section{Melody}

"Melody speaks the language of the heart". 63

Melody can be described as a succession of musical notes that form a distinctive sequence of sound. Melody is the conscious (concrete) element of music as it produces a distinct pattern, generally, allowing the listener to sing or hum along. ${ }^{64}$.

Melody has the ability to express a mood, a thought, an idea, or an emotion, and is a nonverbal communication that can stimulate a wide range of emotional responses from consonance (happy, calm, euphoric, relaxing, soothing) to dissonance (sad, fearful, anxious, panicky, angry, alarmed, edgy).

The direction of a melody can also have an influential effect on human emotions and feelings. Ascending melody passages are commonly felt to increase concern and tension, while a descending melody passages often produces a calming effect. ${ }^{65}$

Researchers have found that the tension of the larynx is influenced by melodies featuring a descending series of notes. Since the larynx is affected by the ongoing stream of one's emotions and thought processes, its reactions to music are possibly indicative of an effect of

\footnotetext{
${ }^{61}$ Susan Weber, “Music: A means of comfort." In Music Therapy in Palliatice Care: New Voices, ed. David Aldridge, 95-104. London: Jessica Kingsley Publishers, 1999.

${ }^{62}$ Murrock, Music and Mood.

${ }^{63}$ Stevens, Music medicine. 53.

${ }^{64}$ Murrock, Music and Mood.

${ }^{65}$ Michelle Lefevre, "Playing with sound," Child and Family Social Work 9 (2004). 333-345.
} 
music upon the psyche. ${ }^{66}$

"The effects of tones upon the larynx indicates, melodies cause a constant saga

of tensions and relaxations to occur within many parts of the body". ${ }^{67}$

Melody is also a combination of pitches. Pitch is the number of cycles the sound vibrates per second; the degree of highness or lowness of a tone. The vibration rate per unit of time can alter moods. Every emotion develops from the intensity of vibrations. As melodies are based on vibration, they activate us emotionally. Rapid vibration is viewed as stimulating and slow vibrations are considered as relaxing.

\section{Harmony}

\footnotetext{
"Harmony is the expression of the soul's desire for balance and connection, helps us to discover the power of togetherness". ${ }^{6}$
}

Harmony, refers to the way musical notes and pitches are blended together to form an amalgamation of sound. Harmony supports the melody and gives the music texture and/or mood.

The natural force of harmony is balance. ${ }^{69}$ Harmony helps us to learn the power of togetherness. We notice harmony within ourselves in the balance of body, mind and spirit.

Harmony is grounded upon consonance and dissonance. In music, dissonance wants to be resolved. It is resolved, tension is released. All music can be measured as an interplay of tension and release. The interplay of consonance and dissonance creates balance. ${ }^{70}$

David Tame claims that researchers have revealed that consonant and dissonant chords,

\footnotetext{
${ }^{66}$ Tame, The Secret Power of Music.

${ }^{67}$ Ibid. 137

${ }^{68}$ Stevens, Music medicine. 81.

${ }^{69}$ Khan, The Mysticism of sound and music.

${ }^{70}$ Stevens, Music medicine.
} 
different intervals, and other elements of music all exercise a reflective effect upon human pulse and respiration.

"Upon their rate and upon whether their rhythm is constant, or interrupted and jumpy. Blood pressure is lowered by sustained chords and raised by crisp, repeated ones". 71

Tension and relief may be manipulated through the organization of music stimuli. The interplay of tension and release can stimulate an individual's awareness. Consonant and dissonant interchanges in music can help reinforce a meditator's attention and concentration. This mixture of consonant and dissonant harmonies also helps music to reflect emotional occurrences and contribute to its effect on mood. ${ }^{72}$

\section{Timbre}

Timbre defines the perceived sound quality of a musical note, or tone. This term is applied mainly to the sound of musical instruments. The distinctiveness of a musical instrument is conveyed by its timbre. The tone of each instrument has its own timbre. Researchers have shown that instrumental timbre contributes to emotional judgments in music. ${ }^{73}$ Aspects of timbre, such as attack and frequency spectrum, contribute to the perception of particular emotions in music. ${ }^{74}$ Nevertheless, the colour of a musical instrument may affect and influence the human mind and body.

\footnotetext{
${ }^{71}$ Tame. The Secret Power of Music, 137

${ }^{72}$ Lefevre, Playing with sound.

${ }^{73}$ Laura-Lee Balkwill and William F. Thompson, "A cross-cultural investigation of the perception of emotion in music: Psychophysical and cultural cues". Music Perception: An Interdisciplinary Journal 17 (1999): $43-64$.

${ }^{74}$ Gabrielsson and Juslin, Emotional expression in music performance, 68-91.
} 
One of the oldest instruments in the East used for meditation is the Vina. ${ }^{75}$ The first Vina, was a bamboo stick with attached gourds. They were crafted in such a way that the sound waves deeply penetrated the mind and body. The Vina can make a dull, monotonous sound called a drone that is capable of creating a meditative atmosphere.

The Rishis, (Hindi saint) used it for their yogic practices because they thought the sound could help their concentration. ${ }^{76}$ Khan claims that string, wind and percussion instruments each have a distinct and particular effect on the human body.

Smith and Noon, in their study, investigated the relationship between different types of contemporary music and mood states. They concluded that music that consists predominantly of brass, percussion, electronic sounds, and bass is frequently associated with feelings of unrest, amplified energy, and increased strength. ${ }^{77}$ Whereas, music that consists mostly of harps, string instruments, bells, and wind chimes affects the heart and soul, and is frequently associated with feelings of relaxation, calmness, and peacefulness. ${ }^{78}$

A musical piece can be analyzed by considering its elements. These elements can be controlled and manipulated while creating the piece, and help to depict the final result. It is exciting to realize that music can be crafted in such a way that it has a direct effect on the activity of our bodies.

Music can help create an ideal atmosphere for meditation and can support the goals of meditation. There are many types of meditation techniques used around the world and as a result, various types of music are also used. Generally, music that pleases the mind is simple and clear melodically, rhythmically and harmonically. Music that contains warm flowing melodies and

\footnotetext{
${ }^{75}$ Khan, The Mysticism of sound and music.

${ }^{76}$ Ibid.

77 J. L. Smith and Joe Noon. "Objective measurement of mood change induced by contemporary music". Journal of Psyhiatric and Mental Health Nursing 5 (1998): 403-408.

${ }^{78}$ Murrock, Music and Mood.
} 
slow moving harmonies can have a calming and relaxing influence. Music that contains regular rhythms that correspond to a normal, healthy heartbeat can help sooth the mind.

Examples of music used in meditation practices around the world are:

- Antonio Vivaldi - Concerto No.1 in E major, Op. 8, RV 269, $2^{\text {nd }}$ movement;

○ Joseph Haydn - Op. 76 No. 6 in C major, $2^{\text {nd }}$ movement;

○ Ludwig van Beethoven - String Quartet No. 15 in A minor, Op.132, $3^{\text {rd }}$ movement;

○ Richard Wagner - Lohengrin, $W W V$ 75, Prelude to Act 1;

○ Paul Horn - Mumtaz Mahal from the Inside album;

- Tony Scott - Za-Zen from the Music for Zen Meditation album;

- Lama Tashi - Mantra of Blessing from the Tibetan Master Chants album;

○ Vanraj Bhatia - Pratihara from the Indian Meditation Music album;

The compositions featured in Part III, make use of the following features:

- Slow, gently tempo, no tempo change, constant pulse, steady pace;

○ Simple rhythmic figures, repeated patterns

○ Distinct, simple melodies;

○ Slow gently moving sound, delicate and quiet, but never sedentary;

- Mostly homorhythmic texture, pedal points, use of drones;

Instruments: woodwinds, strings, harp, bells, gongs, wind chimes and percussions. 


\section{Part III: The Compositions}

\section{Composition I: Eternal Flow}

\section{Compositional process}

The goal of this composition was to create a piece that could be used for meditation and relaxation purposes. One of my objectives was to position my work within the context of traditional chamber music for string quartet.

While researching the field of music used in meditation, I learned that most of the works did not differ too much stylistically as they typically flow from the beginning, to the middle, and to the end. I attempted to avoid any sudden changes in the mood, flow, volume or tempo.

Another intention was to incorporate passages with longer note values that could create a calming and relaxing atmosphere with warm flowing sound. To achieve the proposed task, I aimed to create an organic sound, rich with layers of simple moving harmonic progressions that have a subtle, mind-numbing effect.

To achieve these objectives, I decided to work with various transformations of melody, harmony, texture and rhythm. Using transformations creates a diversity of music that clearly derives from the primary motivic unit.

While searching for a tonality for the piece, I decided to place my work in E flat major tonality. Musicologist and researcher Rita Steblin claims that in eighteenth and nineteenth century this tonality was characterized as the tonality of love, devotion, and openness. ${ }^{79}$

\footnotetext{
${ }^{79}$ Rita Steblin, A History of Key Characteristics in the Eighteenth and Early Nineteenth Centuries, (Ann Arbor, Michigan: UMI Research Press. 1983).
} 


\section{Overview}

Eternal flow is based on a ternary form (ABA) with an introduction and a coda. The piece is divided into following parts:

Table 1: Structure of Eternal Flow

$\begin{array}{cc}\text { Parts } & \text { Measures } \\ \text { Intro } & 1-2 \\ \text { Part I } & 3-35 \\ \text { Part II } & 36-53 \\ \text { Part III } & 54-85 \\ \text { Coda } & 86-91\end{array}$

My analysis is organized according to this form, and shows how decisions were made and ideas organized during the compositional process.

The piece begins with a two measure long introduction. The two voices, presented by violin and cello, are moving in contrary motion based on the dominant chord of section A.

The first part of the piece is grounded in two sections, and on the interchanges between the $\mathrm{C}$ minor tonality and its relative major $\mathrm{E}$ flat. The first part of the piece has the following sections:

Table 2: Eternal Flow's first part sections

Part I Measures

Section A

3-14

Section B

$15-18$

Section $\mathrm{A}_{1}$

19-30

Section $\mathrm{B}_{1}$

31-35 
The A section is constructed on a repeated six measure long melodic theme placed in the $\mathrm{C}$ minor tonality. The first and main melodic theme of the section is built on two motifs (see Figure 1). This two measure motivic unit is one of the main units the piece is based on.

Figure 1: The first motivic unit

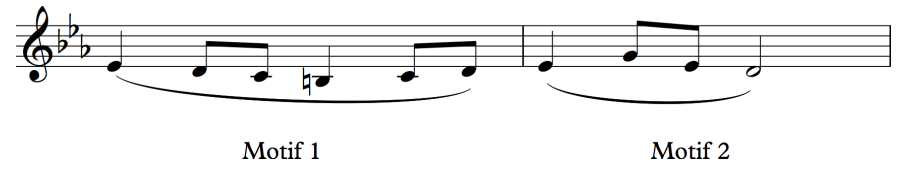

The first main melodic theme is developed and based on those two motifs. The six-measure long melodic theme is based on three phrases (Figure 2). The first two phrases share the same ideas, the third one uses material derived from the first phrase, and is a transition phrase that leads to the next part of the section.

Figure 2: The first part of section A

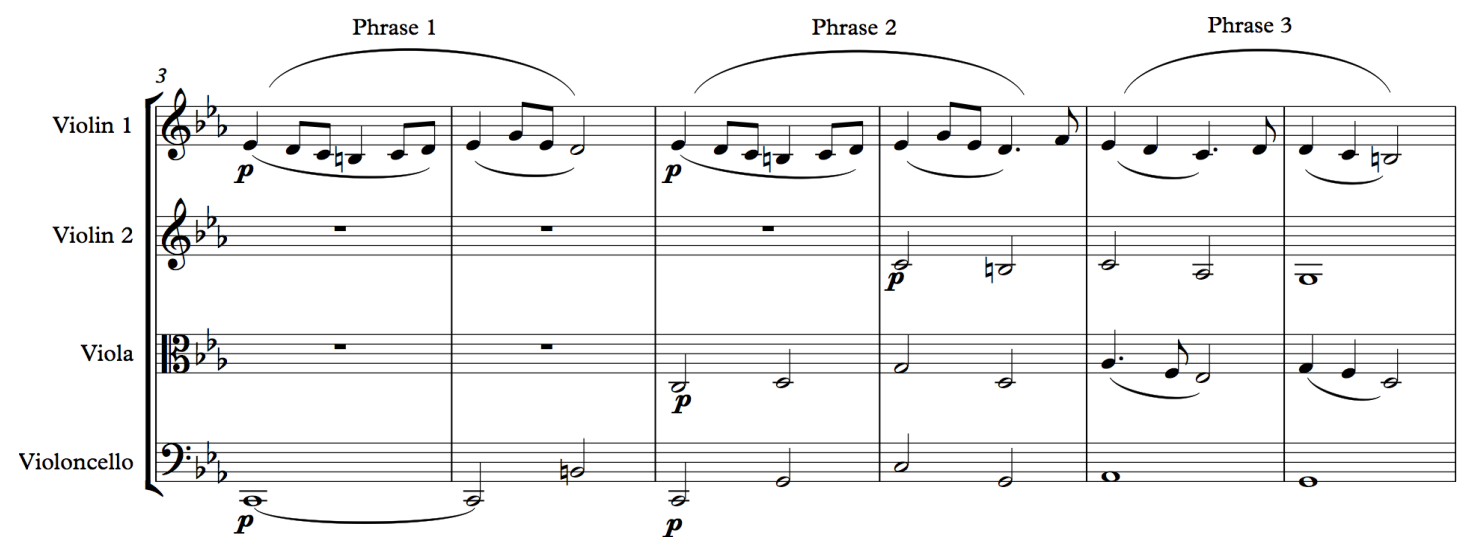

As the section continues, the main melodic theme is repeated. In the last two measures of the section, the last phrase is altered to make the smooth transition into the next section. The section has a functional harmony, tonic and dominant chords are used frequently, as well as suspensions and pedal note passages. The texture of the section is homophonic, one melody line 
with accompaniment. The melody is performed by the first violin; the other instruments mostly perform accompaniment and counter melodies.

The harmonic rhythm of the section is based on a two chord per measure motion. The rhythmic flow of this section is generally simple in style with a tendency for longer notes to appear in the lower parts, and shorter note value in the upper parts, especially in the melody part.

Section B introduces the second main motivic unit of the piece (Figure 3). This motivic unit and the first motivic unit (Figure 1) are the core elements of the piece. These two motivic units were used to generate further material for the piece.

Figure 3: Second motivic unit

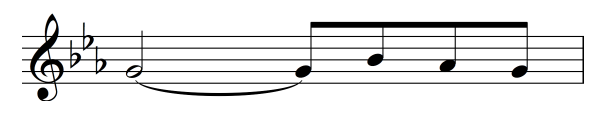

Section B has a length of four measures; the material for this section is generated from the second motivic unit (Figure 4). The last measure of the section, is a transition measure leading back into the A section material.

Figure 4: Section B

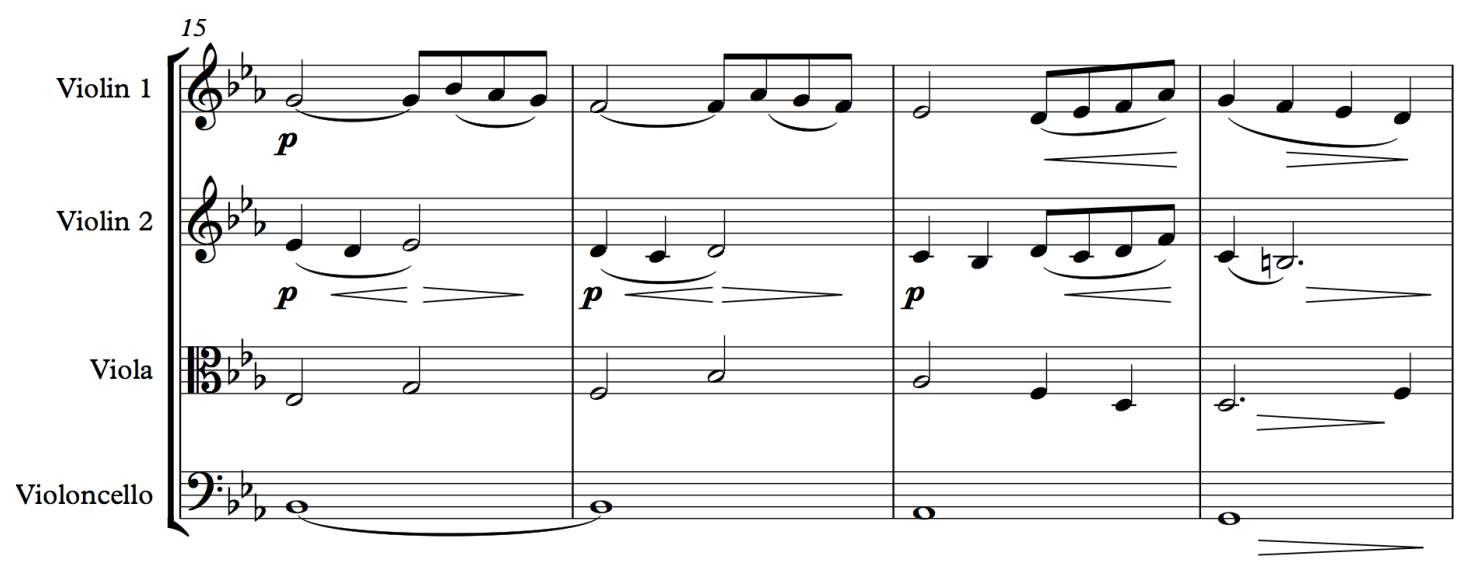


This section is placed in the E flat major tonality. The sequencing melody line and its counter melody part, placed over a slow moving bass part, provides a different and richer texture than the A section. Worthy of note, the dominat pedal point over the one chord in the first measure creates a little tension, which can capture attention. The harmonic rhythm of the section is downgraded to one chord per measure.

In the following section, $A_{1}$, the material from the $A$ section is repeated with a different design. While the tonality remains the same, the melody starts to rise in the first half of the section (Figure 5), and starts with an octave displacement in the second part of the section. Interest is created with the more active inner parts of the section.

Figure 5: The first part of section $A_{1}$

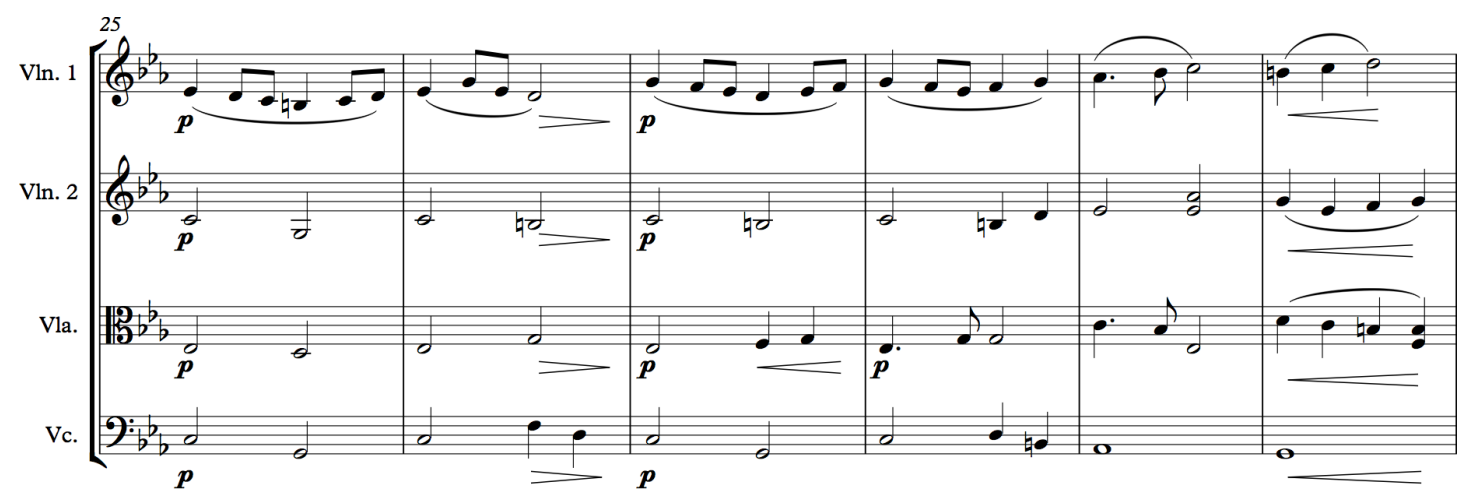

The $\mathrm{B}_{1}$ section repeats the $\mathrm{B}$ section material with delicate alterations. First, the section starts with the tonic bass note, which seeks to establish a feeling of tonality shift. The rest of the piece stays in this tonality. Second, the section is extended with a measure, which creates a transition into the next part of the piece.

The second part of the piece uses materials derived from the two motivic units presented in the first part of the piece. The sections of the second part are structured as follows: 
Table 3: Eternal Flow's second part sections

Part II

Section C

Section D
Measures

$36-43$

44-53

Section $\mathrm{C}$ is constructed as an eight measure long section, which unfolds new musical experiences. In the first part, the melody rises using longer note values, which suggest a soothing and relaxing motion (Figure 6). In the rest of the section, the melody follows an arch shape, which suggests an effortless, balanced atmosphere.

Figure 6: First six measures of section C

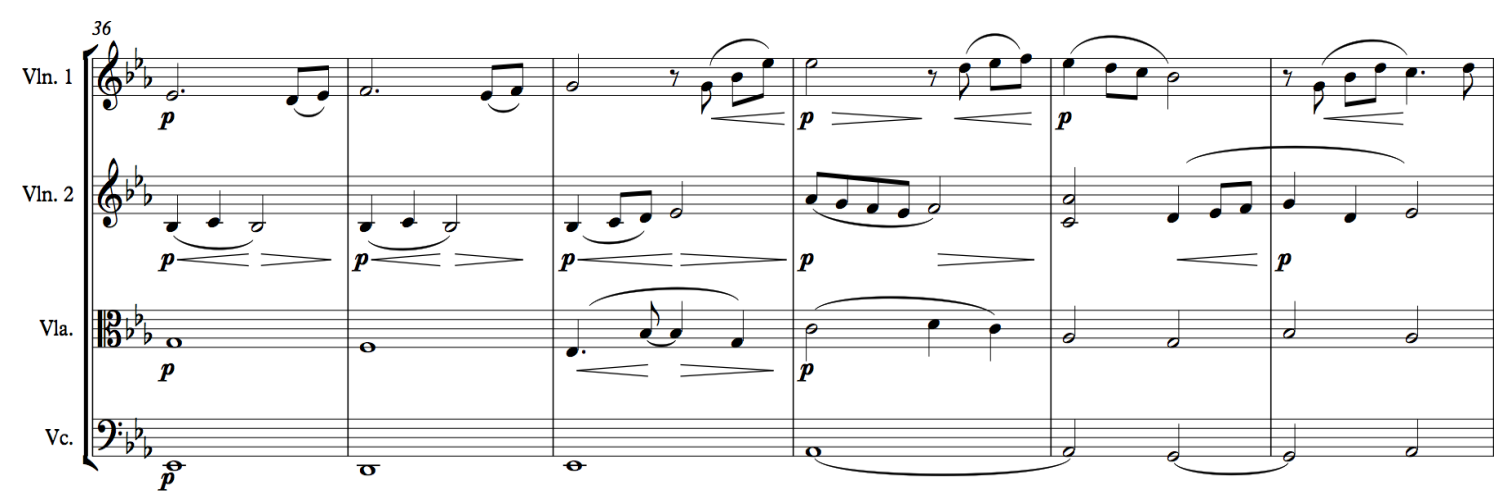

The second violin counter rhythmic pattern is borrowed from the B section material, which suggests continuity and unity. The harmonic material of this section follows a different motion, however, it is developed from the B section's harmonic material.

In the following section, $\mathrm{D}$, the $\mathrm{B}$ section material is used to generate and develop further materials. The same rhythmic motifs are reintroduced for the melodic material with dissimilar shape (Figure 7). The middle part of the section is based on the transition measure of the B section, and is developed and extended. The descending melody motif is shifted between the 
parts. In this part the harmonic rhythm has a slow motion, one chord per measure, simulating a resting point.

Figure 7: First six measure of section D

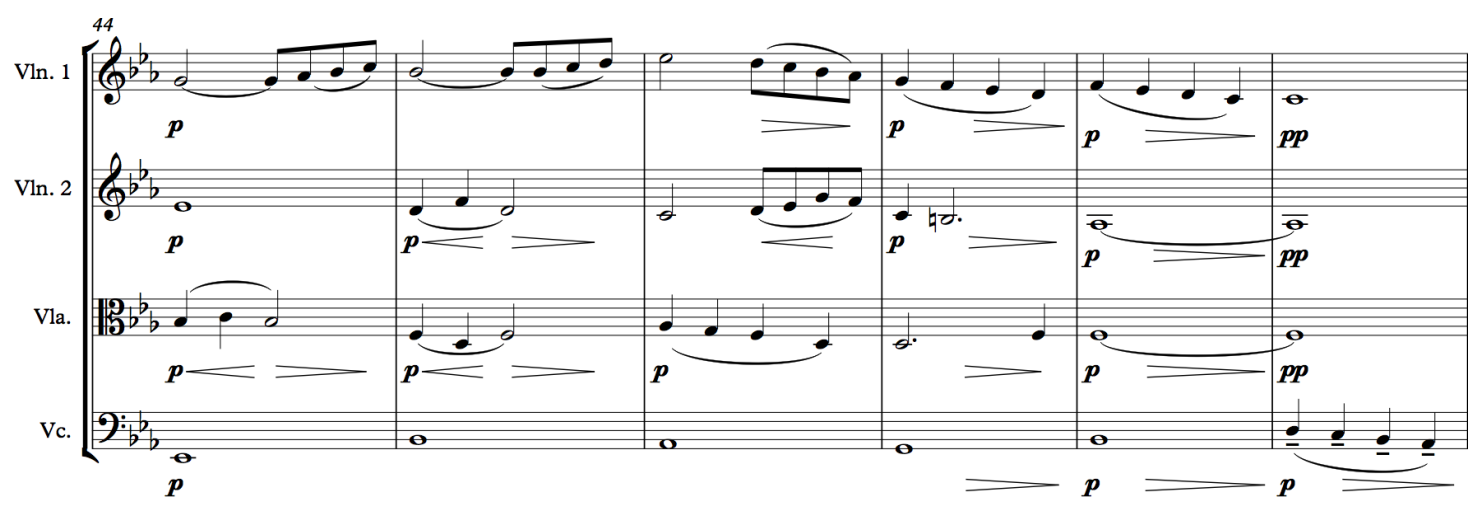

The last part of the D section, a four-measure transition part (Figure 8), leads into the next part of the song. The roving harmony of this part and the smoother texture creates a floating musical experience that intend to captivate awareness and to soothe the mind.

Figure 8: Last four measures of section D

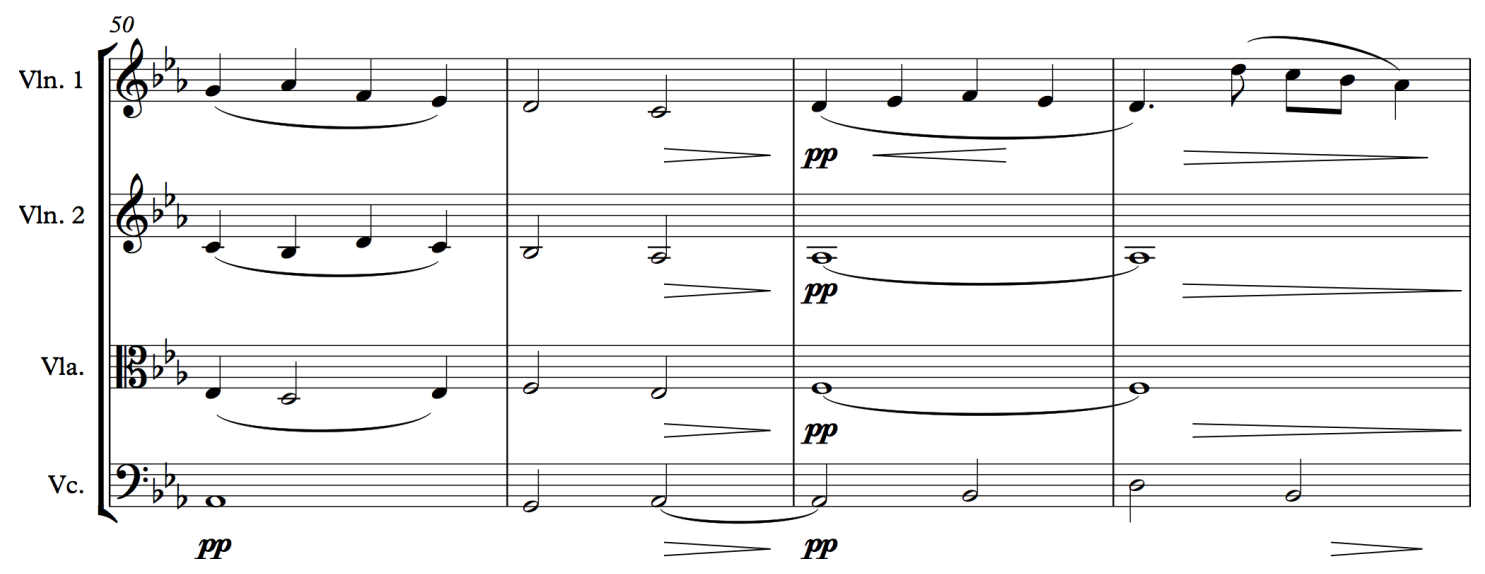

Part III of the piece is a recapitulation. Sections A and B are restated and repeated in the E flat major, the A sections do not return back to the $\mathrm{C}$ minor tonality (see Table 4). 
Table 4: Eternal Flow's third part sections

Part III Measures

Section $\mathrm{A}_{2} \quad 54-65$

Section $\mathrm{B}_{2} \quad 66-69$

Section $\mathrm{A}_{3} \quad 70-81$

Section $\mathrm{B}_{3} \quad 82-85$

In the first part of the $\mathrm{A}_{2}$ section, the melody is presented by the viola; the accompaniment parts are played by the second violin and violoncello. A different texture is presented in this section. The texture and the smoothness of this part creates a unique soothing musical experience that suggests a deeper calming state. As the section continues, the first violin retakes the melody part. As mentioned above, the A section material is placed in the $\mathrm{E}$ flat major tonality, signifying a brighter and lighter atmosphere. Section $\mathrm{B}_{2}$, reiterates the $\mathrm{B}$ section material, with a deviation in the last measure, where the transition melody part rises instead of falls. In the next section, $A_{3}$, the main melodic theme reappears. To create interest, in the first half of the section, the melody reappears on a different scale degree while the harmonic structure does not change. To gain more definition for the melody in the second half of the section, the melody is displaced in the higher register. To produce a unique musical experience, the second violin harmonizes the melody line, which helps to create affection. The last section of this part, the $\mathrm{B}_{3}$ section, repeats the $\mathrm{B}$ section material with more motion in the inner parts. The work ends with a six-measure long coda, where the first melodic unit is recapitulated, and the piece finishes with a perfect cadence.

The different rhythmic and melodic levels of repetition throughout the piece, and the use 
of various transformations of melody, harmony, texture and rhythm, seeks to establish a feeling of unity and continuity. Eternal Flow, with its use of acoustic instruments, and with its enchanting atmosphere, creates a warm musical experience that hopefully can lead to effortless meditation and relaxation. 


\section{Composition II: Inner Zone}

\section{Compositional process}

My intention in composing Inner Zone was to create a piece for 'focused attention' meditation, helping the practitioner to achieve a state of deep inner tranquillity. In 'focused attention' meditation practices, the attention is directed to a single object during the meditation session. This object could be the breath, a mantra, a part of the body, an external object, or a sound.

An essential part of meditation practice can include the use of a mantra. I planned to incorporate a mantra into the composition. As we know, a mantra generally can be a word, a repeated phrase or sound used to help anchor the mind in the present moment and keep it from wandering off. The use of a repeated set of notes as a mantra in the music, is intended to help the meditator concentrate during the meditation practice.

This piece was written for percussion instruments and string quartet (double bass, cello, viola and violin). The percussion includes marimba and singing bowl. The marimba part denotes the mantra. The Singing Bowl, also known as Tibetan Singing Bowl, produces harmonic overtones which creates an effect that is unique to the instrument, that provides a soothing and positive effect. Singing bowls are a type of bell widely used as an aid in meditation practices.

To accomplish my goal, I attempted to integrate a drone effect into the piece using the string quartet. A drone sound is usually a homophonic or monophonic effect or accompaniment where a note or a chord is sounded continuously. Drone sounds tend to evoke calming and relaxation effects. My decision in choosing this string quartet combination was to create a more influential drone effect with the help of the double bass. The piece has a slow tempo, no sudden 
changes in tempo or volume, aiding in generating a soothing and calming ambiance.

Musicologist Rita Steblin notes that some theoretical works of the eighteenth and nineteenth century assigned certain affections or emotional characteristics to different tonalities. ${ }^{80}$ In selecting the tonality for the piece, I considered these characteristics and I opted for the G major tonality. According to Steblin this tonality was thought to express calm, passion and every gentle and peaceful emotion of the heart. ${ }^{81}$

\section{Overview}

The structure of the piece is based on a ABA from with an introduction and coda. The structure of the piece is notated and divided into following parts:

Table 5: Structure of Inner Zone

$\begin{array}{cc}\text { Parts } & \text { Measures } \\ \text { Intro } & 1-5 \\ \text { Part I } & 6-43 \\ \text { Part II } & 44-81 \\ \text { Part III } & 82-127 \\ \text { Part IV } & 128-163 \\ \text { Coda } & 164-174\end{array}$

My overview is organized according to this form, and describes how conclusions were made and organized during the composing process.

The beginning of the piece establishes the mantra's material and drone effect. The repeated

\footnotetext{
${ }^{80}$ Steblin, A History of Key Characteristics in the Eighteenth and Early Nineteenth Centuries.

${ }^{81}$ Ibid.
} 
note series, that is founding the mantra of the piece, is presented by the marimba (Figure 9). The cyclic sound of the mantra rises to a gentle rhythm, like a mesmerizing pulse that embraces awareness can guide the mind into a state of clarity, peace and deep meditation.

Figure 9: Inner Zone's mantra motif

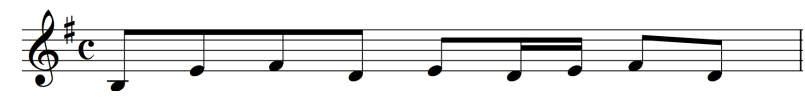

The drone effect is established in the introduction by the double bass, cello and viola. The singing bowl is present in the opening section as well, facilitating the crafting of the piece's character, suggesting a calming and comforting ambiance. The singing bowl pitches used in the composition are the tonic pitch (G) and the dominant pitch (D) of the G tonal center. The concept for the singing bowl is to function as a stimulating tool for the meditative process.

The first part of the piece is based on a ternary form, and is notated as follows:

Table 6: Inner Zone's first part sections

$\begin{array}{cc}\text { Part I } & \text { Measures } \\ \text { Section A } & 6-17 \\ \text { Section B } & 18-25 \\ \text { Section C } & 26-43\end{array}$

The A section introduces the first melodic theme, which is restated in the second part of the section (Figure 10). The melody is based on five pitches which describe a descending shape, and is presented by the violin. The descending melody line intends to evoke a calming effect. 
Figure 10: First melody theme

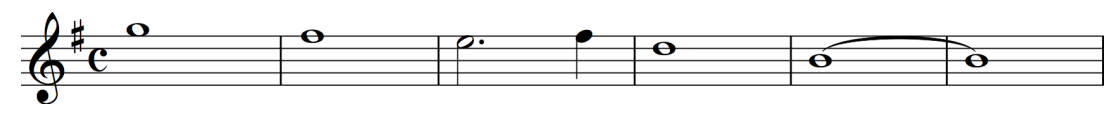

The foundation sound of this section is based on the drone effect that provides the music with a feeling of weight and warmth. The drone effect is produced by the double bass joined by cello and viola in this section (Figure 11). The section has a static harmony; one chord throughout the entire section. This section's texture is a mixture of staggered sustained tones, slow falling melody figure and repeated note series (mantra).

Figure 11: The first part of section $A$

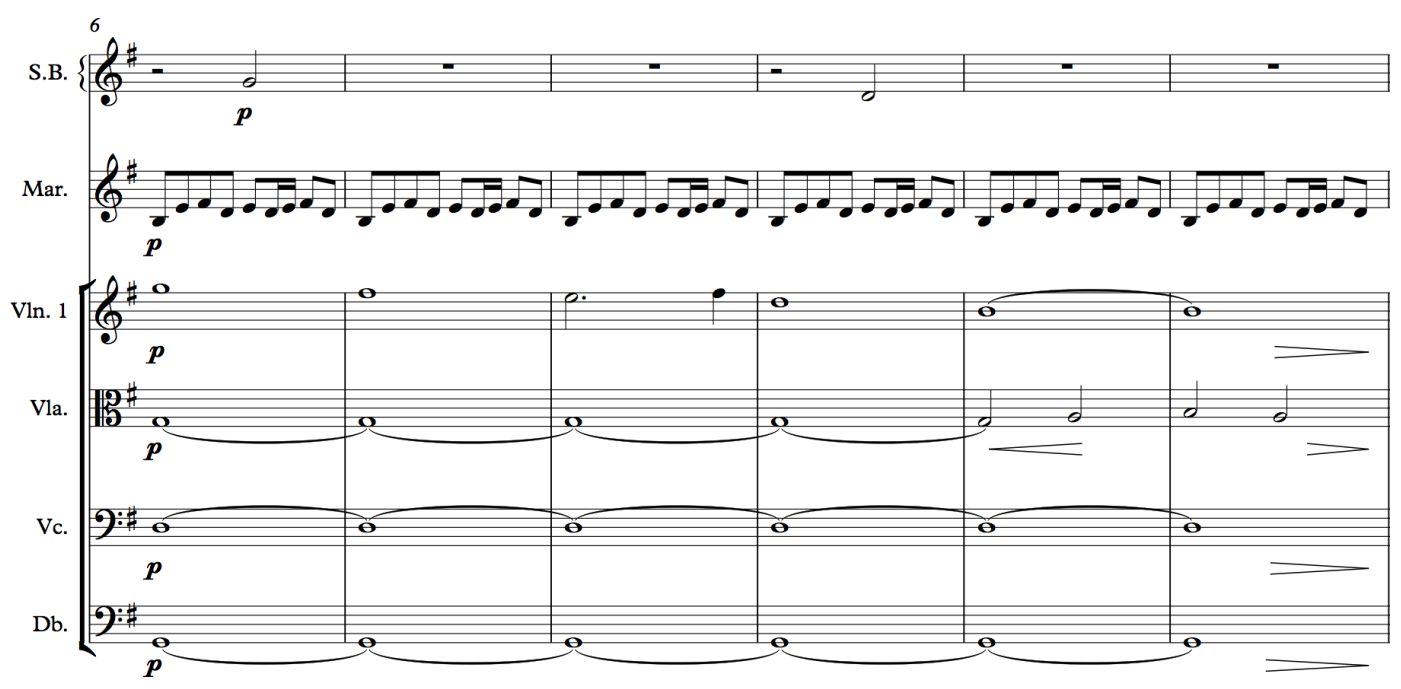

The following B section, presents the second melodic theme, which is based on the same idea descending melody shape within a larger range (Figure 12). The drone effect is suspended in the first part and returns back in the last three measures of the section. The harmonic material changes in this section, with more movement in the inner parts. The harmonic rhythm of this section is mostly one chord per measure. 
Figure 12: Section B

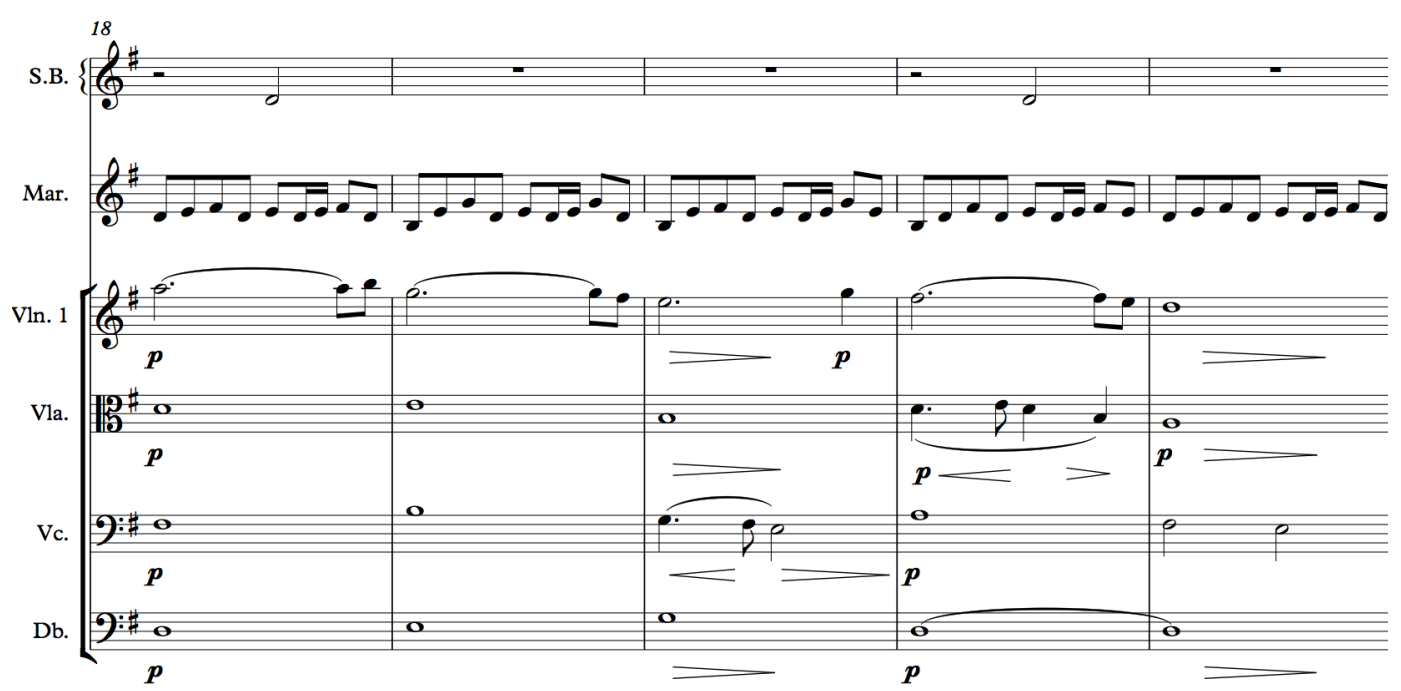

In the following section, $\mathrm{C}$, the third melodic theme is presented by the viola (Figure 13). The melody describes an arch shape and has a range of an octave, tend to create a hovering effect.

Figure 13: The first part of section $C$

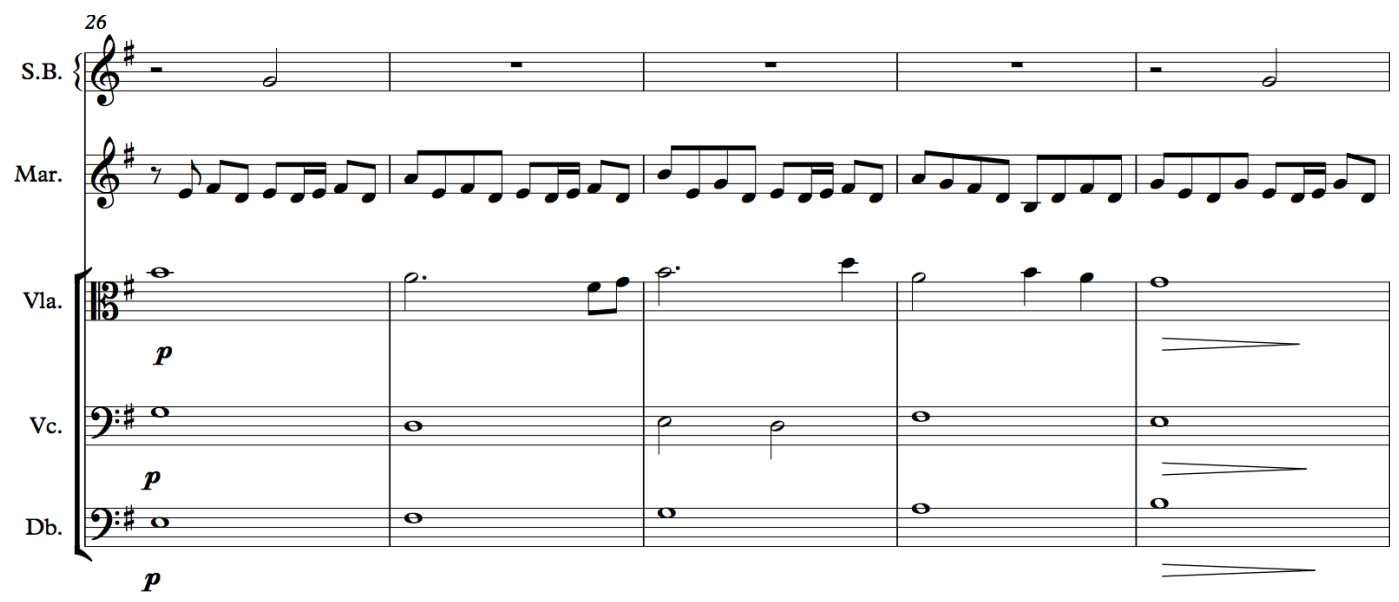

The harmonic material in the first part of the section shifts to the relative minor tonality, E minor, whereas in the second half, the harmonic material shifts back to the G major tonality 
while the melodic theme is repeated. In the second half of the section, motion is created with the counter melody part. Meanwhile, the mantra has been adjusted to follow the harmonic motion, while following the same rhythmic pattern as in the previous sections.

The texture is homophonic in the first part, and becomes polyphonic in the second half of the section. The drone effect returns back in the last four measure of the section, performed by the double bass, and transitions into the next part of the composition.

The second part of the work, provides a reiteration of the previous part within the same structure, but with different texture and arrangement. The string section of this part is crafted for three voices. The second part sections are noted as follows:

Table 7: Inner Zone's second part sections

$\begin{array}{cc}\text { Part II } & \text { Measures } \\ \text { Section } A_{1} & 44-55 \\ \text { Section } B_{1} & 56-63 \\ \text { Section } C_{1} & 64-81\end{array}$

In the $A_{1}$ section, the cello takes over the melody part generating a gentle and softer tone (Figure 14). As the violin part is placed above the melody, with its light sound, creates an airy and brighter effect. The static drone effect has been diminished, as the harmonic material is crafted to add more motion to the section. The mantra pattern returns back to its initial form, providing the material to focus on during meditation. 
Figure 14: The first part of section $A_{1}$

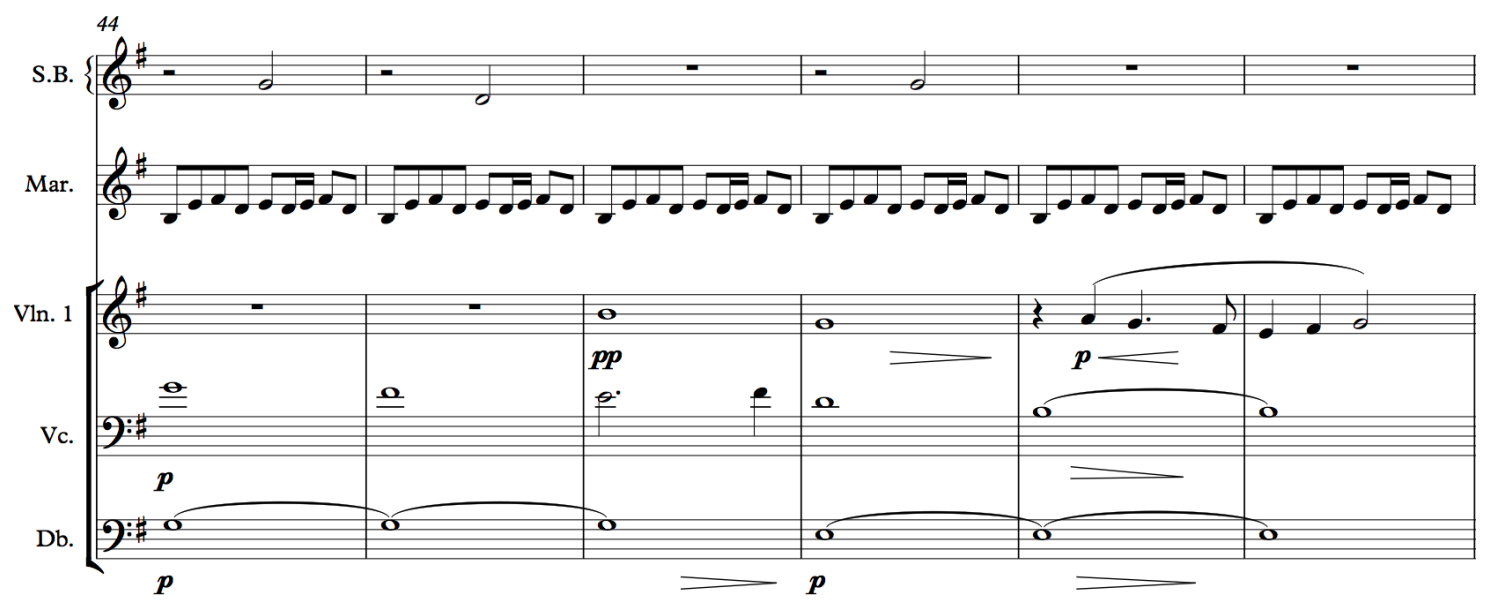

The $\mathrm{B}_{1}$ section recaptures the melody theme from the $\mathrm{B}$ section, presented by the viola. Besides the varied texture, more interest and motion is created in the cello part (Figure 15), with the falling counter melody line.

Figure 15: Section $B_{1}$ string parts

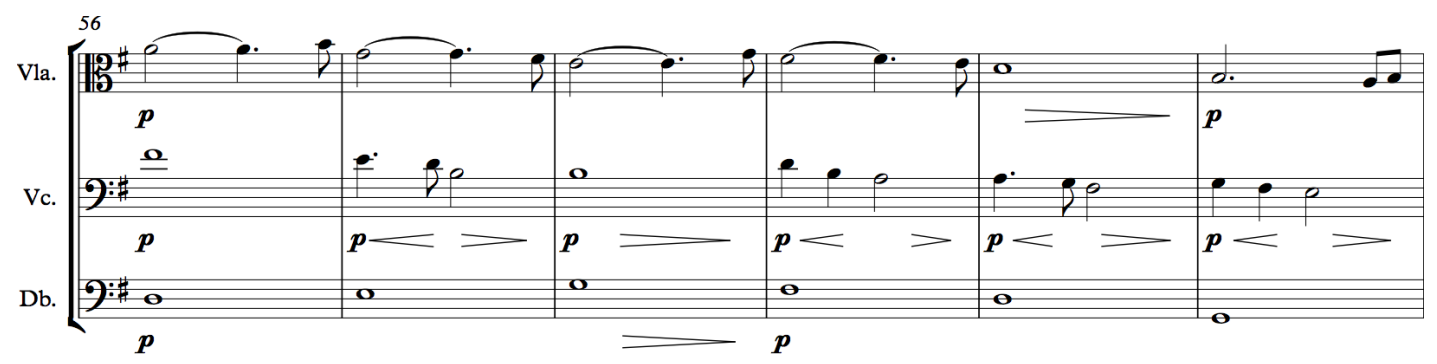

The following $\mathrm{C}_{1}$ section restates the material for the $\mathrm{C}$ section, while the violin presents the melody, and cello and double bass provides the accompaniment parts.

The third part of the piece is constructed to emphasize the drone effect. This part is crafted to stimulate a calming and relaxing feel, and to create a soothing atmosphere, while the dynamics of the part decreases. The sections of Part III are: 
Table 8: Inner Zone's third part sections

$\begin{array}{cc}\text { Part III } & \text { Measures } \\ \text { Section D } & 82-113 \\ \text { Section E } & 114-127\end{array}$

The major idea for the $\mathrm{D}$ section was to highlight and develop the drone effect. The drone starts in the double bass part and provides the foundation for the section. To establish an intense and rich drone sound, the cello and later the viola join in, in the first half of the section, with a slow moving descending line (Figure 16). In the second half of the section, the violin takes the viola's place, and the section moves to a lower pitch, inspiring a deeper state of meditation.

The mantra of this section is diminished to stimulate less motion, and to help to create an effortless static effect. The singing bowl, with its periodic sound and its pulsating tone, is intended to enhance the awareness of the mind.

Figure 16: The middle part of the section D

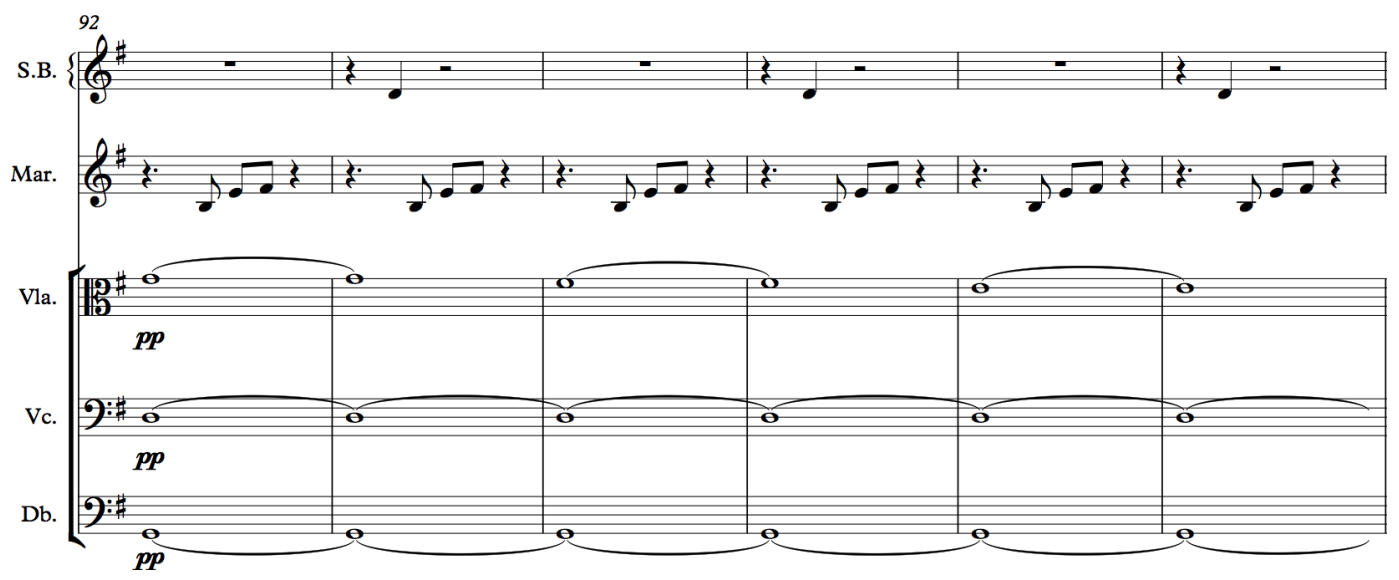

The E section is constructed to serve as a transition section into the next part of the piece.

The string parts of the section have a homorhythmic (chordal) texture (Figure 17). The harmonic 
material changes in this section and is based on a slow ascending bass motion that stimulates an elevating effect. The harmonic rhythm of the section is one chord per two measures. The percussion material remains the same, as in section $\mathrm{D}$, to generate continuity to this part.

Figure 17: The first part of section $E$

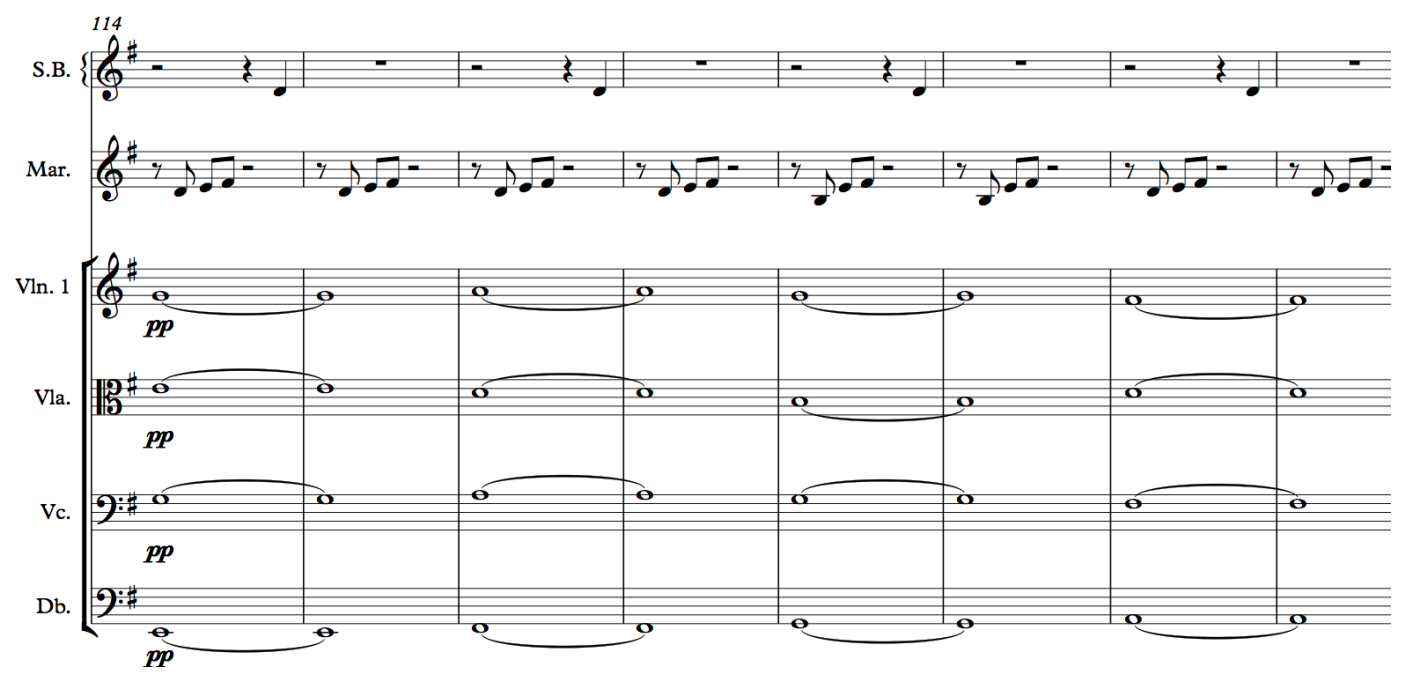

The last part of the piece, recapitulates the first part's material following the same layout, and the sections are noted as follows:

Table 9: Inner Zone's fourth part sections

$\begin{array}{cc}\text { Part IV } & \text { Measures } \\ \text { Section } \mathrm{A}_{2} & 128-139 \\ \text { Section } \mathrm{B}_{2} & 140-147 \\ \text { Section } \mathrm{C}_{2} & 148-163\end{array}$

The melody is presented in the lower register by the viola in the $\mathrm{A}_{2}$ section, with an 
elegant, light and soft texture. Meanwhile the mantra pattern is restated to recreate the first part of the piece; the drone effect is being restated as well.

As the fourth part continues, the $\mathrm{B}$ section material is repeated in the $\mathrm{B}_{2}$ section, while the melody is performed in the lower register by the violin. The accompaniment in the following $\mathrm{C}_{2}$ section, is extended to a three-part accompaniment for the C section's material. The coda section recapitulates the first melody theme sustained by the drone effect, and ends with a plagal cadence into the D major tonality.

The repeated series of notes that provides the mantra to the music helps to anchor and to keep the mind focused. Also, it serves as an entity that can help to bring back the mind into the present state. The goal of this piece is to create interest and help to clear away mental clutters through the use of diverse musical soundscapes. Floating effortlessly above the powerful sound created by the drone effect can lead to enter into a deeper state of meditation. 


\section{Composition III: Spectrum}

\section{Compositional process}

In creating Spectrum, my goal was to create a piece for open monitoring meditation. In the open monitoring meditation, the meditator cultivates an objectless awareness, monitoring the content of ongoing experience, without judgment or attachment. All perceptions, internal (thoughts, feelings, memories) or external (sounds, images, smells), are acknowledged and seen for what they are. One of the ideas to accomplish this goal was to depict different soundscapes that mesmerize awareness and soothe the mind.

The second intent for this composition was the texture and instrumentation. I wanted to combine and blend the traditional string quartet with pitched and non pitched percussion instruments to obtain diverse textures. Also, I intended to incorporate a mantra in the piece a repeated series of notes that provides a mantra effect.

My selection for percussion instruments were: Cajon, Crotales, Marimba and Hang. The cajon is a box-shaped non pitched percussion instrument, played by slapping the front or rear faces with the hands or fingers. Crotales are pitched percussion instruments consisting of small tuned cymbals. The hang is a musical instrument in the idiophone class. An idiophone instrument creates sound primarily by the instrument as a whole vibrating, without the use of strings or membranes. The Hang is a newer instrument, developed in the beginning of twentyfirst century in Switzerland. The Hang is made from two deep drawn steel hemisphere hardened together. It is played by hands and fingers. There are different generations of Hangs with different tunings and pitches. The Hang that I selected for the piece produces the following 
pitches: D3, A3, Bb3, C4, E4, F4 and A4. Based on the pitch collections of the Hang, I opted for the D minor tonality. Musicologist Rita Steblin notes that the D minor tonality can be described as the tonality that suggests rumination, melancholy and pious. ${ }^{82}$

\section{Overview}

Spectrum is composed for a small chamber ensemble comprised of two violins, viola, cello, cajun, crotales, marimba, and Hang.

The piece is divided into sections of sixteen measures long with an introduction and a coda (see Table 10). The piece is organized according to this form, as that is how decisions were made and organized during the creative process.

Table 10: Structure of Spectrum

$\begin{array}{lc}\text { Sections } & \text { Measures } \\ \text { Introduction } & 1-8 \\ \text { Section A } & 9-24 \\ \text { Section } \mathrm{A}_{1} & 25-40 \\ \text { Section B } & 41-56 \\ \text { Section C } & 57-72 \\ \text { Section D } & 73-88 \\ \text { Section } \mathrm{A}_{2} & 89-104 \\ \text { Section } \mathrm{A}_{3} & 105-120 \\ \text { Coda } & 121-128\end{array}$

${ }^{82}$ Steblin, A History of Key Characteristics in the Eighteenth and Early Nineteenth Centuries. 
The mantra is based on an eighth-note rhythmic figure performed by the Hang (see Figure 18). This mantra pattern provides the foundation and background material for the piece.

Figure 18: Spectrum's mantra pattern

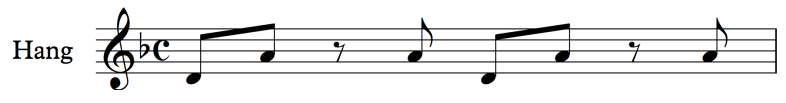

The introduction is constructed as an eight-measure section shaped by the percussion instruments. The cajon sets up and provides the pulse of the piece. The crotales help to highlight the pulse of the section designed with a descending melody line. The marimba part is created by a simple rhythmic motif that is repeated through the introduction (Figure 19).

Figure 19: Introduction

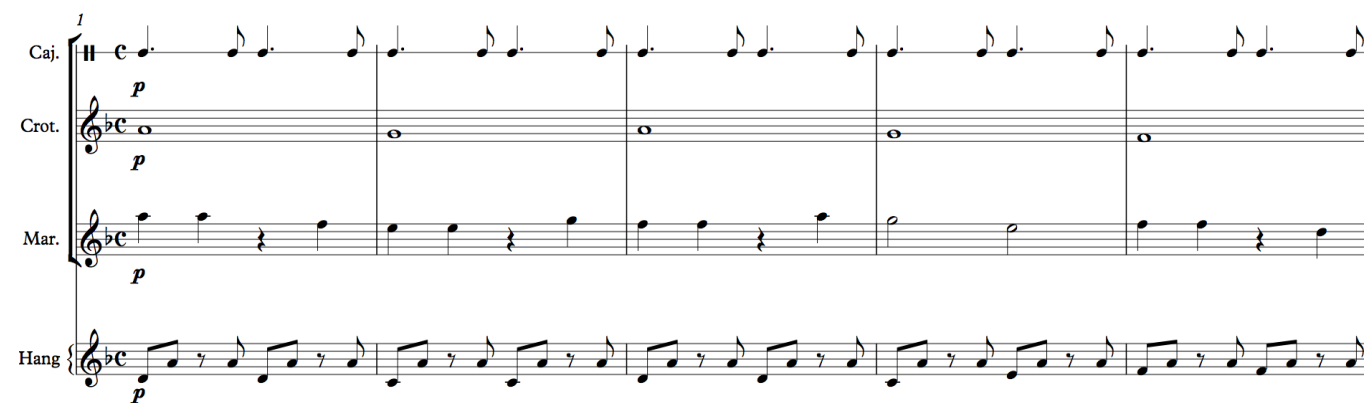

The first section of the piece, section A, is based on two melodic theme, each eight measure long. The first melodic theme is presented by the cello (Figure 20).

Figure 20: The first melodic theme

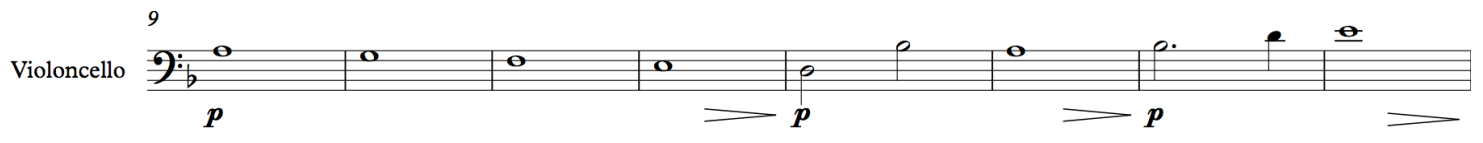

The shape of the melody is based on a falling line in the first part of the theme and a 
rising line in the second part. As the section continues, the second melodic theme is introduced by the first violin (Figure 21). This melody line is developed from the first melody theme following the same idea in the beginning, the falling melody. The second part of the melody theme unfolds a different path.

\section{Figure 21: Second melodic theme}

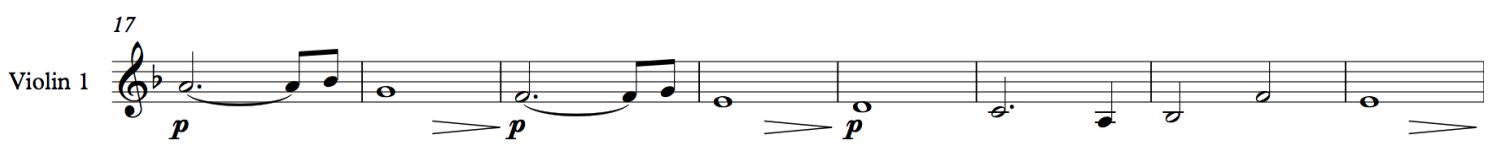

The harmonic motion of the piece is grounded on an eight measure long progression (Figure 22). All sections of the piece are founded on the same repeated harmonic progression with adjustments where needed. The music repeatedly cycles through the progressions that gently builds and releases, conveying a sense of diverse occasions, and even includes a feeling of euphoria from time to time.

Figure 22: Harmonic motion

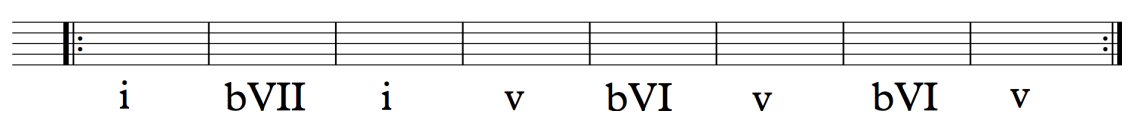

The texture of the A section is homophonic, one melody line accompanied by the percussion instruments (Figure 23). The rhythmic flow of the sections is created by the blend of the percussion instruments and the slow moving melody rhythm. The blend of the melody rhythmic flow and the mantra's eight notes figure pattern creates motion for the piece. The harmonic rhythm of the A section is based on one chord per measure. 
Figure 23. Section A

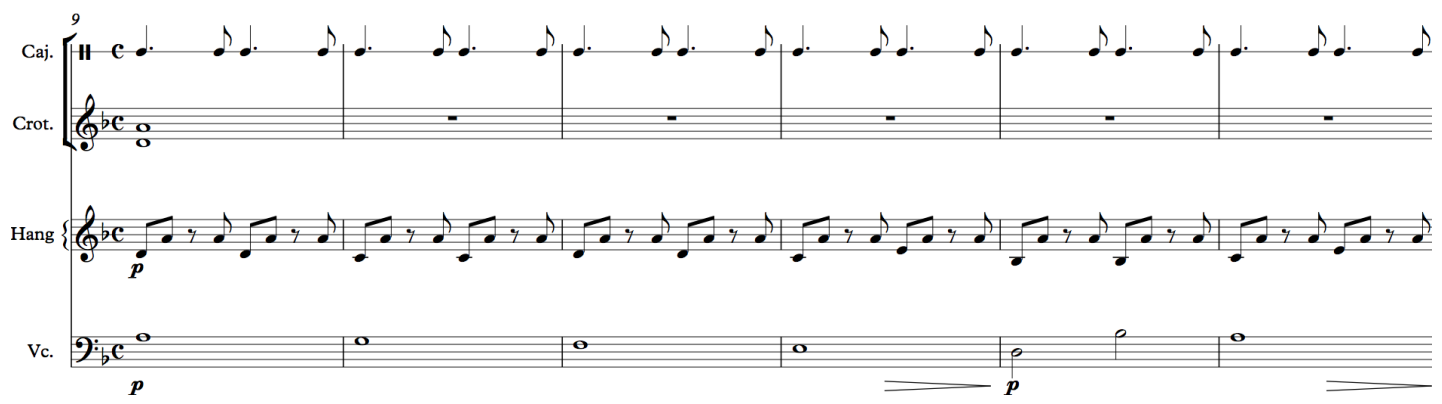

In the second section of the piece, section $A_{1}$, is a reiteration of the $\mathrm{A}$ section material with variations (Figure 24). The melodic themes are presented in the same order as in the previous section, but both are performed by the cello.

The melodies are joined by counter melody lines. The first counter melody is presented by the viola, and the second one is presented by the second violin. The counter melodies use material derived from the first melody theme.

Figure 24: Section $A_{1}$

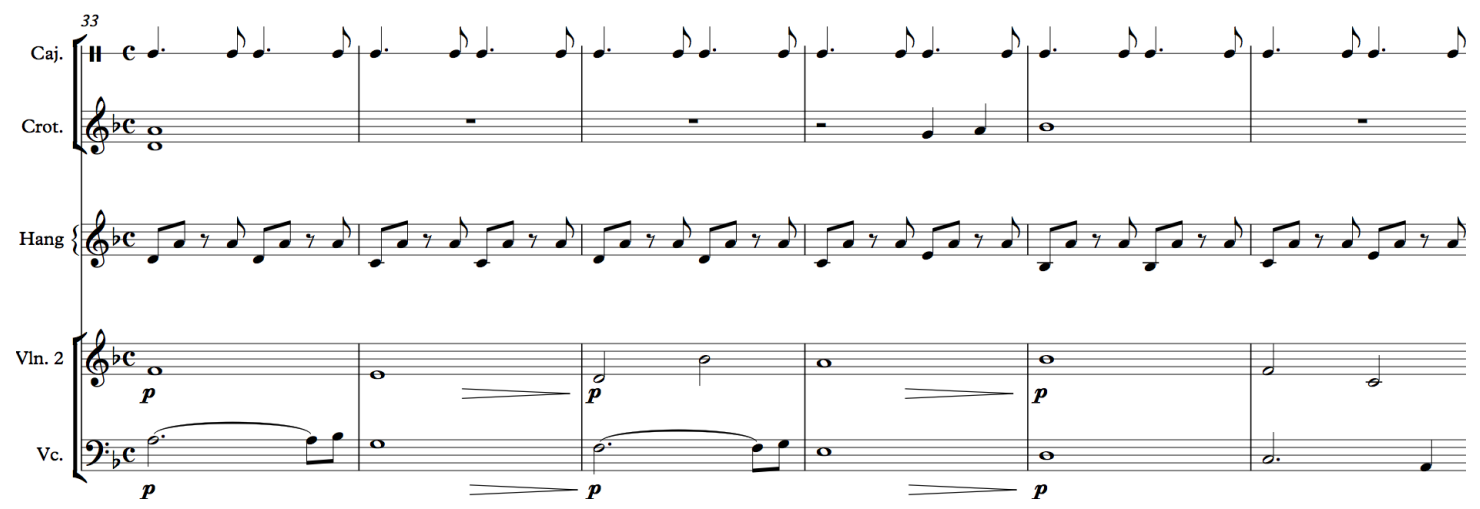

In section $\mathrm{B}$, new material is introduced with new texture. All the instruments perform together for the first time in this section (Figure 25). In the first half of the section, the marimba presents a rhythmic pattern generated from materials introduced in the introduction. This pattern 
adds a new colour to the section's texture. The melodic material presented by the violin is crafted from the first main melodic theme. Also, the cello pizzicato part adds yet another colour to the texture. This palette of sounds creates a new and distinct soundscape intended to release the mind from analytical thinking, and the slow moving harmony creates a calming effect.

\section{Figure 25: The first part of section B}

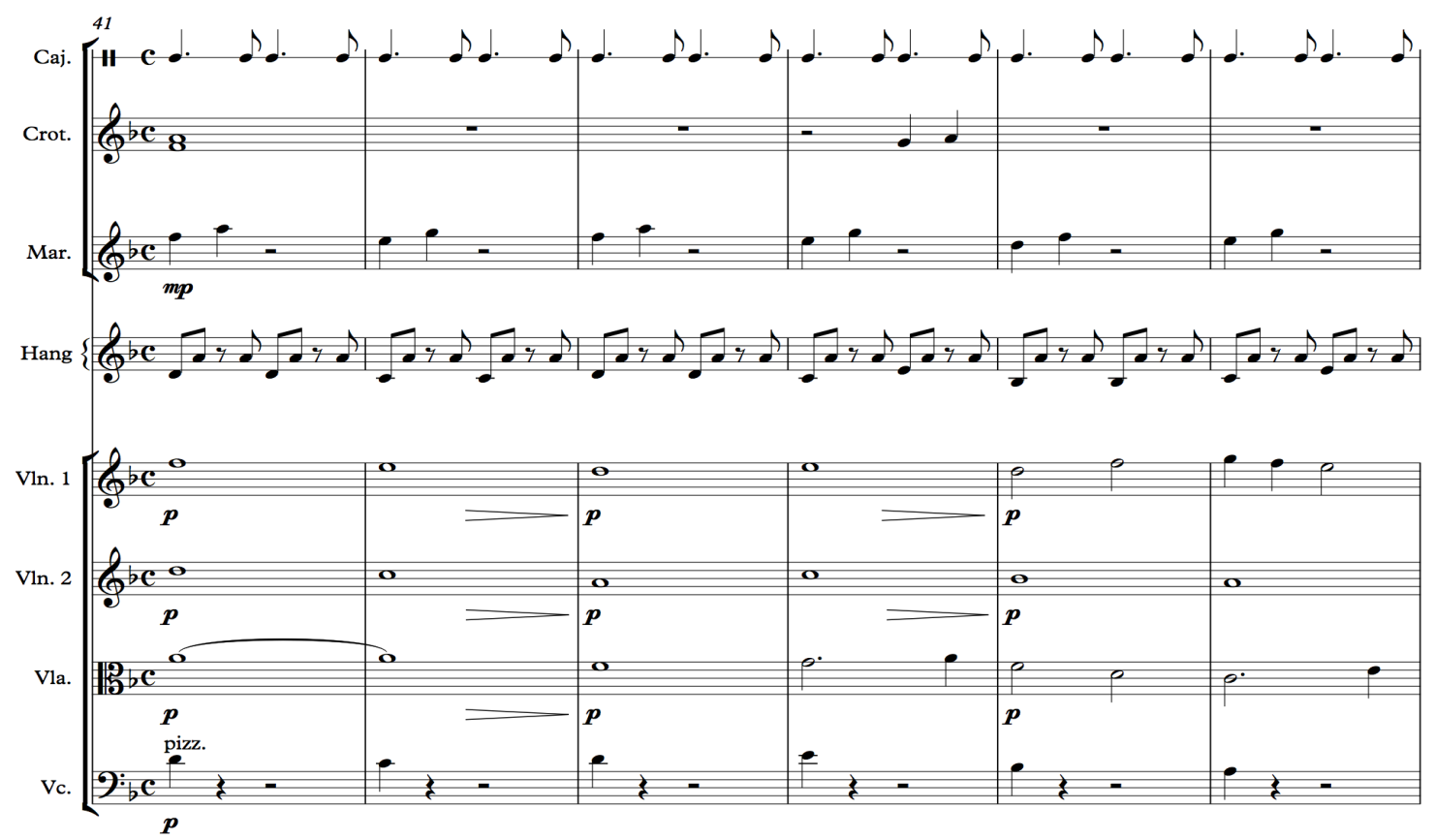

In the second part of the B section the second melodic theme is restated within a new texture. The melody is presented by the first violin, in a higher register, depicting a new image about this melody theme with different background materials, crafting a diverse soundscape.

The first part of the following $\mathrm{C}$ section, presents a two-measure long new melodic motif (Figure 26). Interest in this part is created by the moving melodic motif between the string parts. Texture created by the background material and the falling melodic motif creates content with ongoing temptation, and seeks to captivate awareness. 
Figure 26: The first part of section $C$

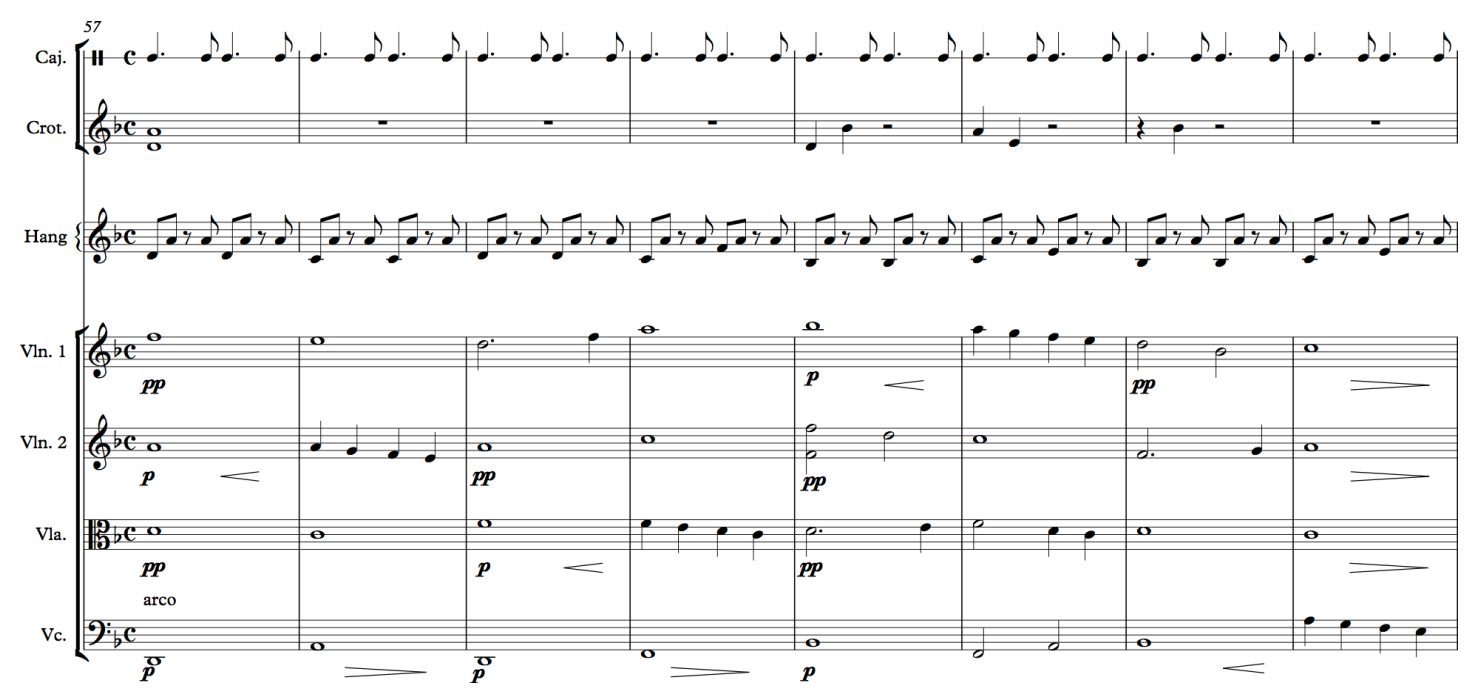

The second part of section $\mathrm{C}$ restates the first melodic theme, presented by the viola and accompanied by cello, second violin and percussions (Figure 27). The melodic theme has been slightly altered and placed in a delicate soundscape to create a soothing influence.

Figure 27: The second part of section $C$

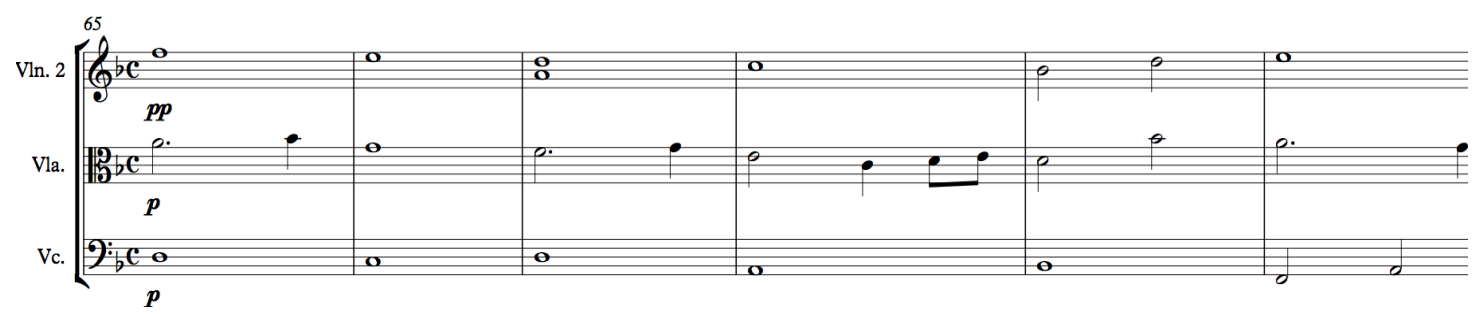

The $\mathrm{D}$ section of the piece creates another complete soundscape, by bringing back all members of the ensemble. The homorhythmic texture in the first part of the section, crafted by the string quartet combined with the percussions, creates a resting, calming feel (Figure 28). 
Figure 28: The first part of section D

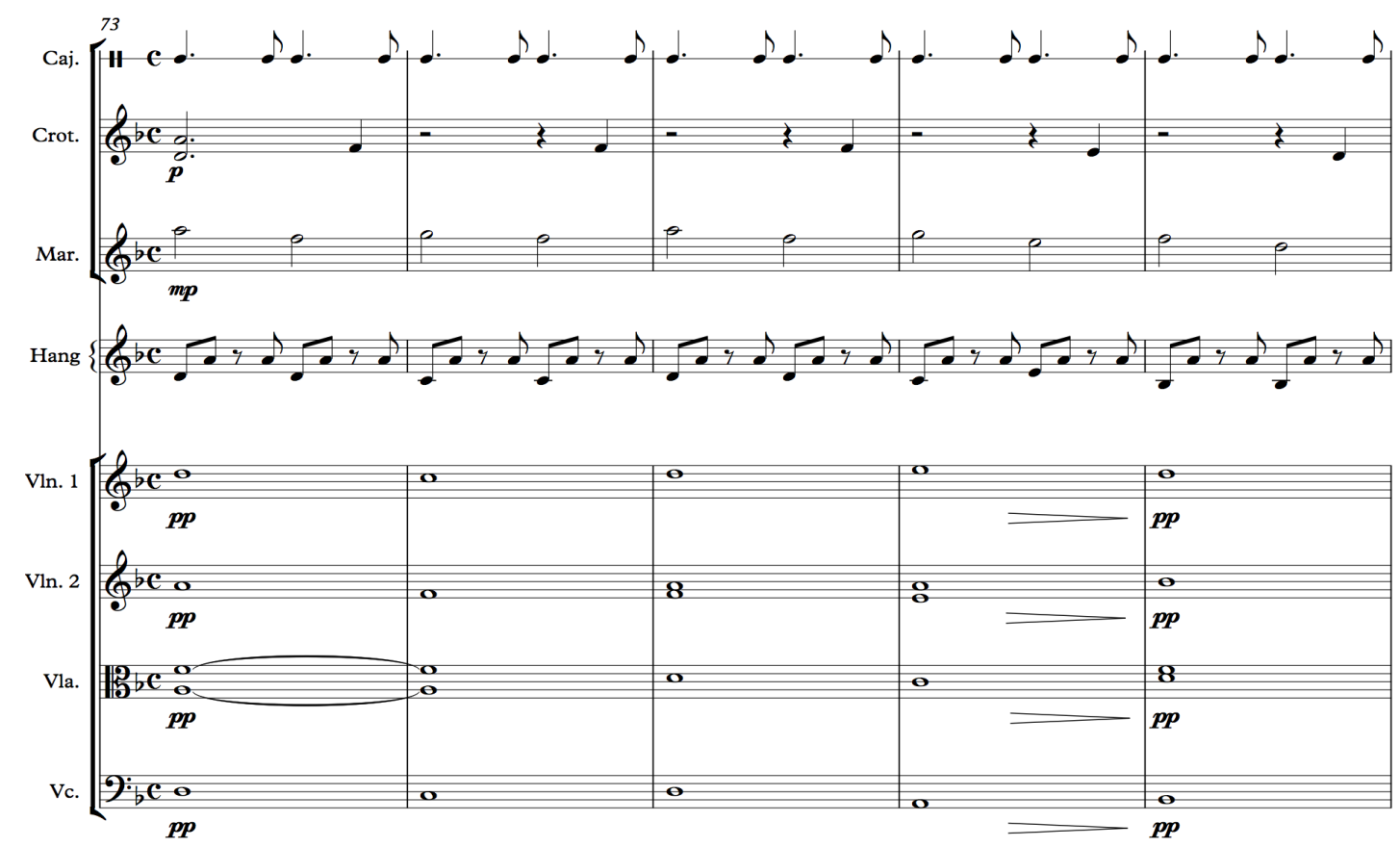

The periodic bright sound, created by the crotales in this section, can help to absorb the meditator's attention to clear away mental clutters. Another sound also, can be noted, is the pattern presented by marimba. The periodic marimba pattern helps to focus mindfulness in the present moment, to move past mental noise. The texture thickens in the second part of D section (Figure 29).

Figure 29: The second part of section D

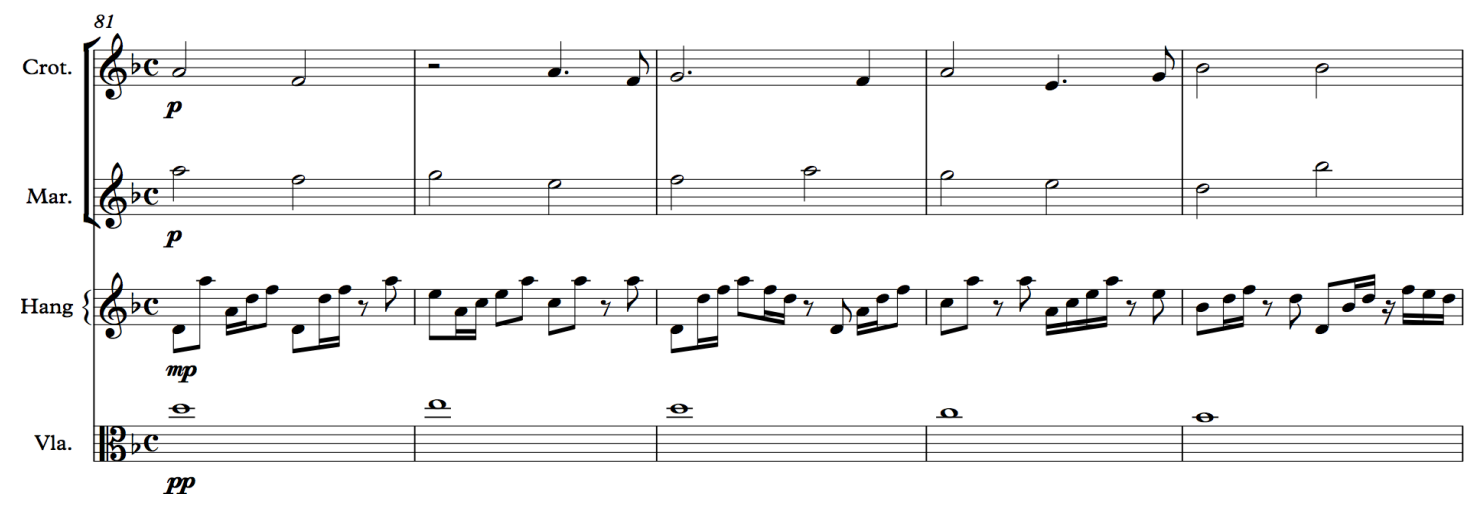


Interest is created by the arpeggiated rhythmic pattern presented by the Hang. The diverse combination of the instruments and the foreground material are intended to create a soothing musical experience that promotes insight.

The following section $A_{2}$ is a reappearance of the A section material, with both main melodic themes restated. The second melody theme is presented by the second violin, and is destined with the bass part. It recreates the same musical experience as in the beginning of the piece.

The last section of the piece, $\mathrm{A}_{3}$, echoes the second main melody theme twice in the higher register. The percussions restate material from the D section, which helps to emphasize the unity of the piece. The last two sections of the piece suggest an atmosphere to explore the relationship to the music, as a path of self-discovery. The piece ends with a coda, using a descending melody line with a homorhythmic texture in the string section along with percussions.

In the process of composing the soundscapes of the piece, the goal was to captivate objectless awareness and to calm the mind without ever becoming a distraction, with no unexpected change generated in volume or tempo. 


\section{Conclusions}

Composing the pieces for this project was a great experience for me. I was able to incorporate my musical knowledge, and take risks both in my writing and in my personal interpretation of the selected ideas.

One of the deliberations I made was exploring a wide range of sonic possibilities, and deciding which options were desirable for this project.

Having the opportunity to use the works in my meditation practices, I found that the use of repeated note series incorporated in music as mantra, helps to keep the mind focused and also to bring it back into the present moment when it wonders. I concluded that melodies with less motion tend to evoke a more calming or relaxing effect than melodies with more motion. Also, I found that the use of longer note values and slow moving harmonies helps to create a balanced and soothing atmosphere. The most successful work that help me to achieve a meditative state is Eternal Flow. The use of the drone effect and the repeated note series helps to create a calming atmosphere for meditation.

This thesis has offered numerous methods in creating compositional material based on interpreting stylistic qualities from a certain framework. My research into this unique history and inner working of chamber music and meditation music has allowed me to further appreciate these musical genres. The vast amount of research involved in the project has brought to my attention many different texts and guidebooks that I wish to further explore.

The development and challenges of this project required me to deal with diverse issues during the creative process resulting in moments of revelation and discovery, and provided me with inspiration for future projects. 


\section{Bibliography}

Abelson, Peter. Schopenhauer and Buddhism. Honolulu: University of Hawaii Press, 1993.

Adler, Samuel. The Study of Orchestration. New York: W. W. Norton , 2002.

Batchelor, Stephen. The Awakening of the West. Berkeley, California: Parallax Press, 1994.

Beales, D. Enlightenment and Reform in Eighteenth-Century Europe. London: Tauris. 2005.

Benson, Herbert. The Relaxation Response. New York: Morrow, 1975.

Bowker, John. The Concise Oxford Dictionary of World Religions. Oxford: Univ. Press, 2000.

Bronkhorst, Johannes. The Two Traditions of Meditation in Ancient India. Second. Delhi: Motilal Banarsidass, 1993.

Copland, Aaron. What to listen for in music. New York: Mentor, 1988.

Csikszentmihalyi, Mihaly. Flow: The Psychology of Optimal Experience. New York: Harper and Row, 1990.

Davies, Stephen. "Emotions expressed and aroused by music" in Handbook of Music and Emotion, edited by Patrik N. Juslin and John A. Sloboda. Oxford: Oxford University Press, 2011.

Everest, F. Alton. Master handbook of acoustics. New York: McGraw-Hill Education, 2015.

Everly, George S. Jr., and Jeffrey M. Lating. A clinical guide to the treatment of human stress response. New York: Springer, 2013.

Fields, Rick. How the swans came to the lake: a narrative history of Buddhism in America. New York: Shambhala, 1981.

Gawler, I., and Bedson, P. Meditation:an in-depth guide. New York:Tarcher/Penguin, 2011.

Harvey, P. An Introduction to Buddhism. Teachings, history and Practices. Cambridge:

University Press, 1995.

Hindemith, Paul. The craft of musica composition. New York: Associated Music Publ., 1941.

Kaplan, Aryeh. Jewish Meditation. New York: Schocken Books, 1985.

Khan, Hazrat Inayat. The Mysticism of sound and music. Boston: Shambhala, 1996. 
Langer, Susanne K. Philosophy in a new Key: a study in the symbolism of reason, rite, and art. New York: New American Library, 1951.

Leeds, Joshua. The Power of Sound. How to Be Healthy and Productive Using Music and Sound. Rochester: Healing Arts Press, 2010.

Lendvai, Ernõ. Béla Bartók: An analysis of his music. London: Kahn \& Averill, 1971.

Menuhin, Yehudi. Theme and Variations. New York: Stein and Day, 1972.

Messiaen, Oliver. The Technique of my Musical Language. Paris: Alphonse Leduc, 1956.

Meyer, Leonard B. Emotion and meaning in music. Chicago: University of Chicago Press, 1956.

Murrock, Carolyn J. "Music and Mood." In Psychology of moods, ed. Anita V. Clark, 141-153. New York: Nova Science Publishers, 2005.

Murphy, M., and S. Donovan. The Physical and Psychological Effects of Meditation. Petaluma: Inst. of Noetic Sciences, 1997.

Reybrouck, Mark. "The Musical Code between Nature and Nuture." In The Codes of Life: The Rules of Macroevolution, by Marcello Barbieri. Ferrara: Springer Science, 2008.

Samuel, Geoffrey. The Origins of Yoga and Tantra: Indic Religions to the Thirteenth Century. Cambridge: Cambridge University Press, 2008.

Schoenberg, Arnold. Fundamentals of Musical Composition. London:Faber and Faber Ltd. 1967.

Schoenberg, Arnold. Structural Functions of Harmony. New York: Norton \& Compan , 1954.

Schoenberg, Arnold. Style and Idea. New York: Philosophical Library, 1950.

Smith, Jonathan C. Relaxation, meditation, and mindfulnes: a practical guide. New York: Springer Pub. Co., 2005.

Steblin, Rita. A history of key characteristics in the eighteenth and early nineteenth centuries. Ann Arbor, Mich.: UMI Research Press, 1983.

Stevens, Christine. Music medicine: the science and spirit of healing yourself with sound. Boulder, Colo.: Sounds True, 2012.

Stevenson, A., and M. Waite. Oxford English Dictionary. New York: Oxford Univ. Press, 2011.

Tame, David. The Secret Power of Music. Rochester, Vermont: Destiny Books, 1984. 
Weber, Susan. "Music: A means of comfort." In Music Therapy in Palliatice Care: New Voices, edited by David Aldridge, 95-104. London: Jessica Kingsley Publishers, 1999.

Wilson, V. E., and Cummings, M. S. Learned, Self-Regulation. Toronto: York St. A.\& M., 2015.

\section{Journal Articles}

Baime, Michael J. "Meditation and Mindfulness." In Essentials of Complementary and Alternative Medicine. New York: Lippincott, Williams and Wilkins, (1999): 523-537

Balick, M. J., and R. Lee. "The power of sound: Ethnomedical tradition and modern science." Alternative Therapies 9 (2003): 63-72.

Balkwill, L. L., and Thompson, W. F. "A cross-cultural investigation of the perception of emotion in music: Psychophysical and cultural cues". Music Perception: An Interdisciplinary Journal, Vol. 17, (1999): 43-64.

Cahn, R. B., and J. Polich. "Meditation states and traits: EEG, ERP, and neuroimaging studies." Psychological Bulletin 132, no. 2 (2006): 180-211.

Gabrielsson, A., and P. N. Juslin". Emotional expression in music performance: Between the performer's intention and the listener's experience". Psychology of Music. (1996). 68-91.

Gaston, E. T. "Dynamic music factors in mood change." Music Educators Journal (1951): 42-44.

Gilman, L., and F. Paperte. "Music and your emotions." Journal of Clinical and Experimental Psychopathology and Quarterly Review of Psychiatry and Neurology (Liveright), 1949: 9-13.

Hevner, K. "Experimental Studies of the Elements of Expression in Music." The American Journal of Psychology 48 (1936): 246-268.

Khobragade, Y., Khobragade, S., and Abbas, A. bin L. Michelle."Hypertension and meditation: can meditation be useful in preventing hypertension?" Int. Journal of Community Medicine and Public Health 3. (2016):1685-1695.

Lefevre, Michelle."Playing with sound: the therapeutic use of music in direct work with children." Child and Family Social Work 9 (2004): 333-345.

Raffone, A., and N. Srinivasan. "The exploration of meditation in the neuroscience of attention and consciousness". Cognitive Processing. (2010): 1-7.

Smith, J. L., and J. Noon. "Objective measurement of mood change induced by contemporary music." Journal of Psyhiatric and Mental Health Nursing 5 (1998): 403-408.

Strevy, S. R. "Listen to the music." Nursing 29 (1999): 32-38. 
Taylor, I.A., and F. Paperte. "Current Theory and Research in the Effects of Music on Behaviour." Journal of Aesthetics 17, no. 2 (1958): 251-258.

\section{Web Sites}

Consumers, Dorland's Medical Dictionary for Health. The Free Dictionary.

http://medical-dictionary.thefreedictionary.com/meditation (accessed Nov. 7, 2016).

Madani, Linda. "The Power of Mantra Chanting." Intuitive Flow. Aug. 06, 2016.

http://www.intuitiveflow.com (accessed Jan. 9, 2017).

Ruth, Diana St. BBC UK, Religions. 08 18, 2005.

http://www.bbc.co.uk/religion/religions/buddhism/history/britishbuddhism_1.shtml (accessed Oct. 15, 2016). 


\section{Discography}

Arellano, Pablo. Enjoy \& Relax Healing Music: Sacred Moments. Healing Music B01BF1AYHQ. 2016, compact disc.

Arellano, Pablo. Moon Light Piano Healing Music. Pablo Arellano B00FFSA8F0. 2013, compact disc.

Beethoven, L. van. String Quartets, Vol.9. Kodály Quartet. Naxos. 8.554594. 2001. compact disc.

Bhatia, Vanraj. Indian Meditation Music. Music Today. 026. 1994. compact disc.

Coltrane, John. A Love Supreme. Impulse! B001097002. 1945. digital.

Coltrane, John. Om. Impulse! 39118. 1989. compact disc.

Conway, Chris. Music for Relaxation \& Healing: Yoga Gold. Paradise Music PMCD0038. 2009, compact disc.

Finzi, Gerald. Meditation. Simon Streatfeild \&Manitoba Chamber Orchestra. CBC Records. SMCD5204. 1999. compact disc.

Halpern, Steven. In the Om Zone. Halpern Inner Peace. 8030. 2007. compact disc.

Haydn, Joseph. Haydn. String Quartets, No. 53/61/66. Jerusalem Quartet. Harmonia Mundi. 2961823. 2008. compact disc.

Hindemith, Paul. The Sonatas for Viola and Piano/Meditations. Imai, N. \& Pontinen R.BIS-CD651. 1994. compact disc.

Horn, Paul. Inside the Taj Mahal. Epic Records. Pet-26466. 1968. vinyl.

Mozart, W. A. Mozart for Meditation. János Bálint. Naxos. 8.557651. 2005. compact disc.

Oliveros, Pauline. Deep Listening. Stuart Dempster, Panaiotis. New Albion Records. 22. 1988. compact disc.

Pärt, Arvo. Arvo Pärt Portrait. Angèle Dubeau \& La Pietà. Analekta. 28731. 2010. compact disc.

Pruess, Craig. Sacred Chants of Buddha. Heaven On Earth Music B001959Q3C. 2002, compact disc. 
Ravel, Maurice. Ravel: Bolero. Arthur Fiedler \& The Boston Pops Orchestra. Sony M. 00004TCP7. 2000. compact disc.

Schoener, Eberhard. Meditation. Kuckuck 12059-2. 1982, compact disc.

Scott, B., Michell, C. Tibetan Chakra Meditations. Oradea Music B000QZWETO. 1999, compact disc.

Scott, Tony. Music for Zen Meditation and Other Joys. Verve. 9884041. 2005. compact disc.

Tashi, Lama. Tibetan Master Chants. Spirit Music. B00030M9Z6. 2004. compact disc.

Tymoczko, Dmitri. Beat Therapy. Bridge Record Inc. 9353, 2011. compact disc.

Vivaldi, Antonio. Sonatas for strings, Vol.1. Purcell Quartet. Chandos. CHAN0502. 1990. compact disc.

Wagner, Richard. Lohengrin. Karajan, H. von/ Berlin Philharmonic Orchestra. EMI Music Distribution. 66519. 1997. compact disc. 


\section{Appendix A: Types of Meditation}

A brief description about the meditation types mentioned in the paper.

Chakra Meditation - the practitioner focuses on one of the seven chakras of the body (centers of energy), typically doing some visualizations and chanting a specific mantra for each chakra. Guided Meditation - is a process by which one or more participants meditate with the help of a meditation teacher, or by listening to a guided meditation recording, helping to guide the meditator's attention to achieve a meditative state.

Mindfulness Meditation - is the practice of intentionally focusing on the present moment, while calmly acknowledging and non-judgmentally paying attention to the sensations, thoughts, and emotions that arise.

Sound Meditation - the type of meditation that is focusing on sound. Firstly, starts with meditation on external sounds, such as music, whereby the practitioner focuses all his attention on just hearing, to calm the mind. The final goal is to hear the internal sounds of the body and mind.

Taoist Meditation - the main characteristic of this type of meditation is the generation, transformation, and circulation of inner energy. The purpose is to calm the body and mind, unify body and spirit, find inner peace.

Transcendental Meditation - a technique for detaching oneself from anxiety and promoting harmony and self-realization by meditation, it involves the use of a mantra.

Vipassana Meditation - in general emphasize starting with mindfulness of breath in the first stages, to stabilize the mind, then the practice moves on to developing clear insight on the bodily sensations and mental occurrences, noticing them moment by moment and not clinging to any. Zen Meditation - is a Japanese school of meditation emphasizing the value of meditation and intuition, revolves around observation of your thoughts and how mind and body operate. 


\section{Appendix B: Scores}

\section{Eternal Flow}
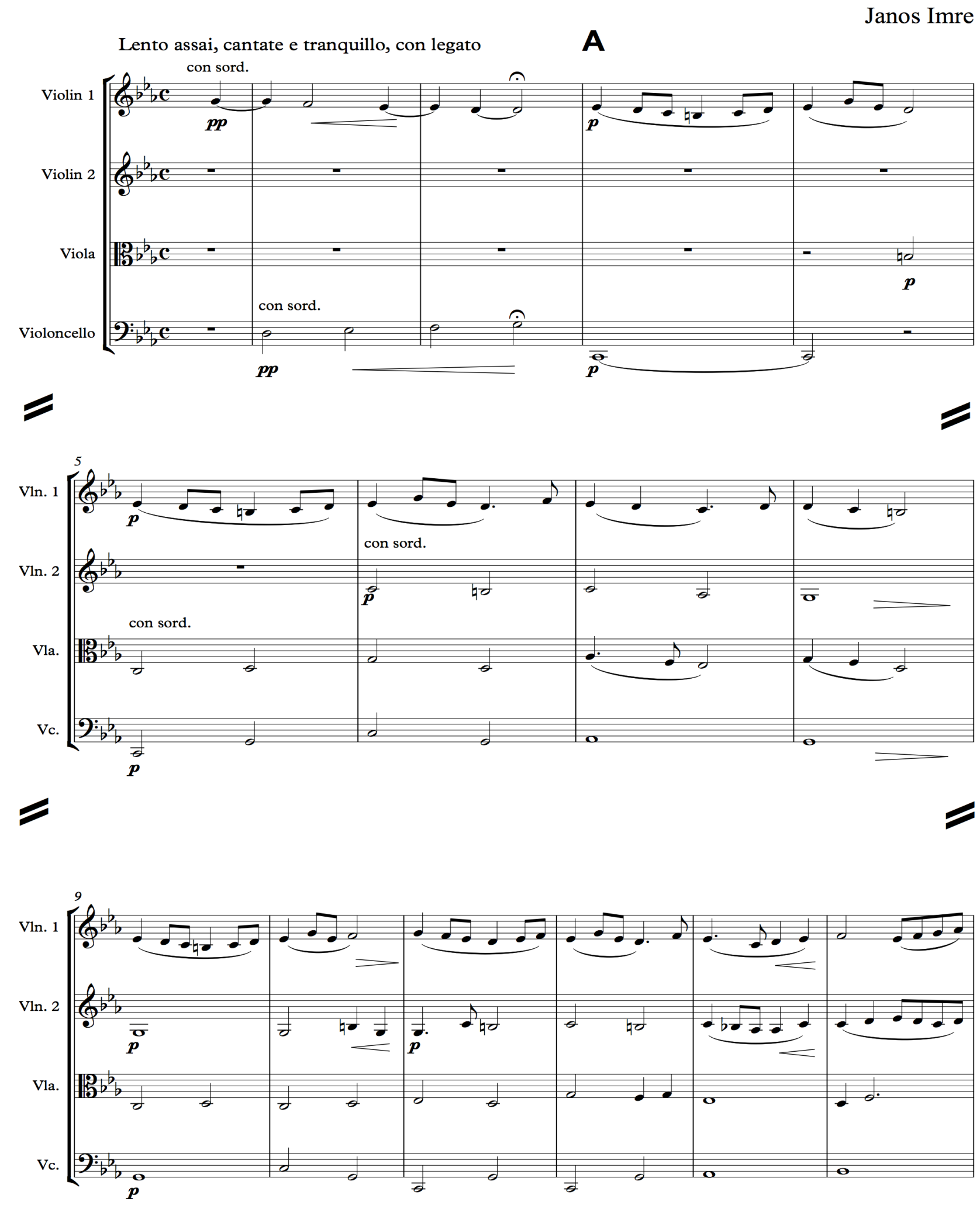

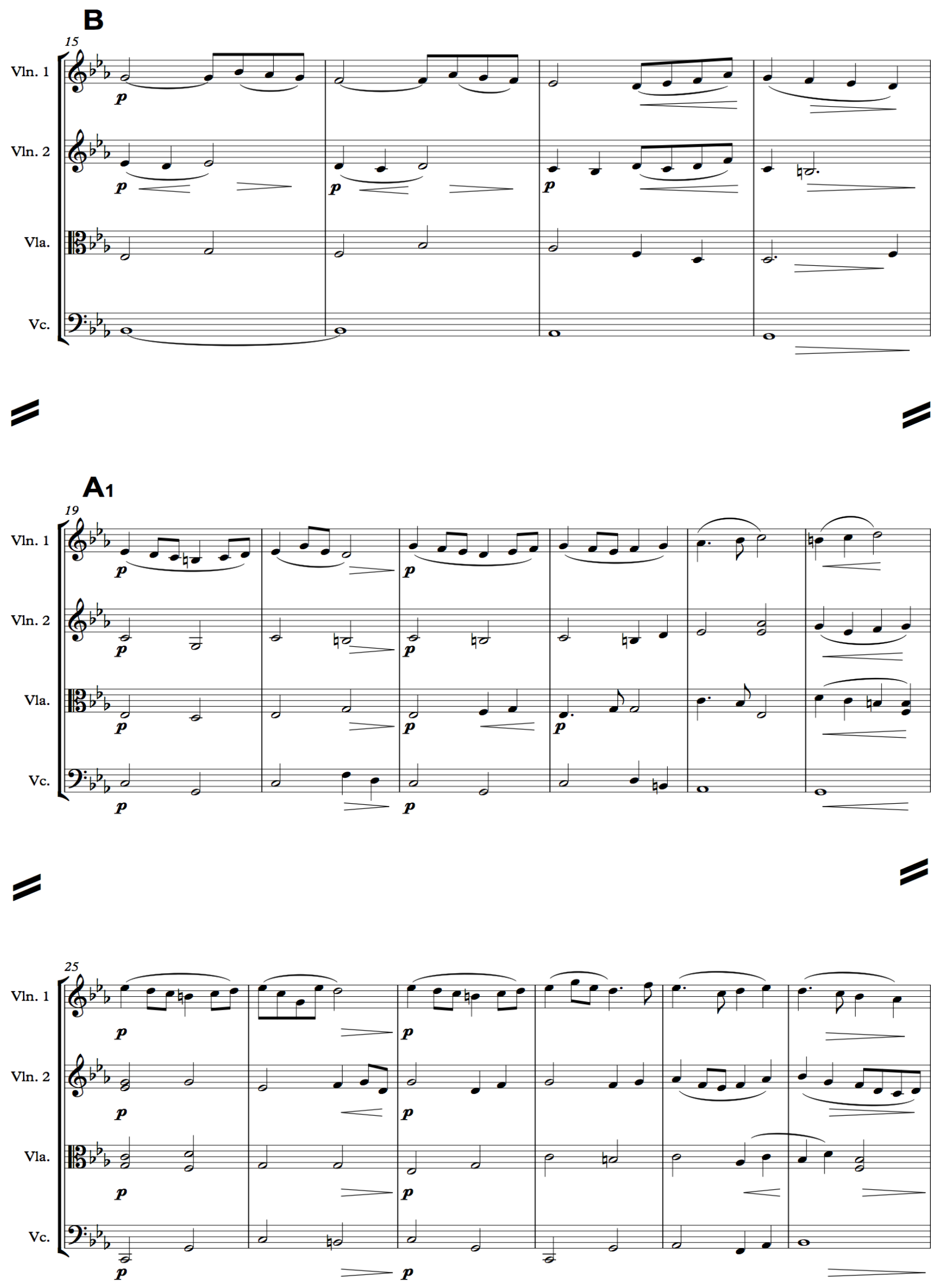

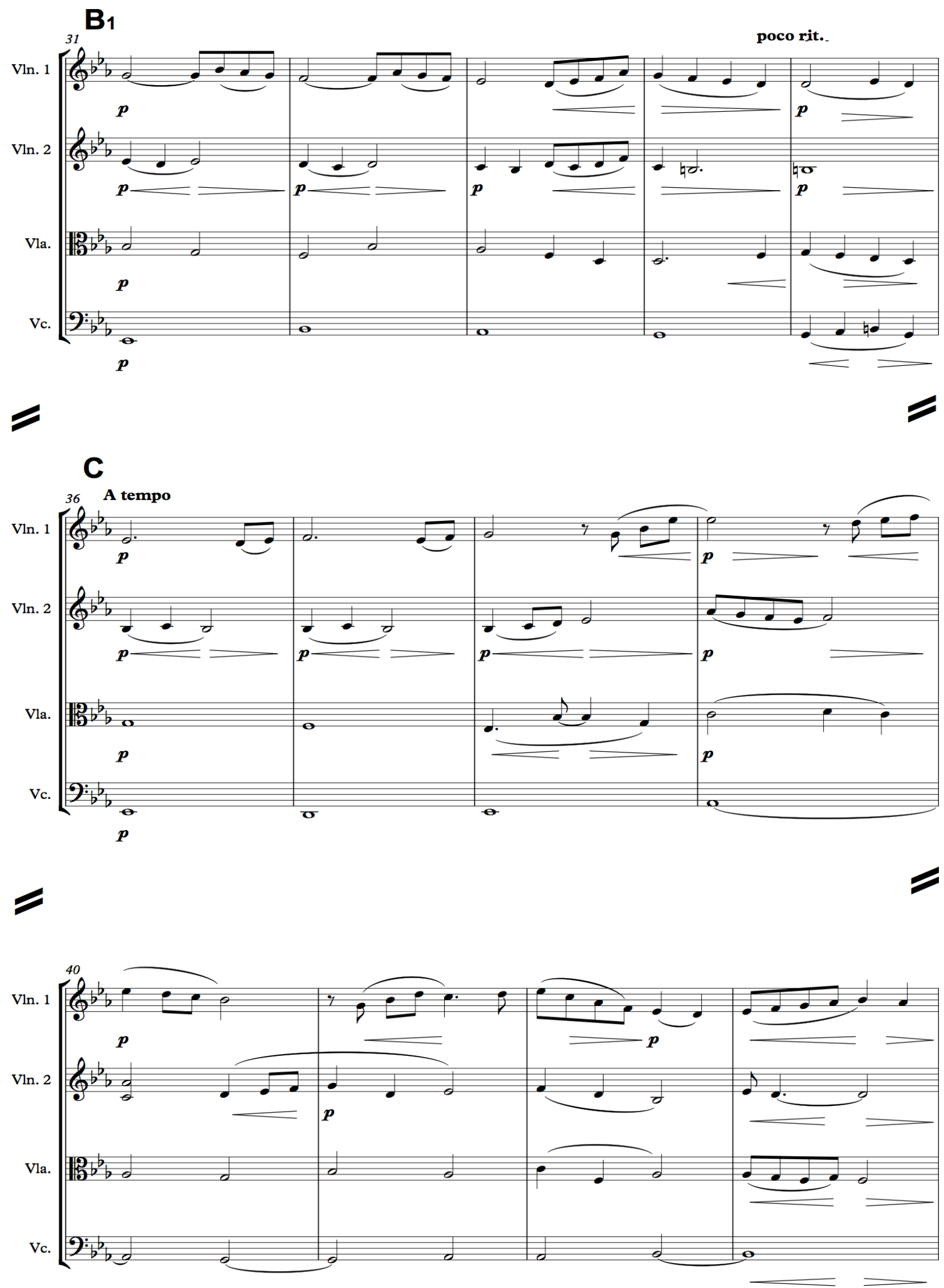

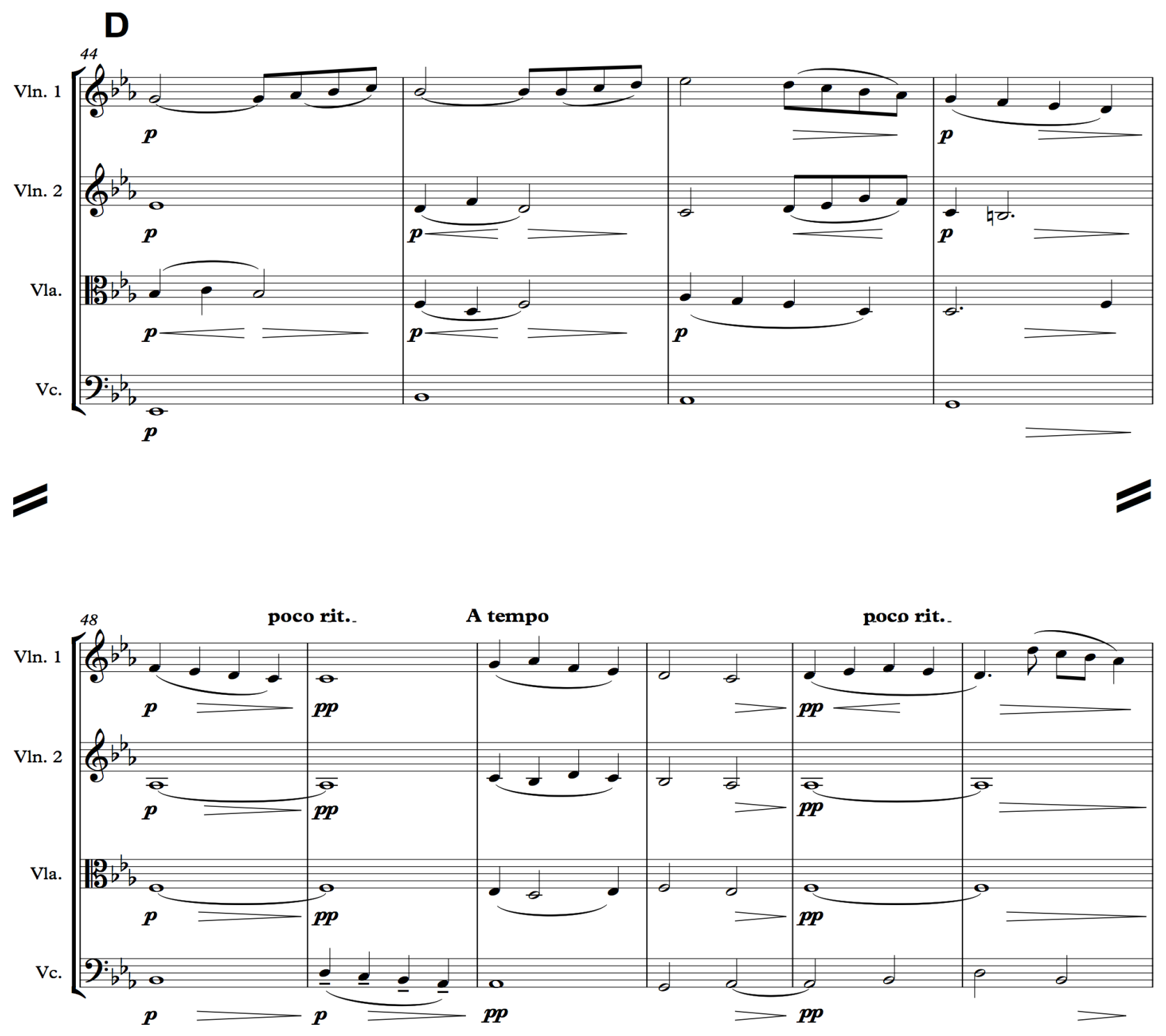

A2

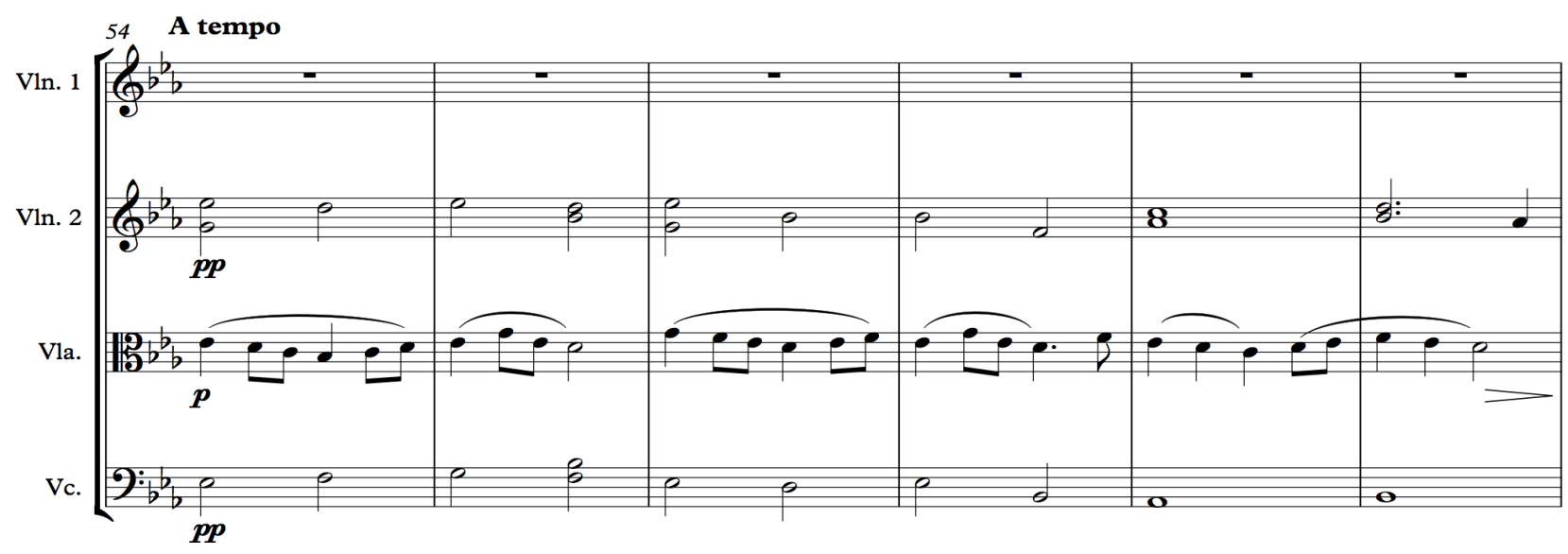




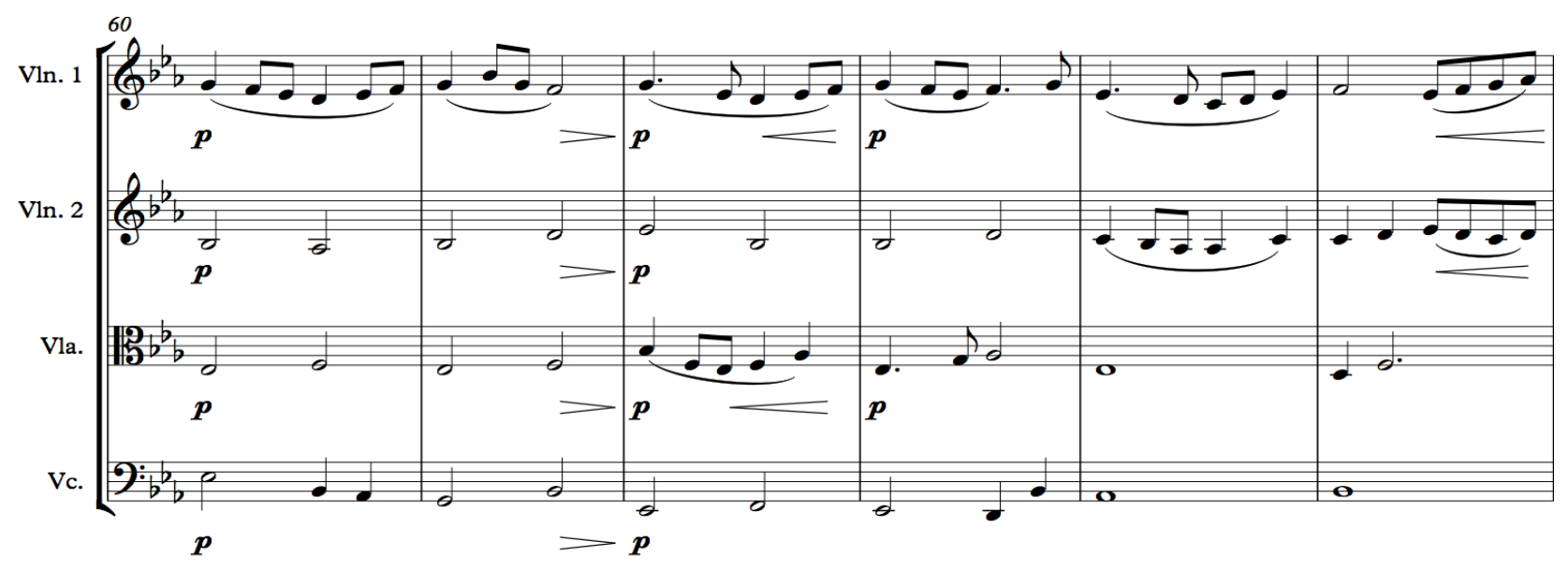

$\mathrm{B}_{2}$

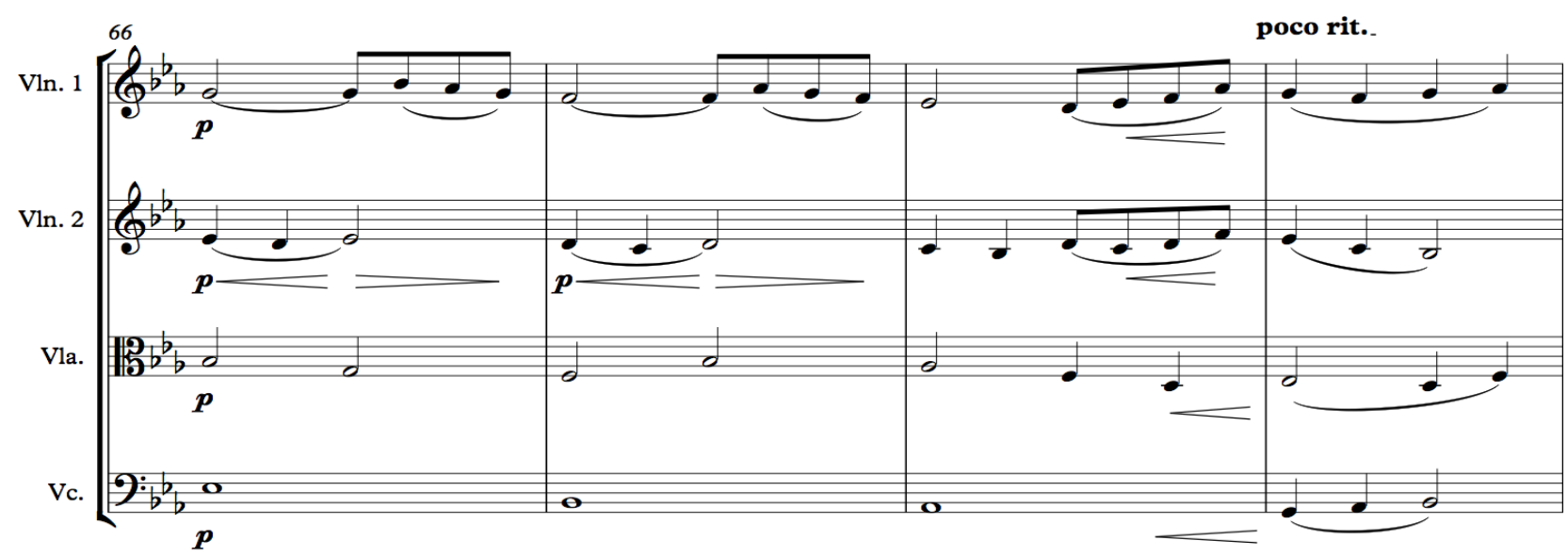

$\mathrm{A}_{3}$

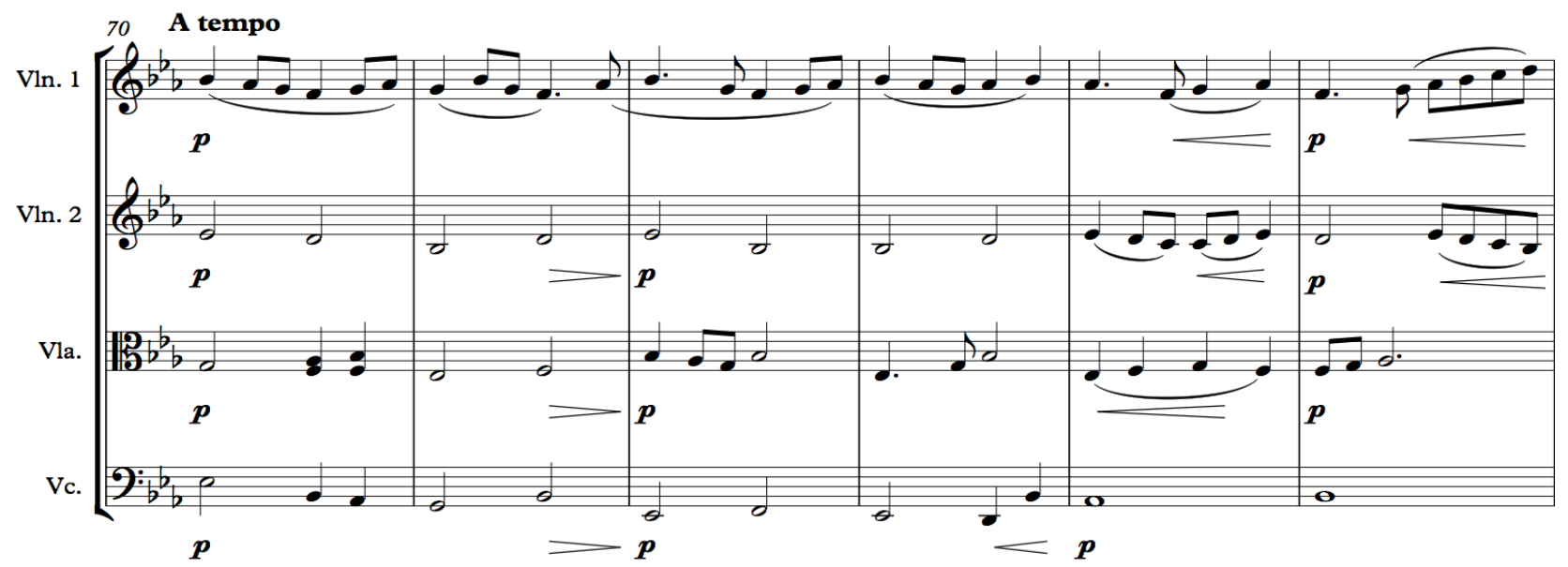




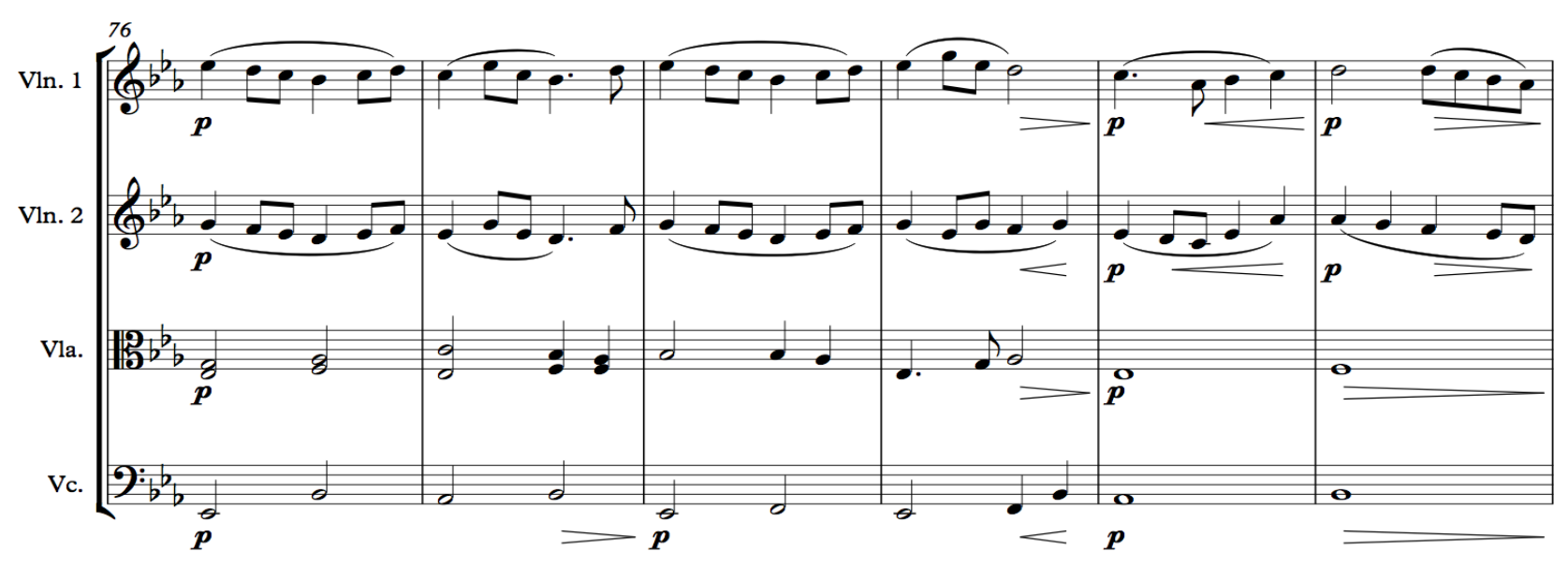

\section{B3}

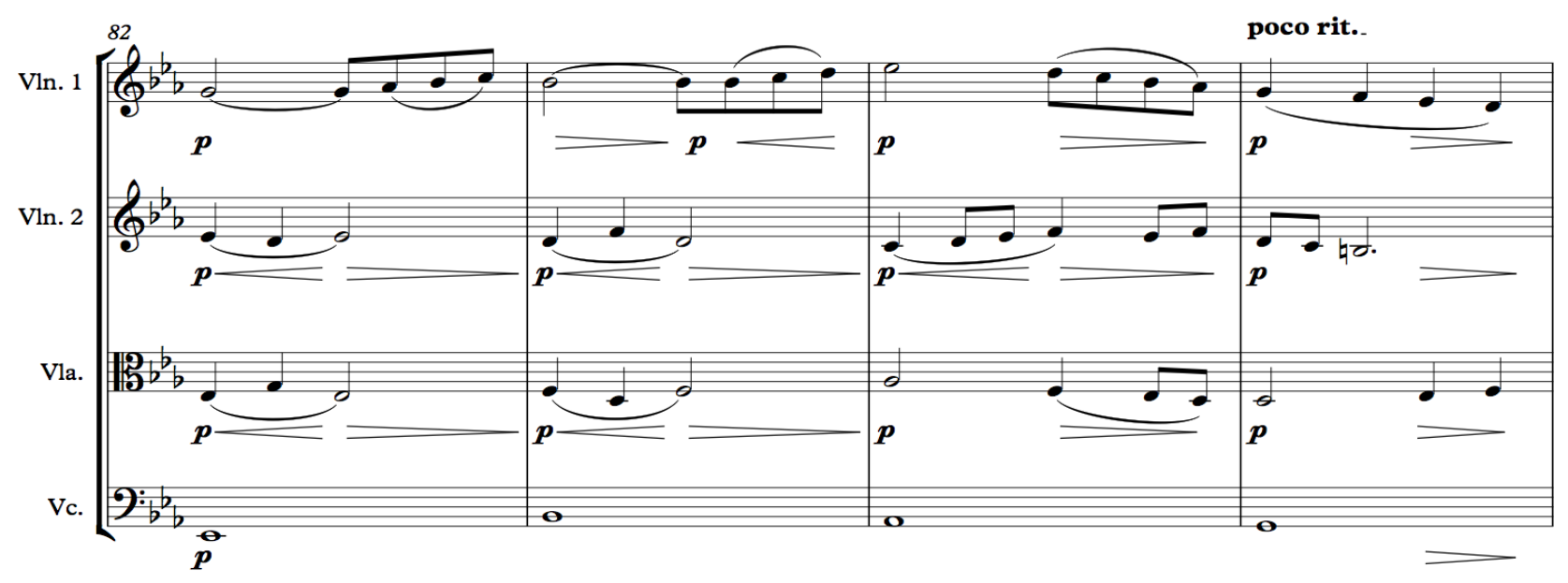

\section{Coda}

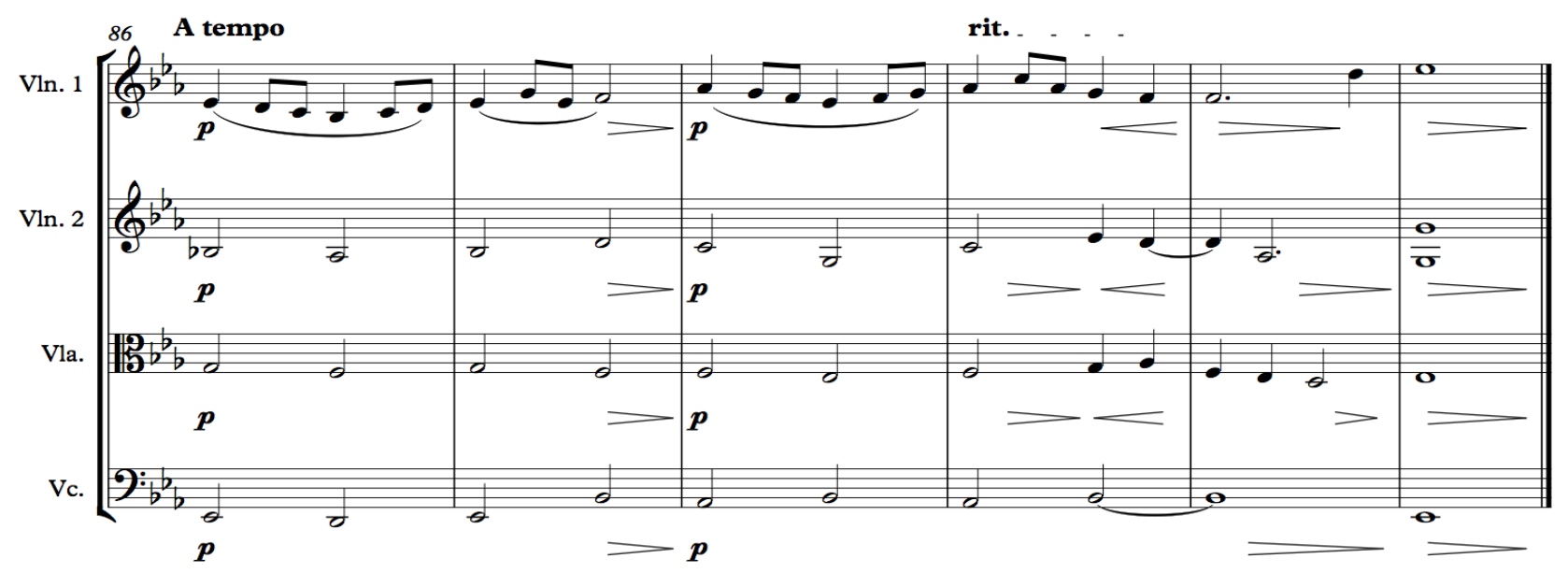




\section{Inner Zone}

Janos Imre

Larghetto, espressivo con legato

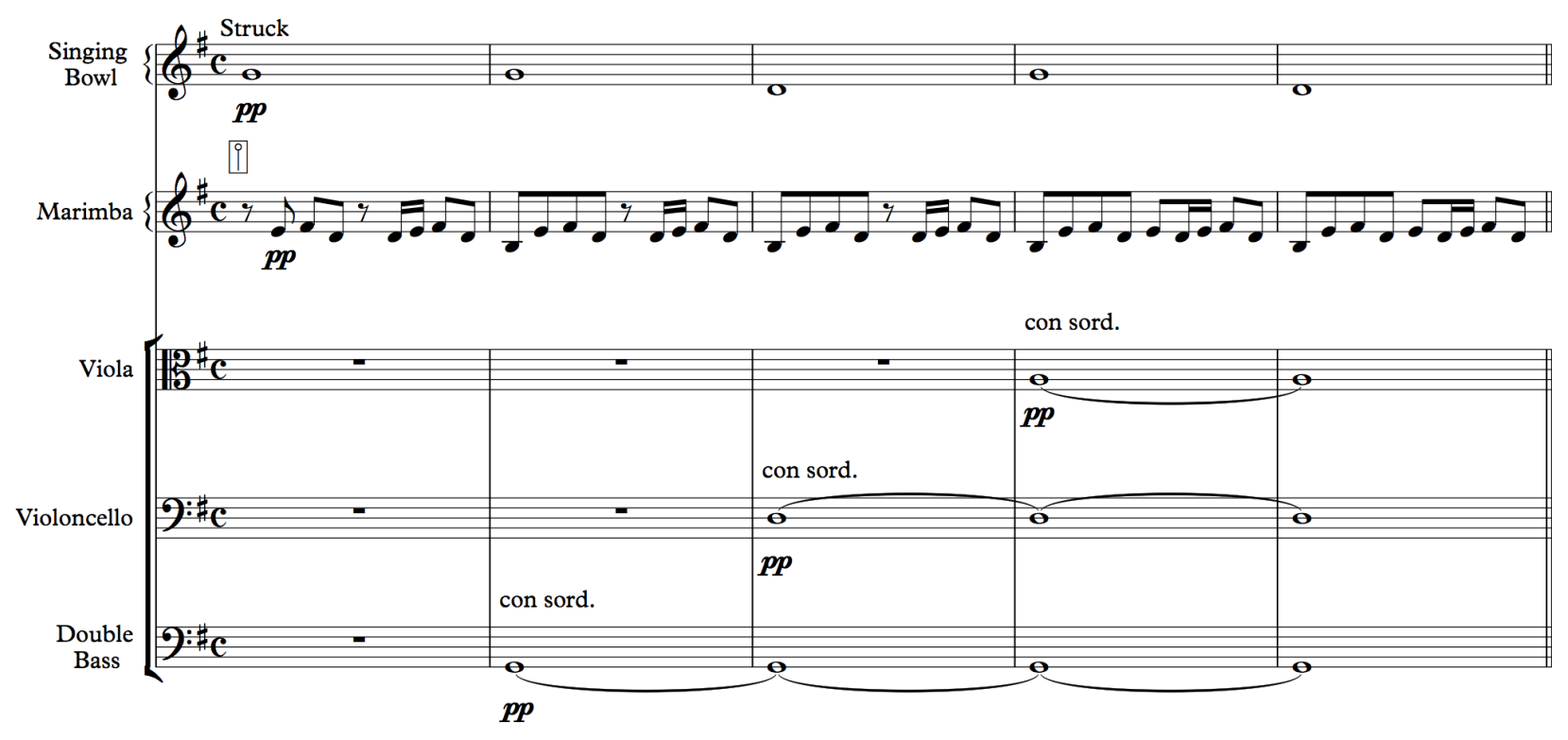

A

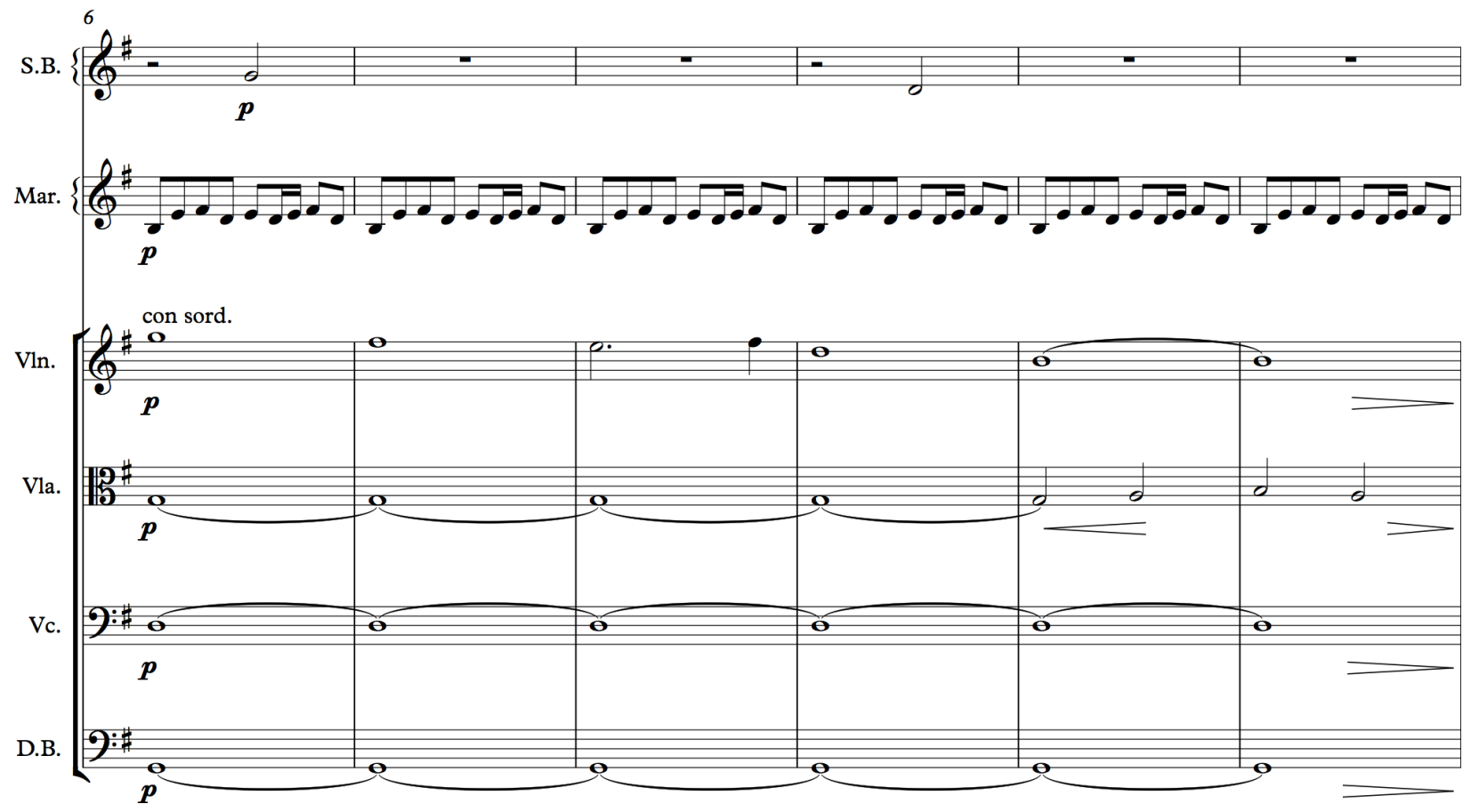



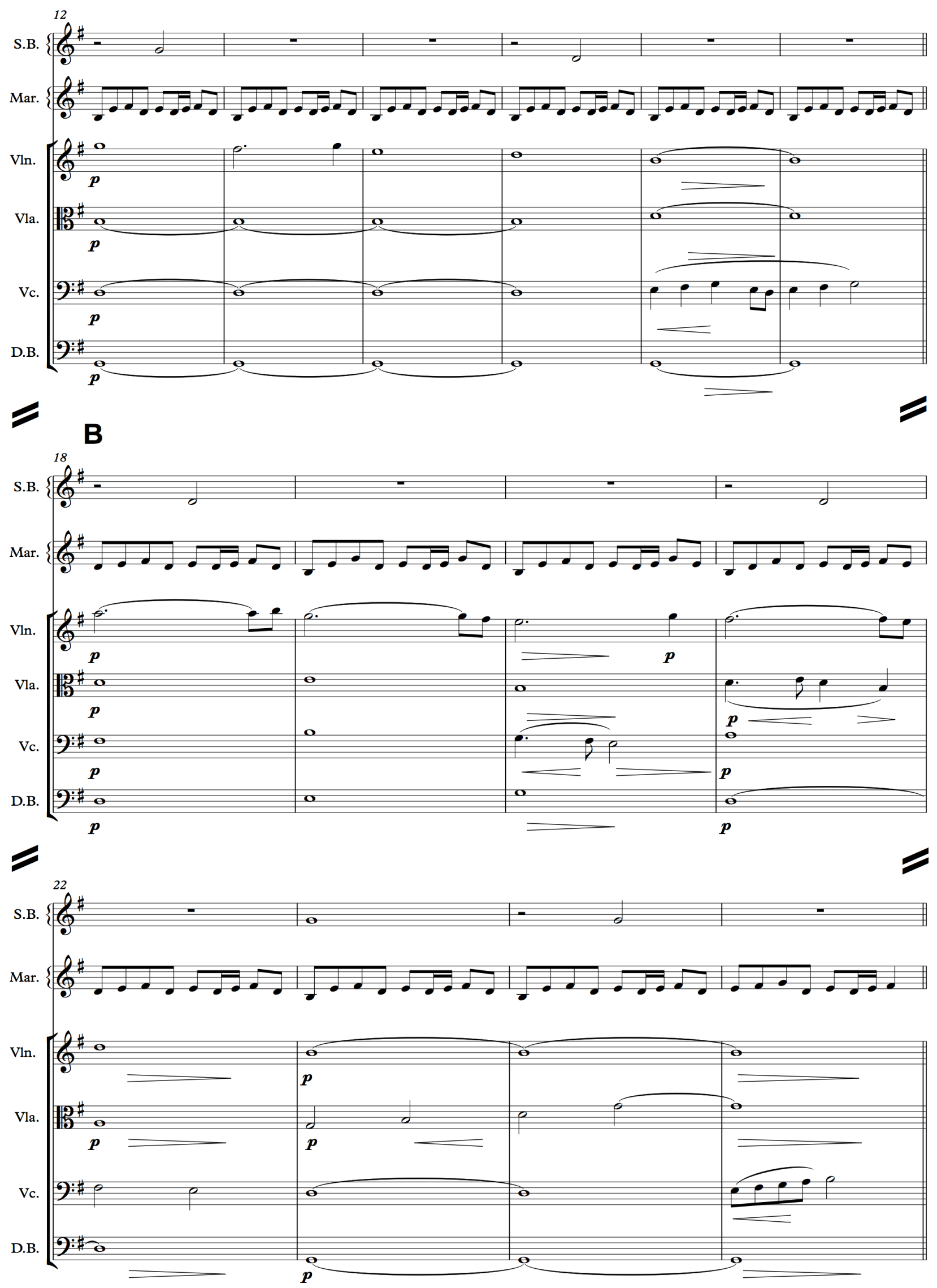

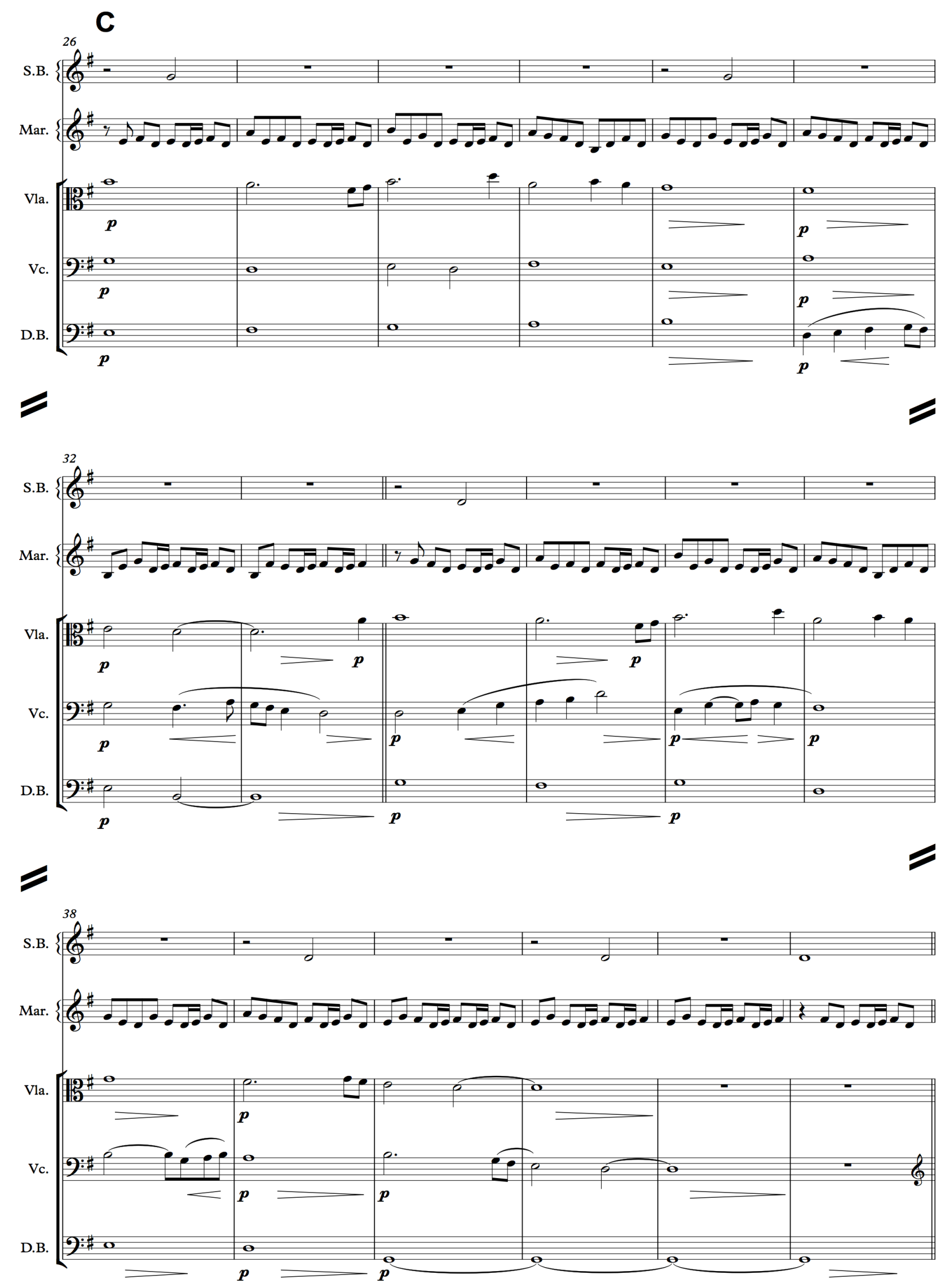

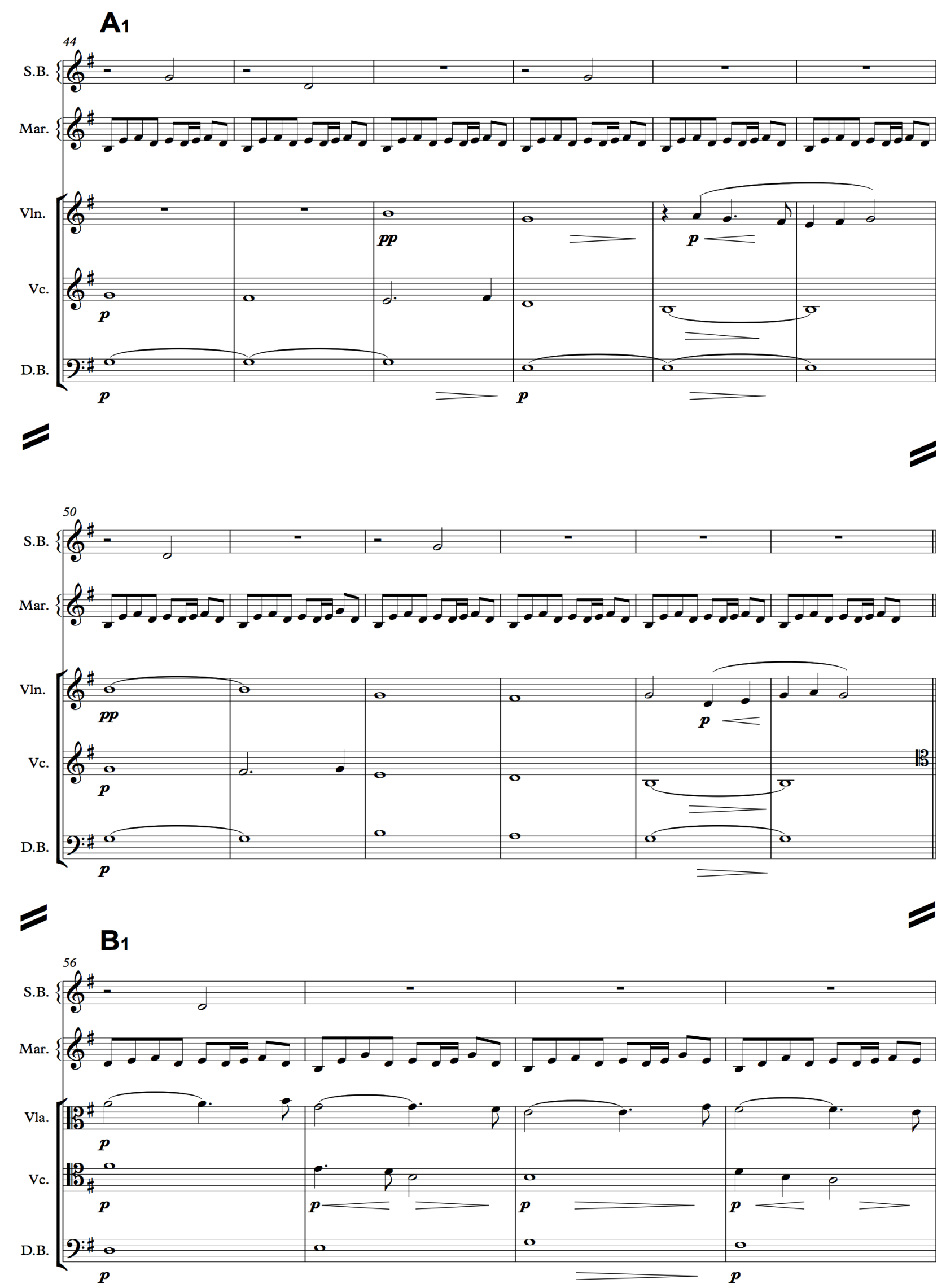

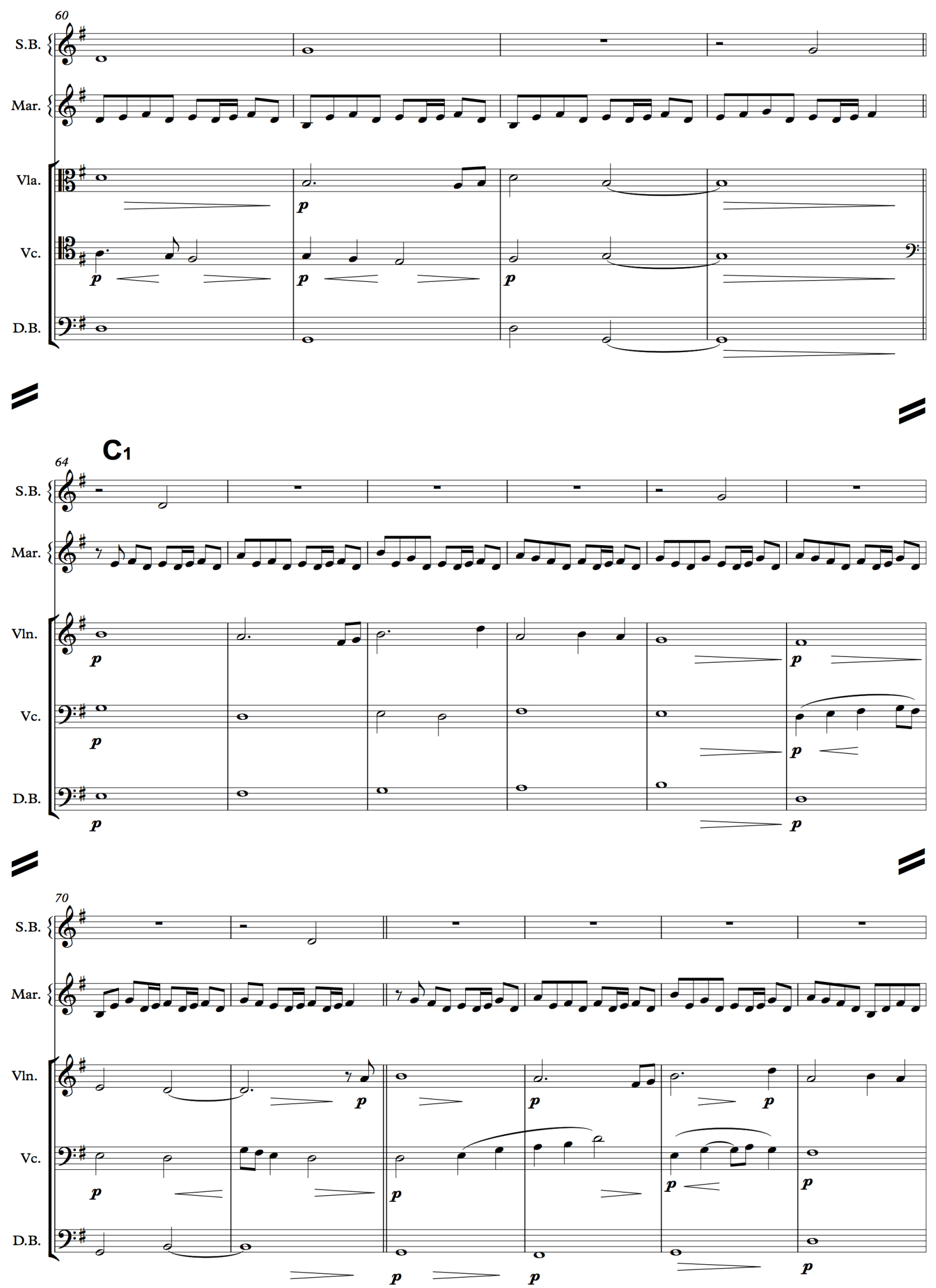

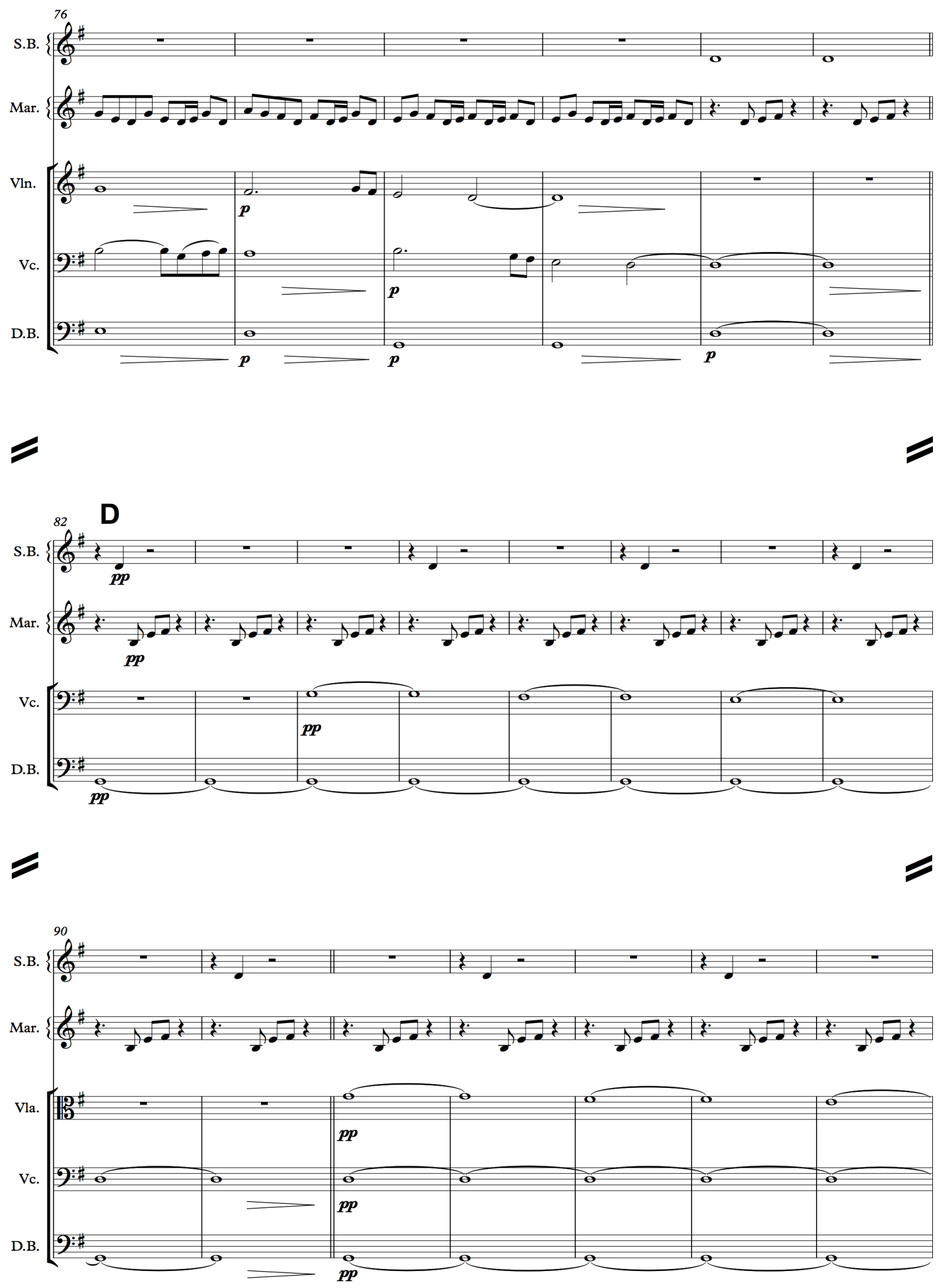

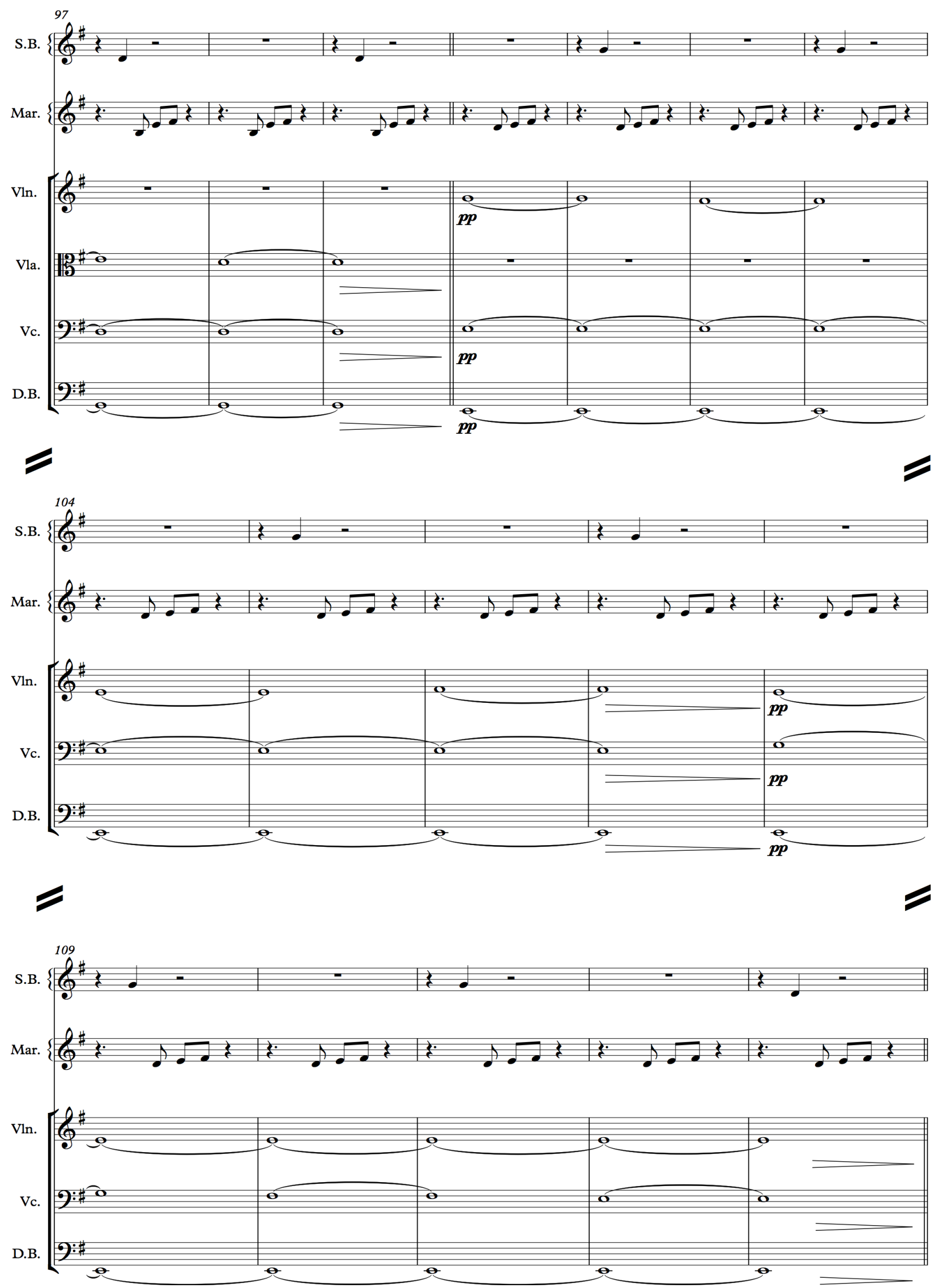

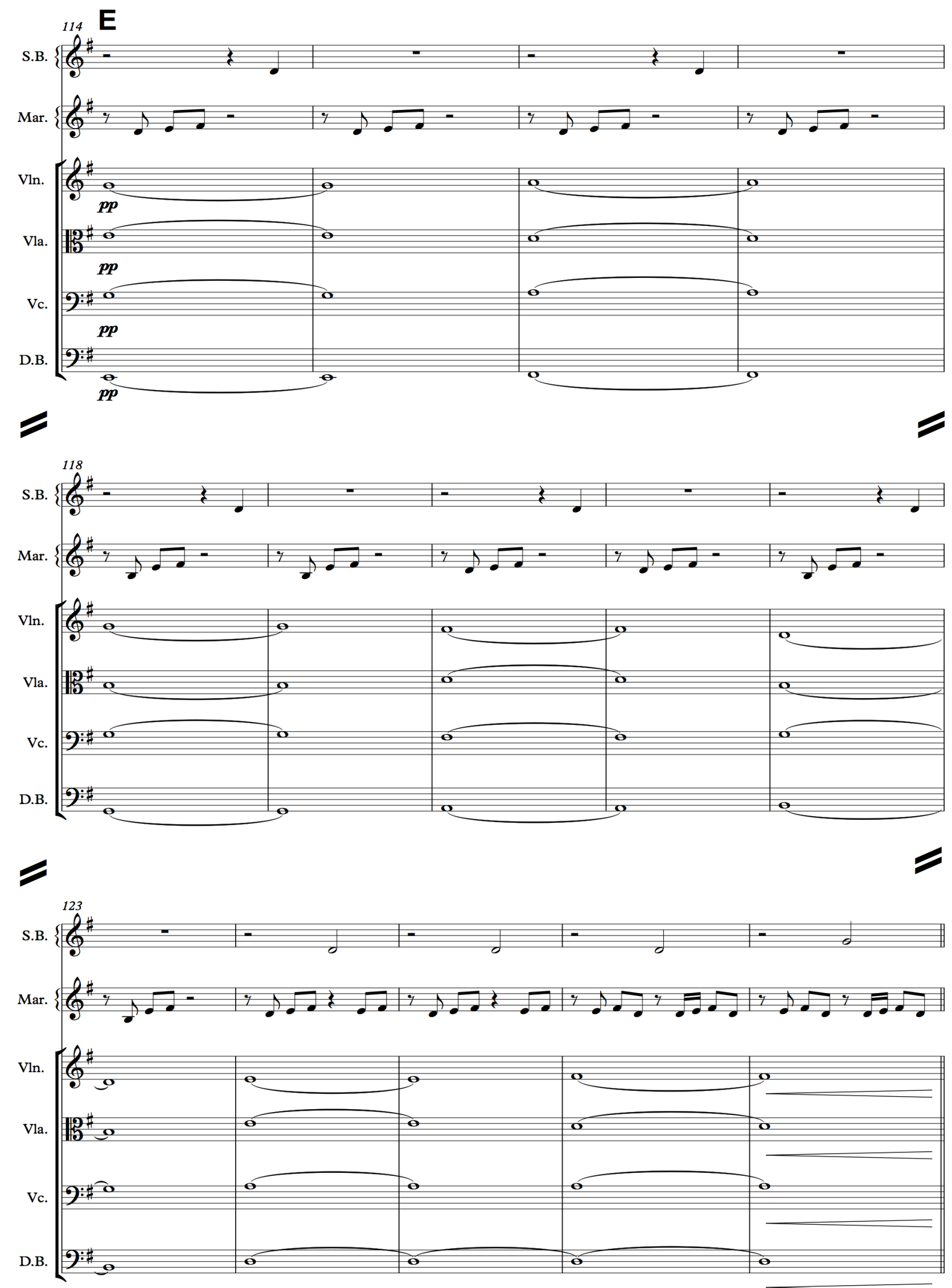

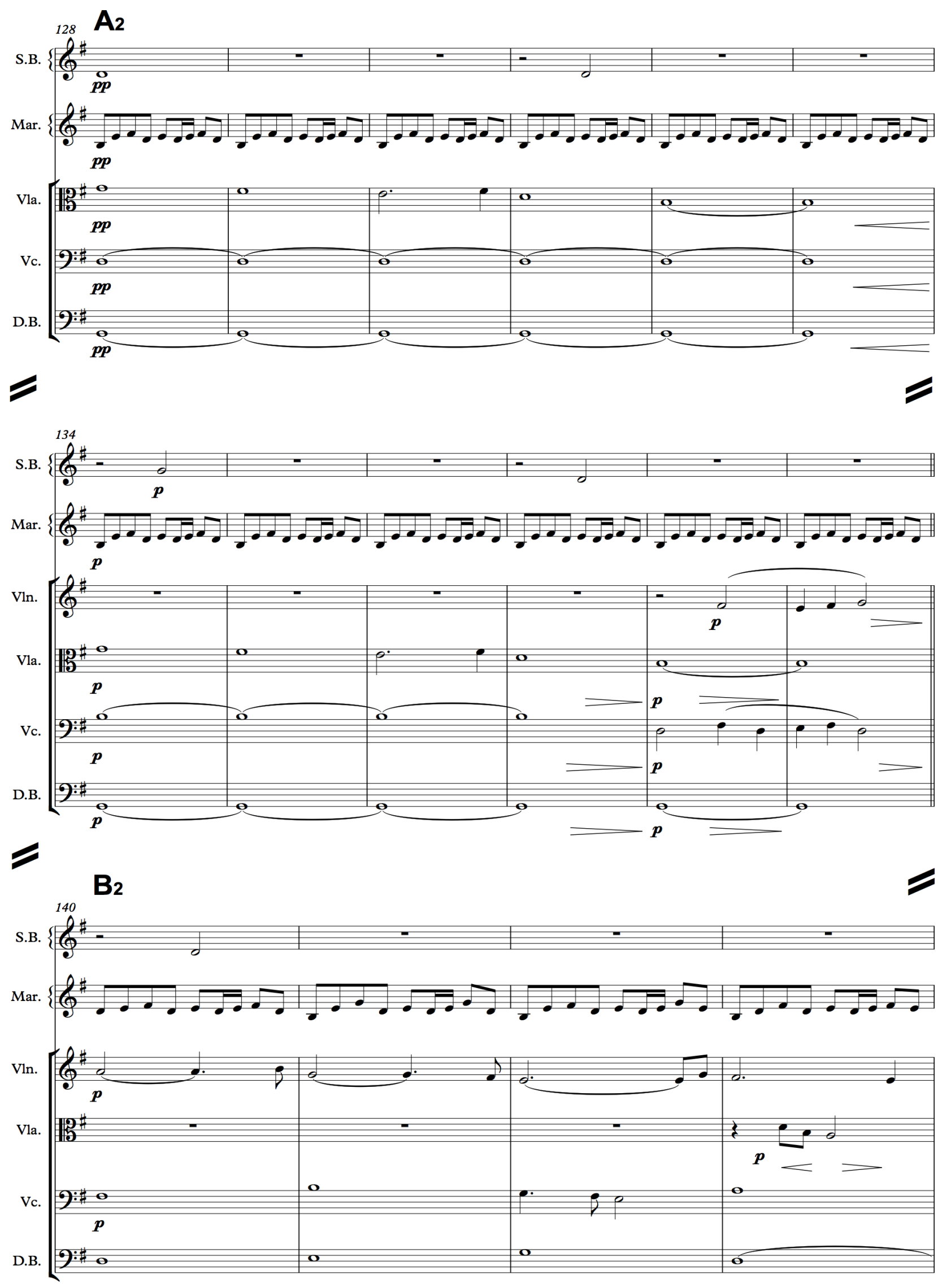

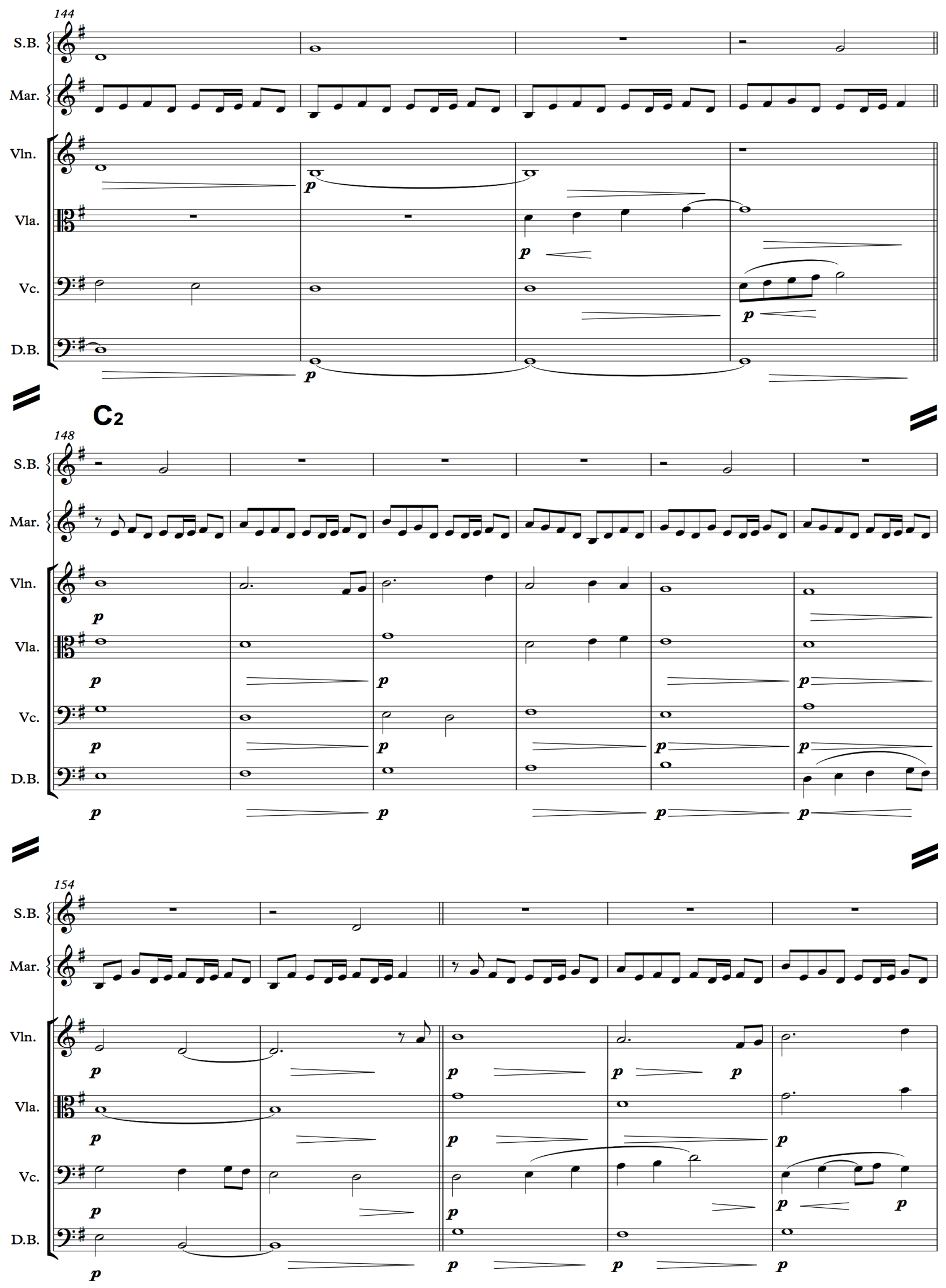

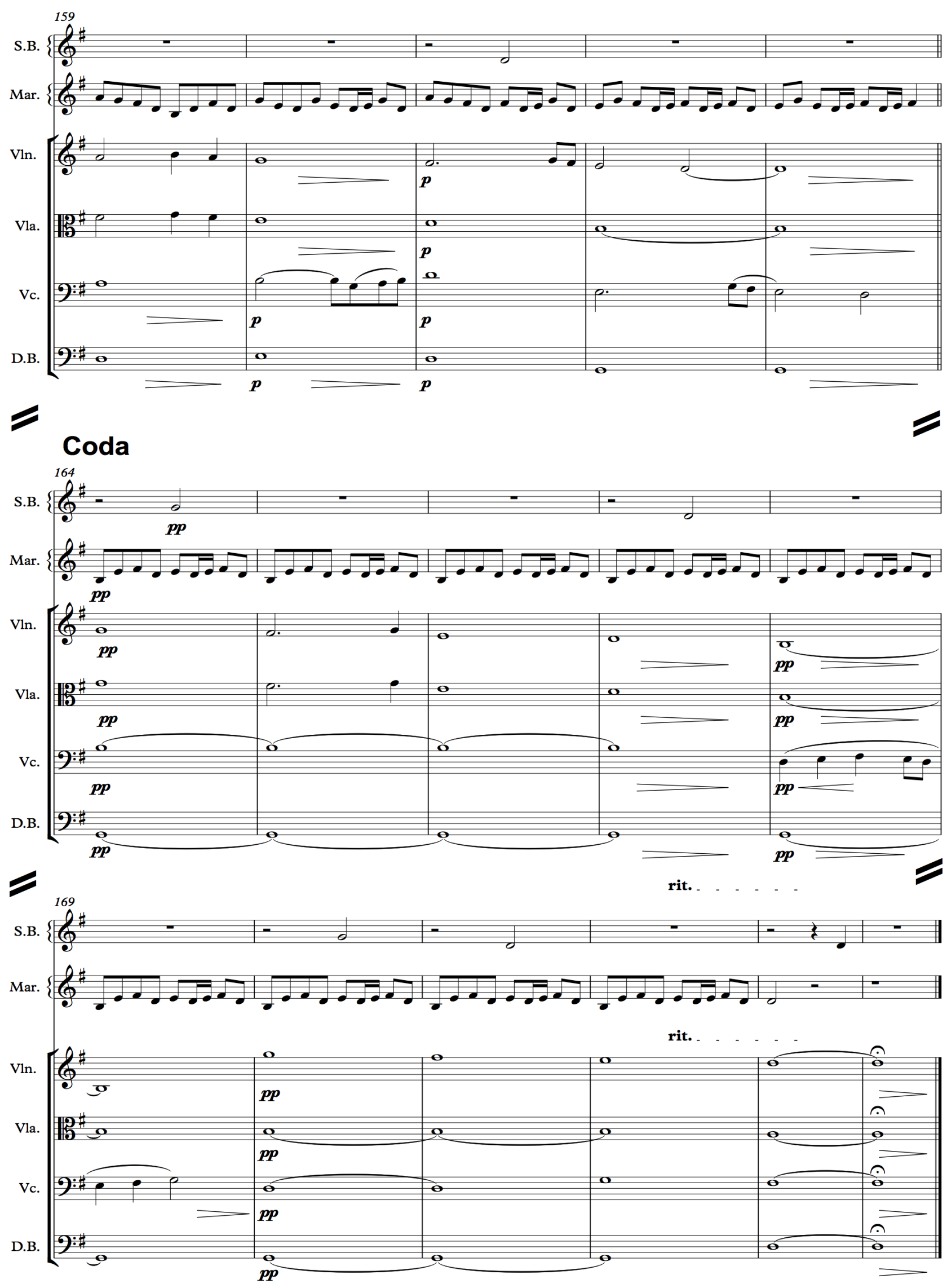
Spectrum

Adagio affetuoso ed appassionato, con legato

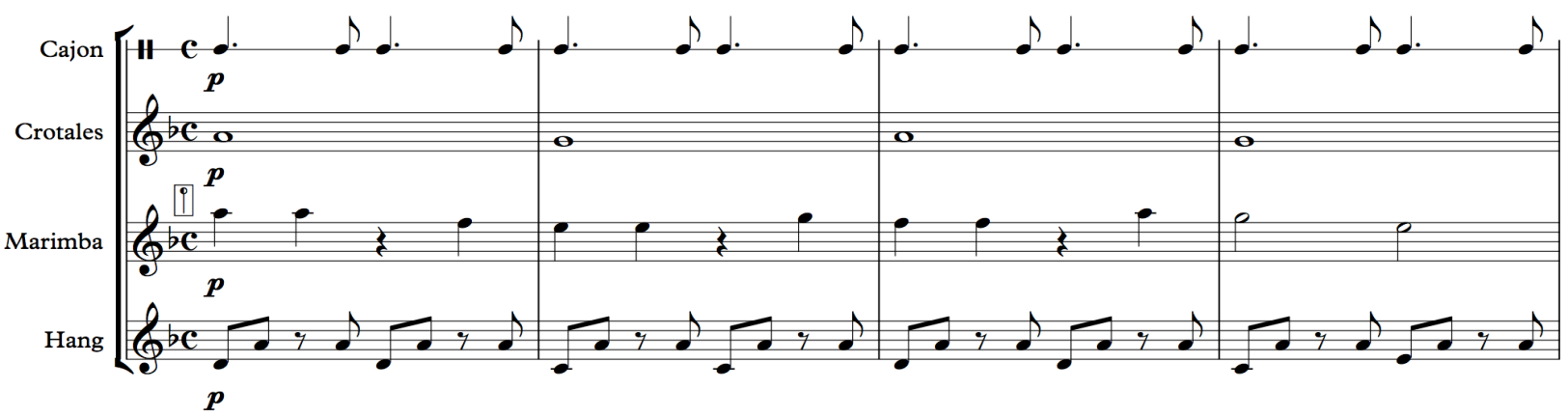

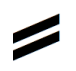

$=$

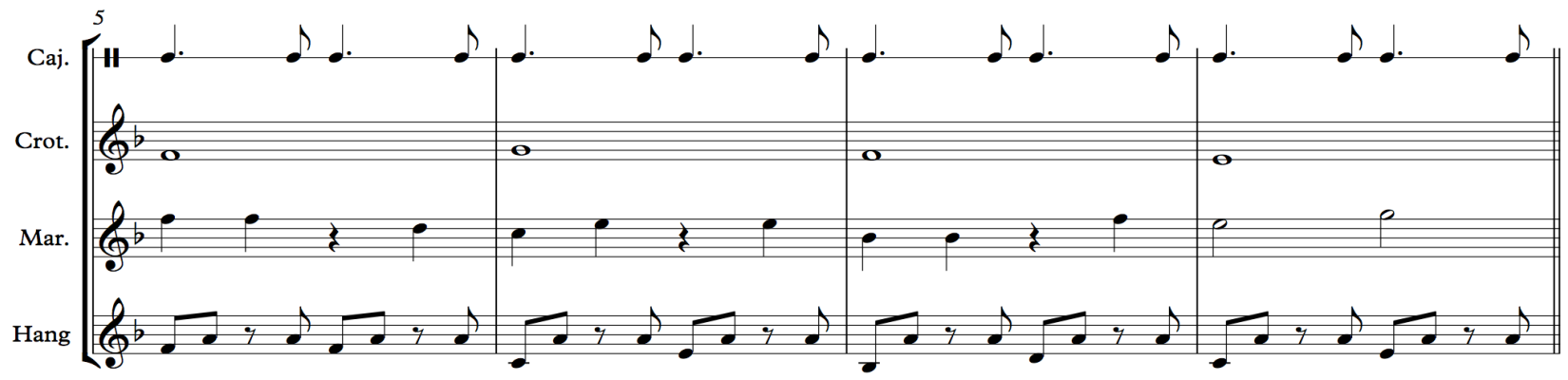

$=\mathrm{A}$

$=$
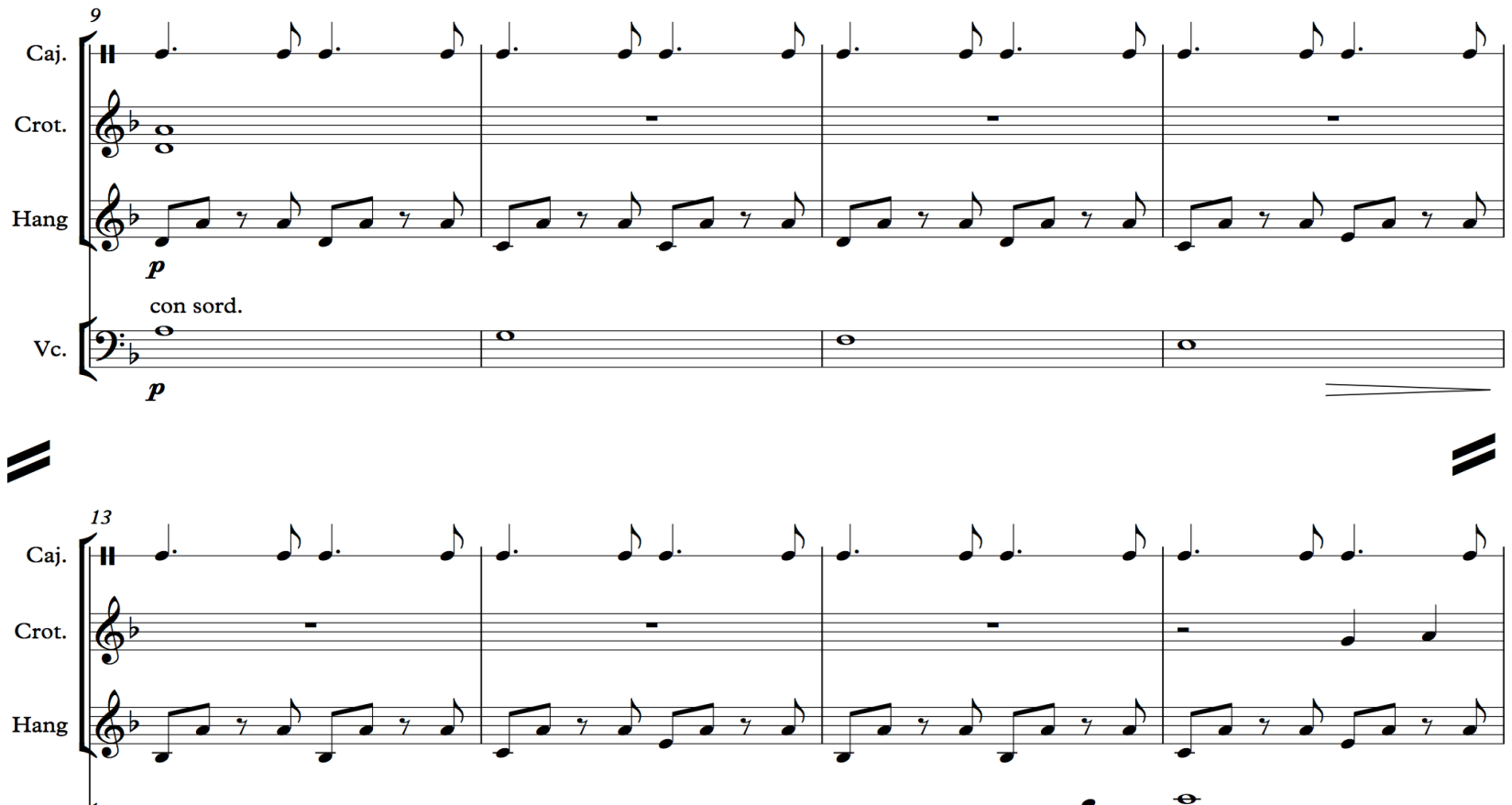

vc.

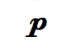

- $\boldsymbol{p}$

74 

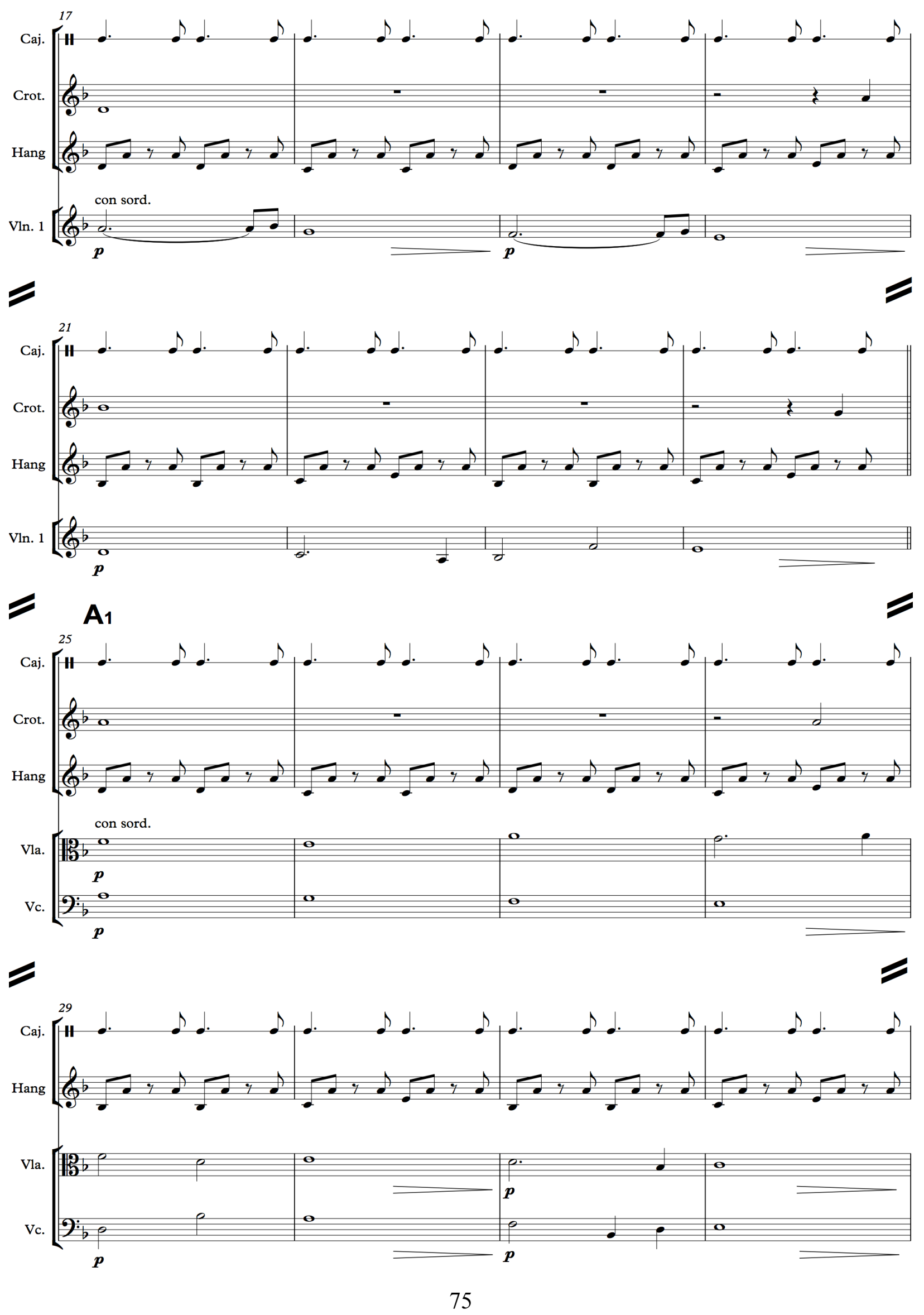

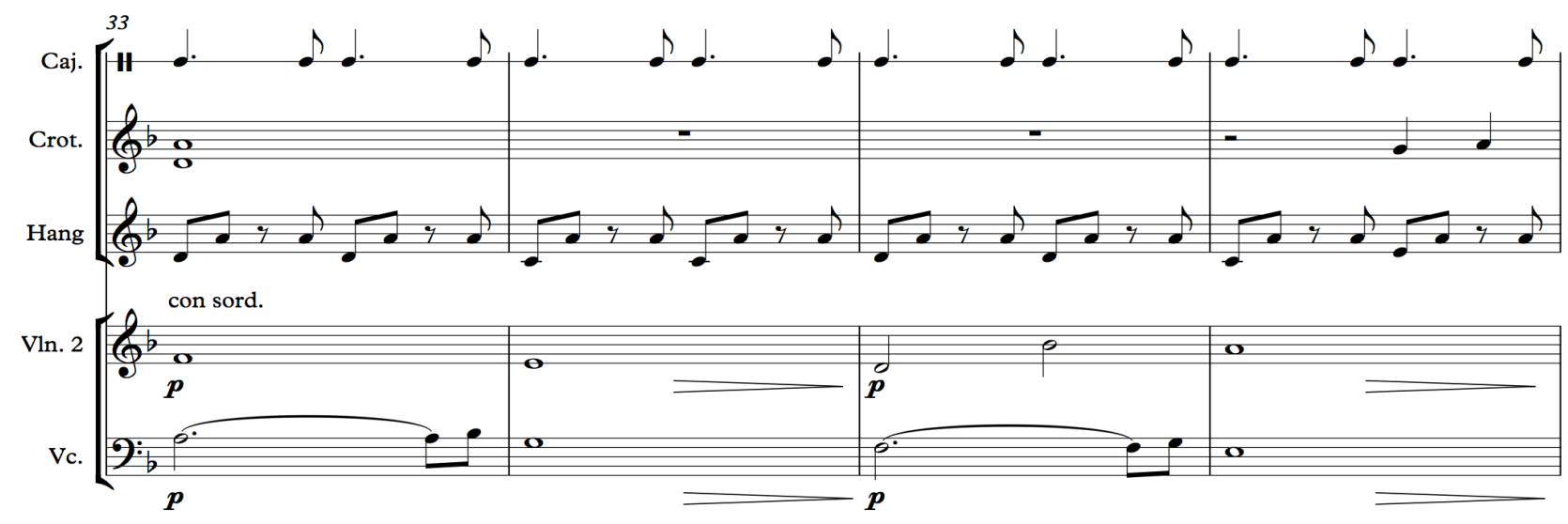

$$
2
$$

2

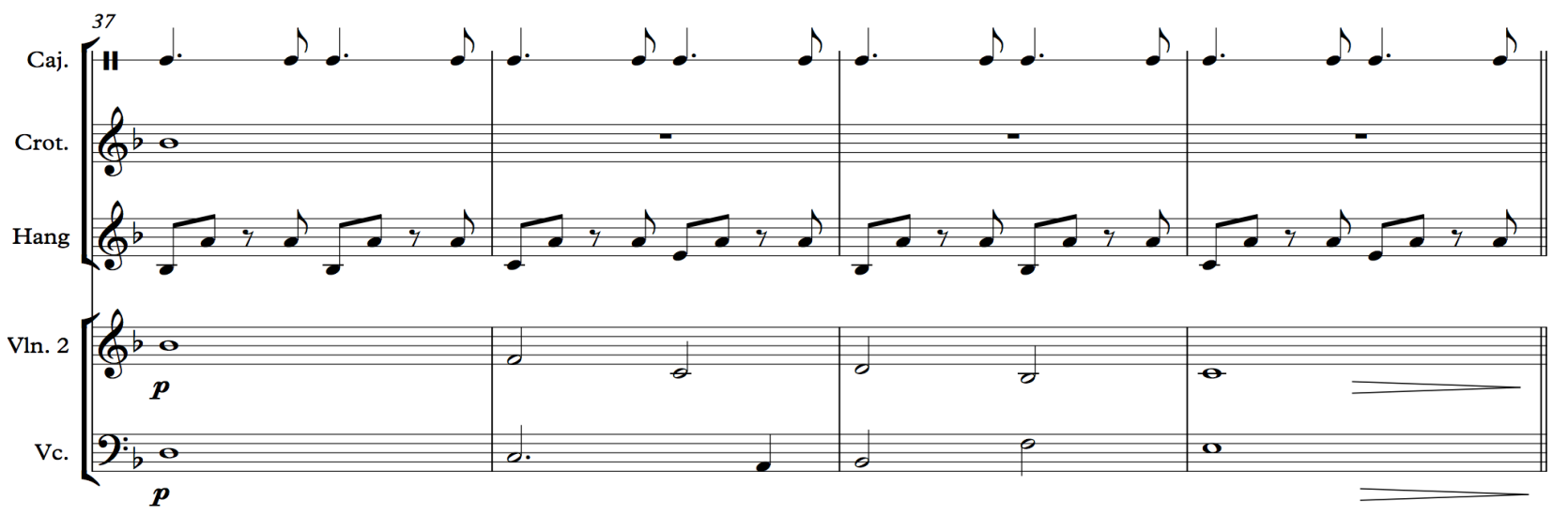

$$
\text { ₹ }
$$
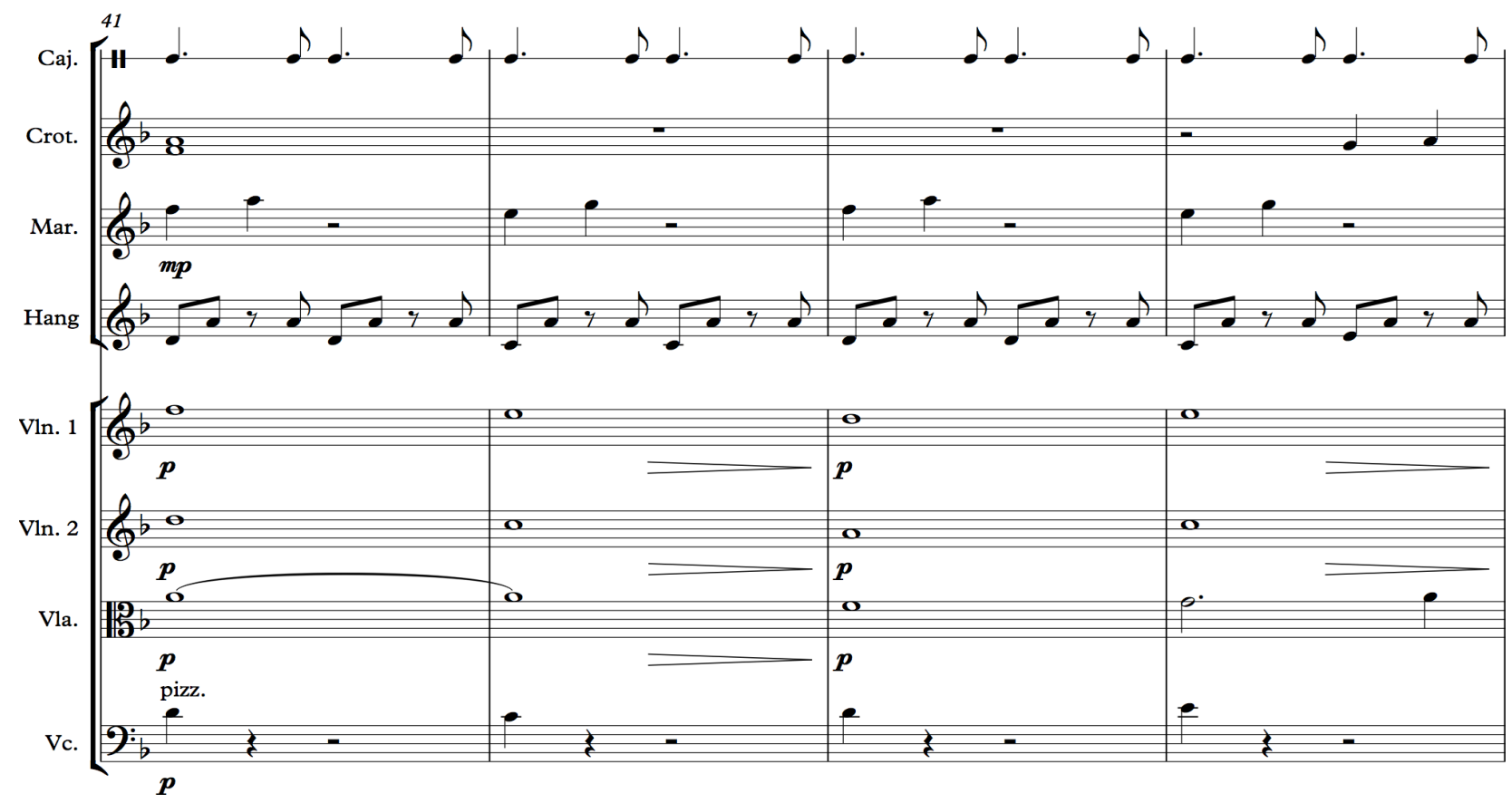

76 


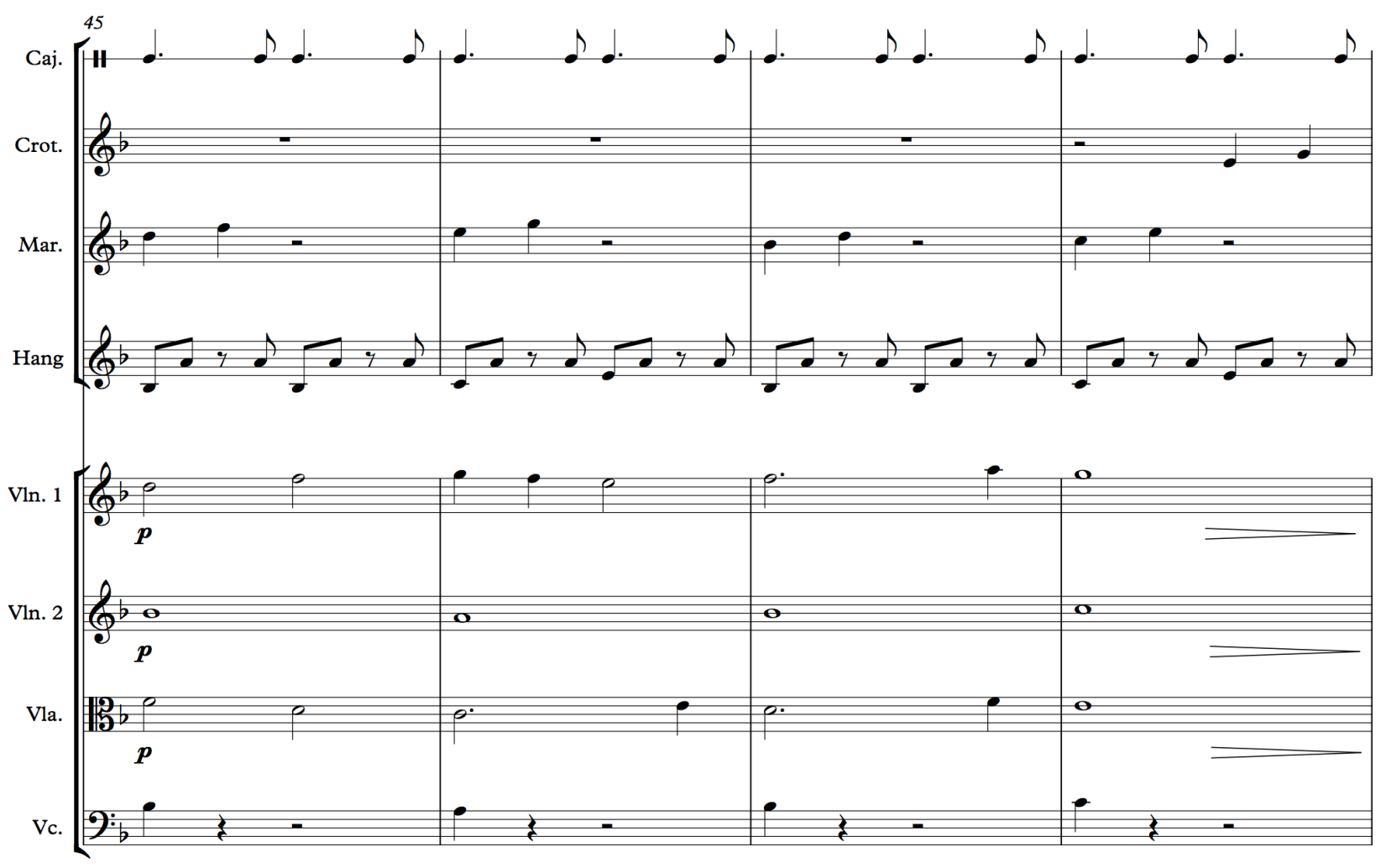

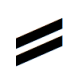

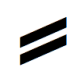

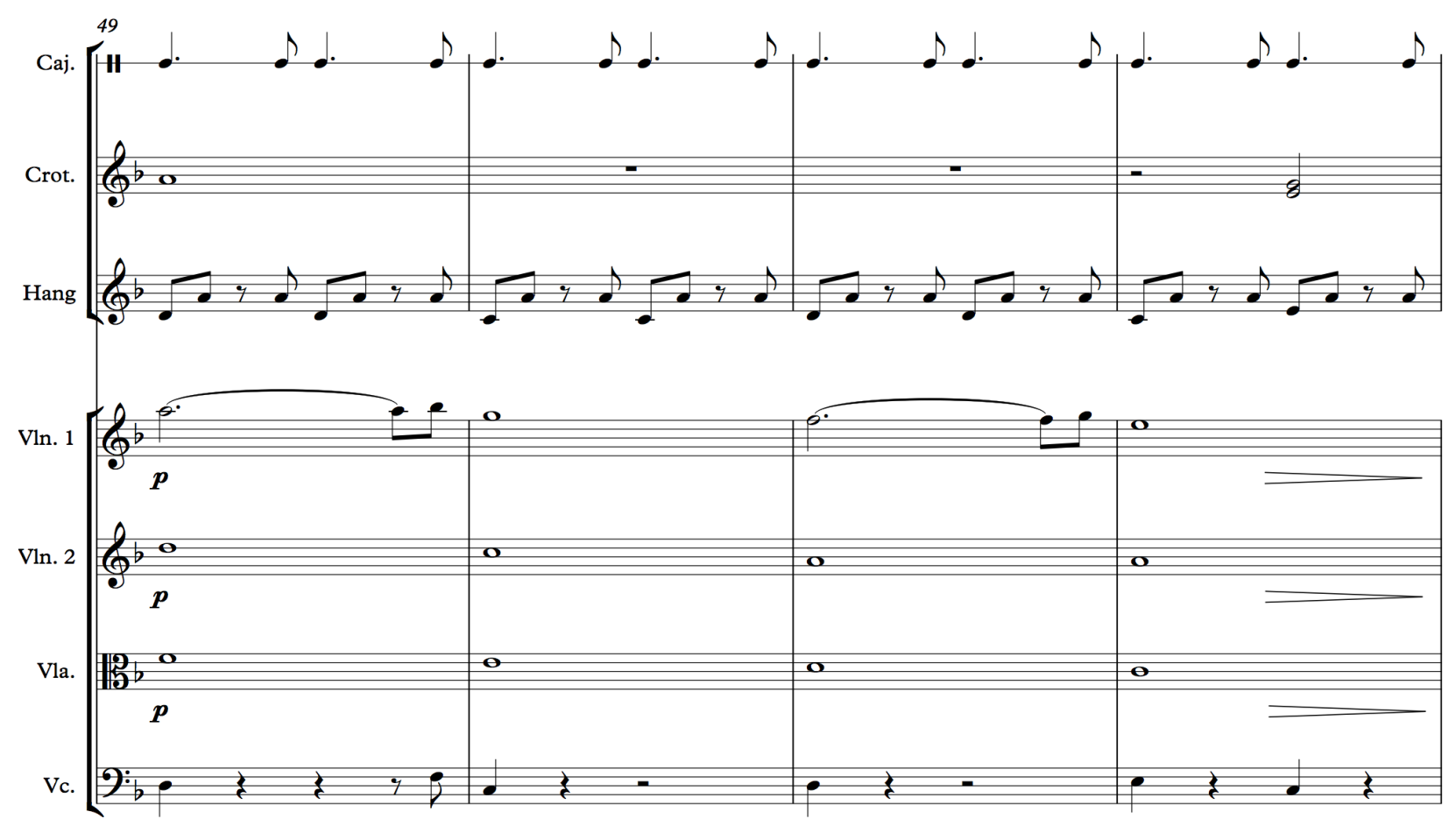

77 


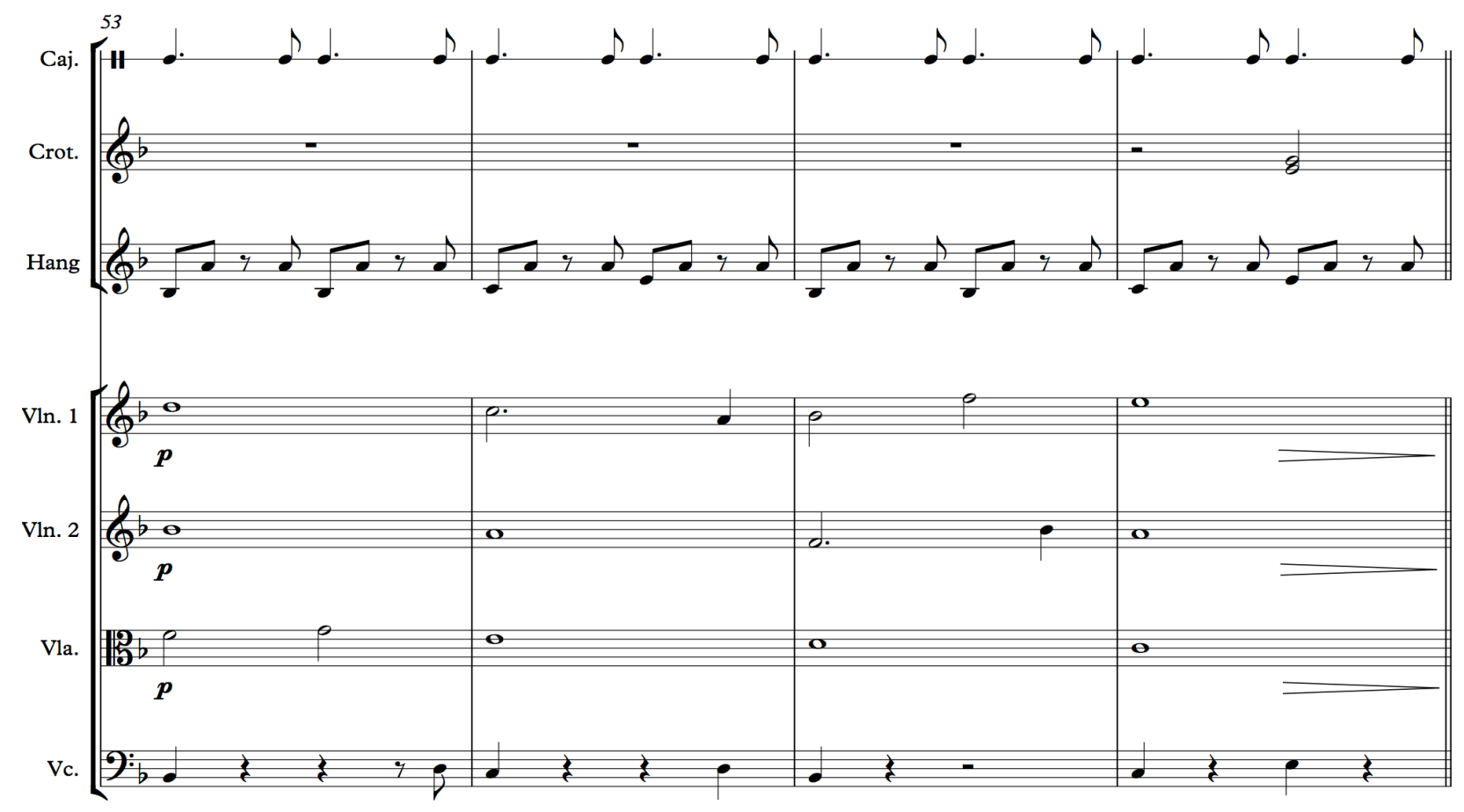

2

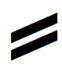

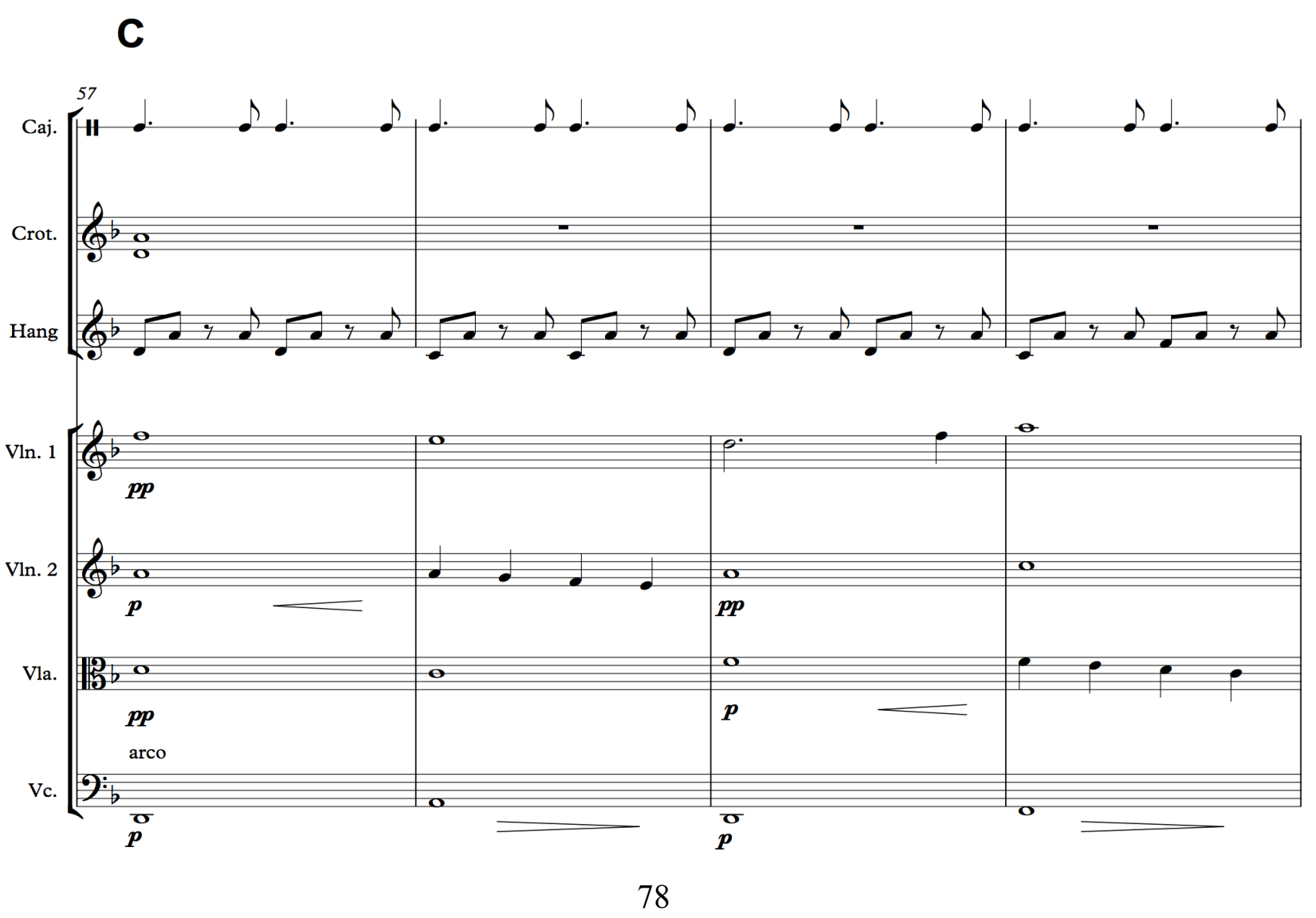



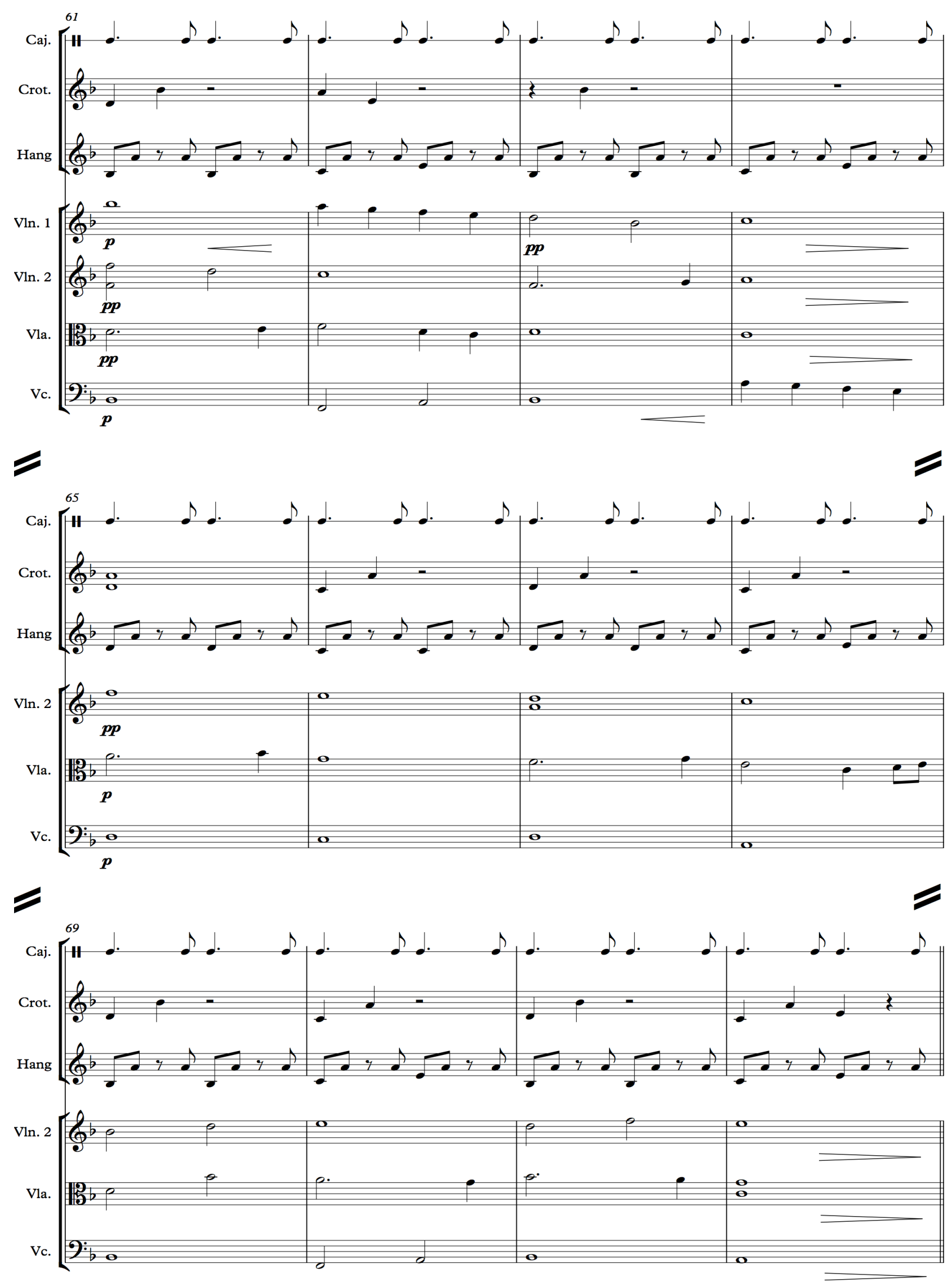

79 


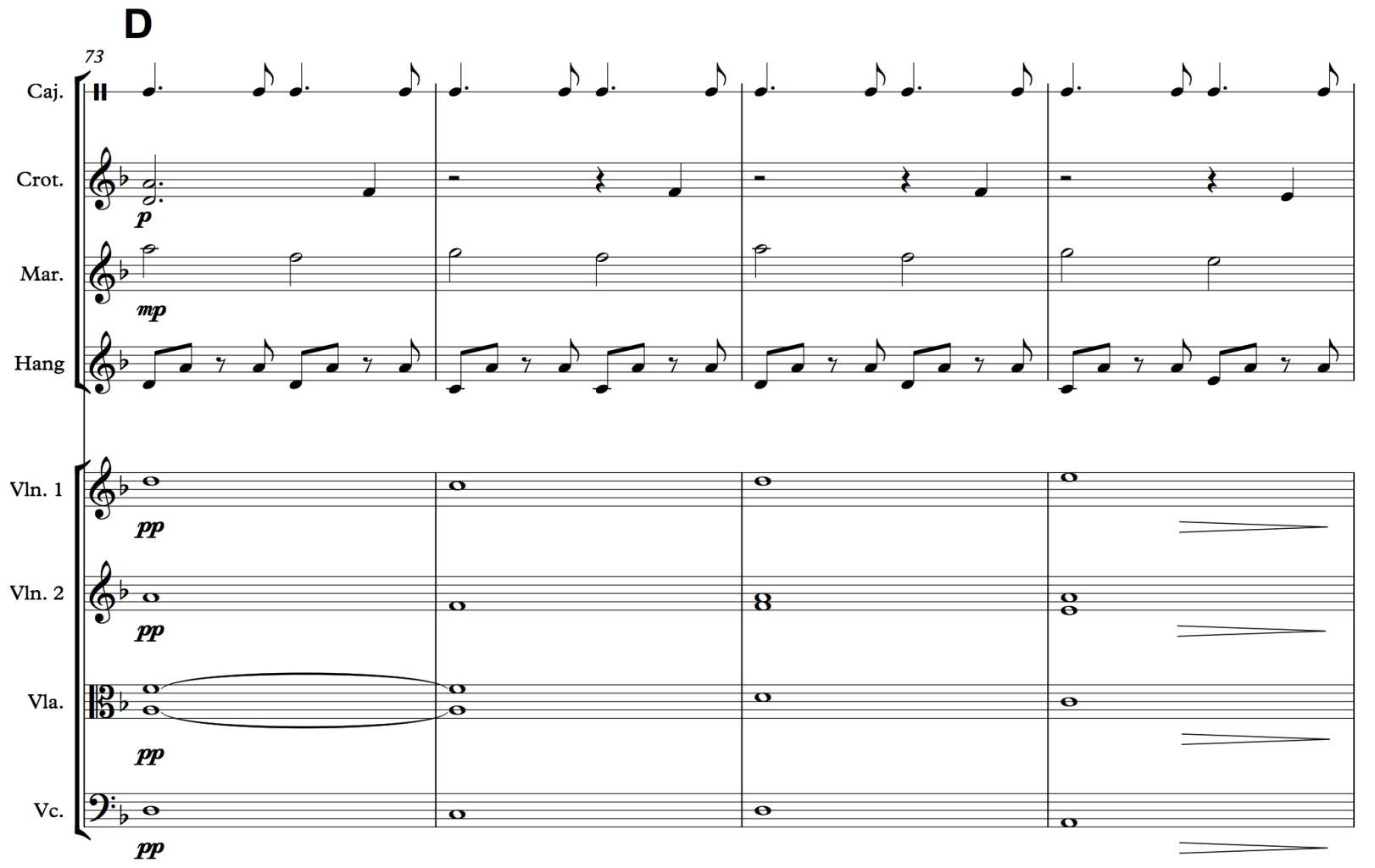

$=$

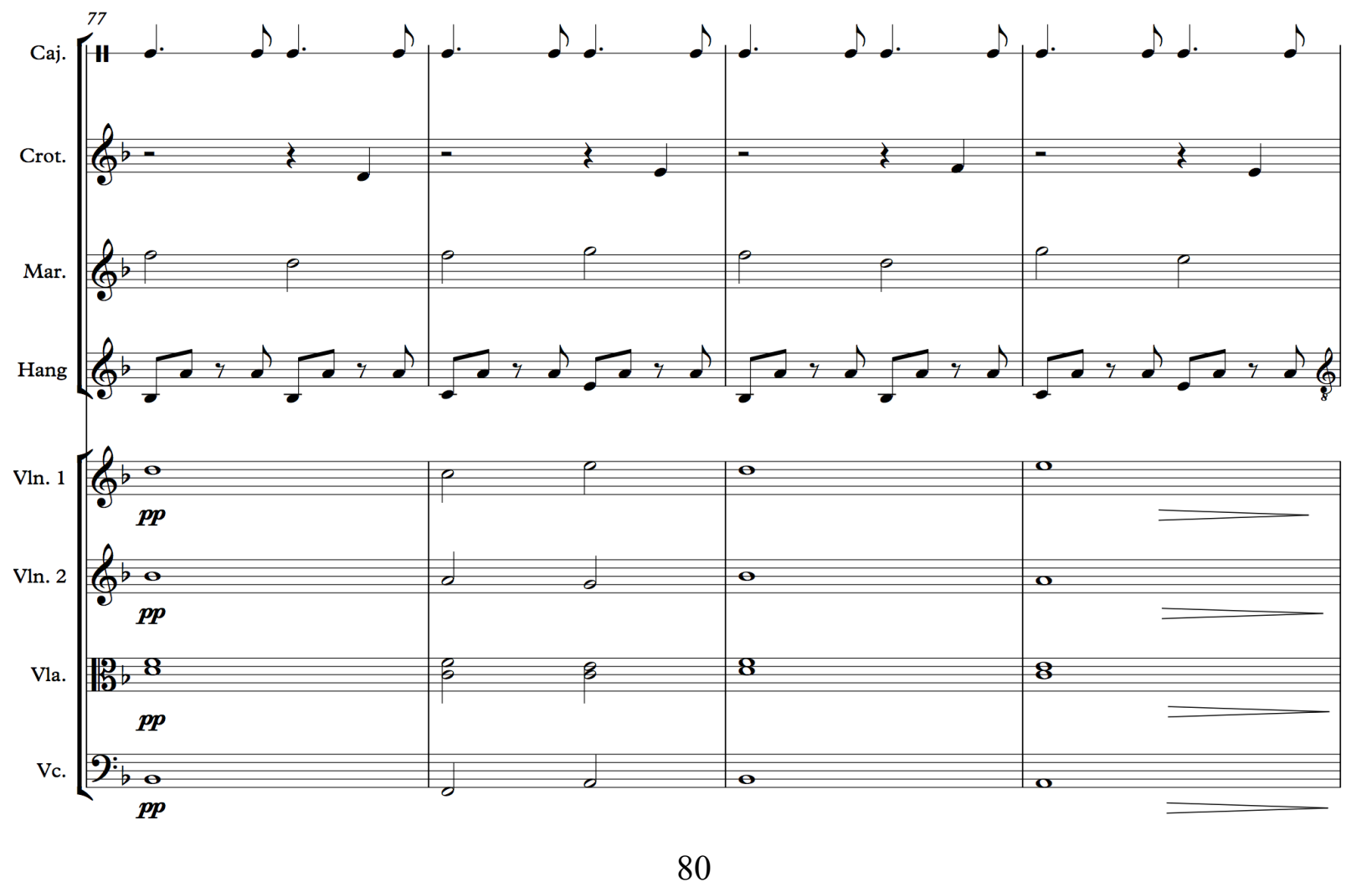



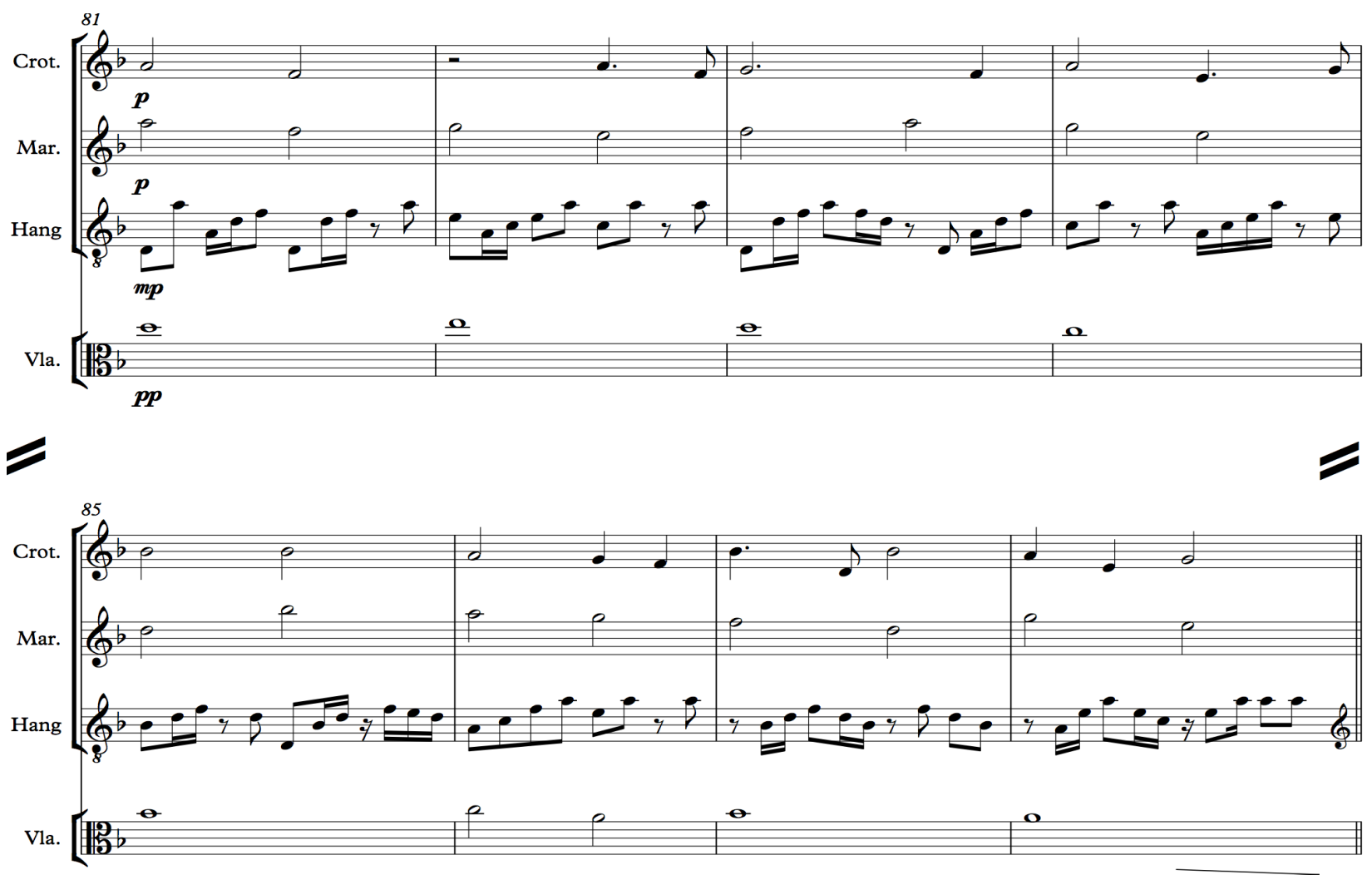

$\geqslant A_{2}$
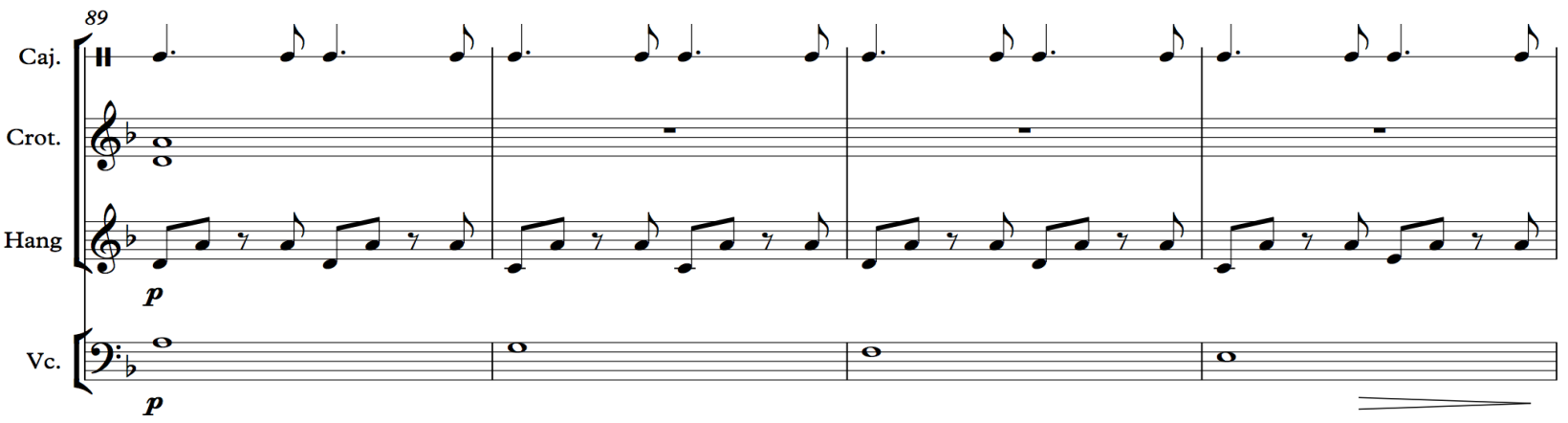

$=$

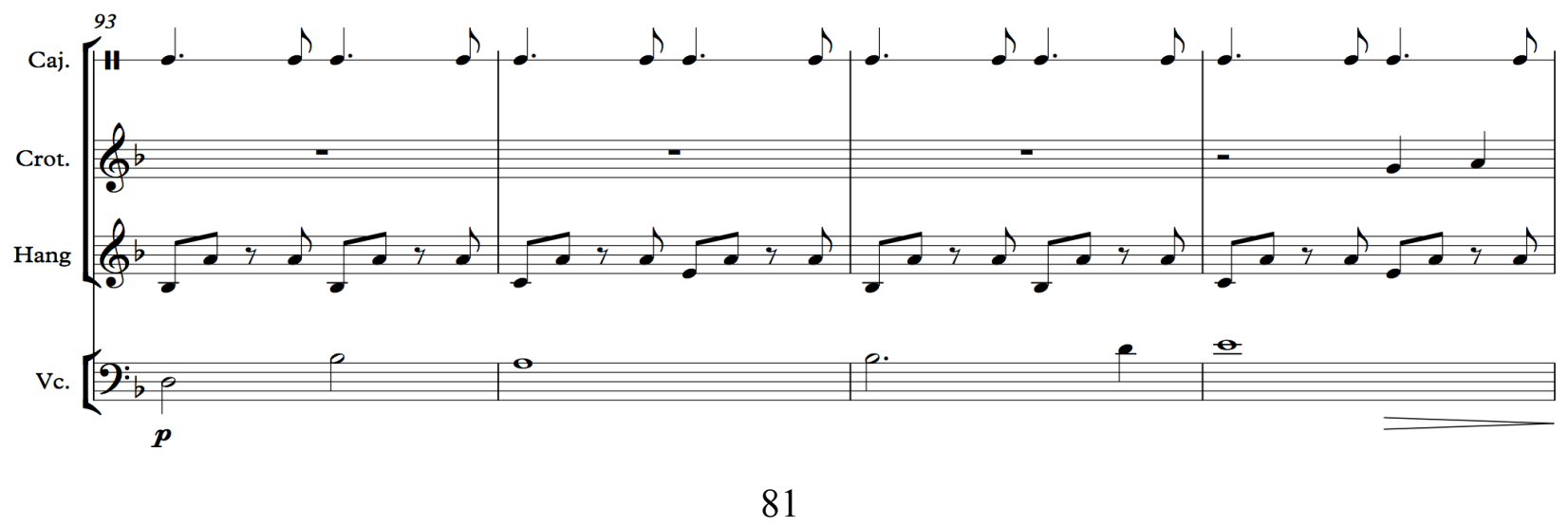



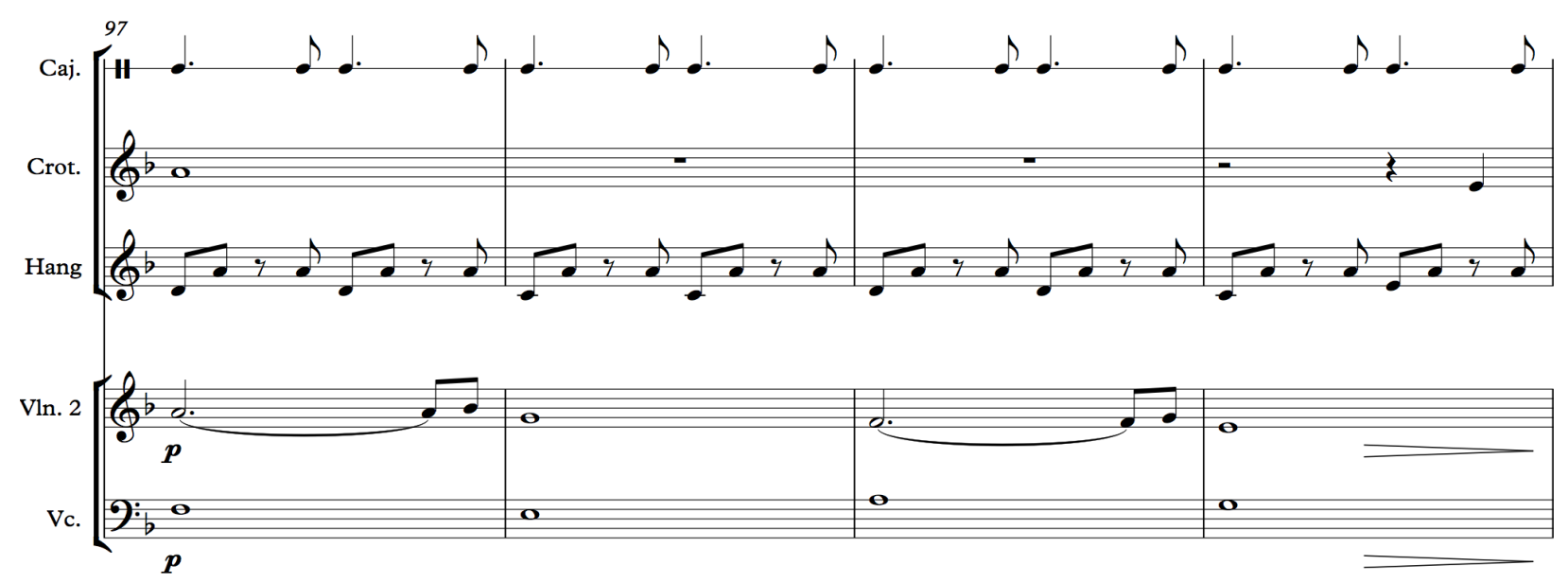

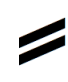
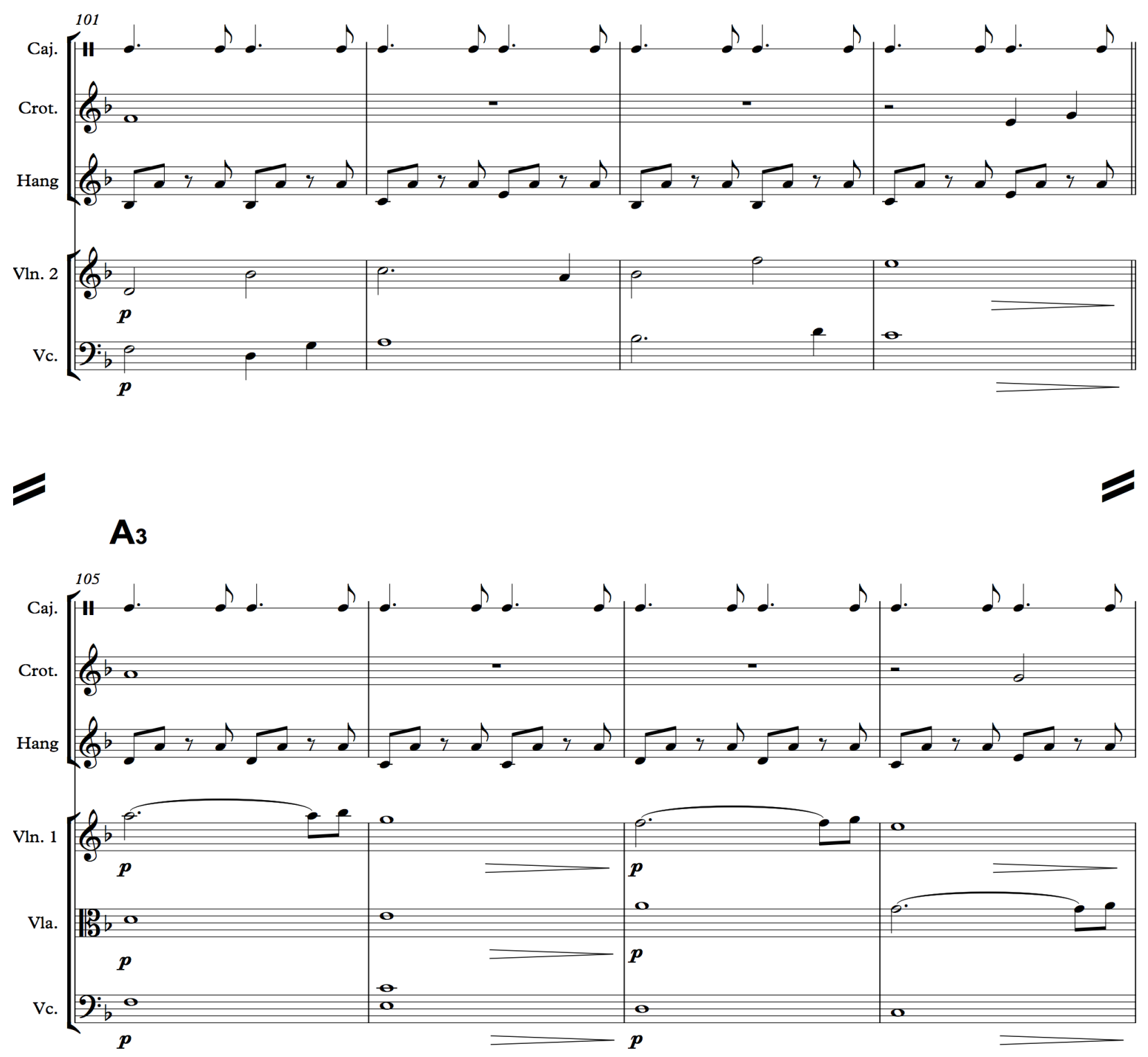


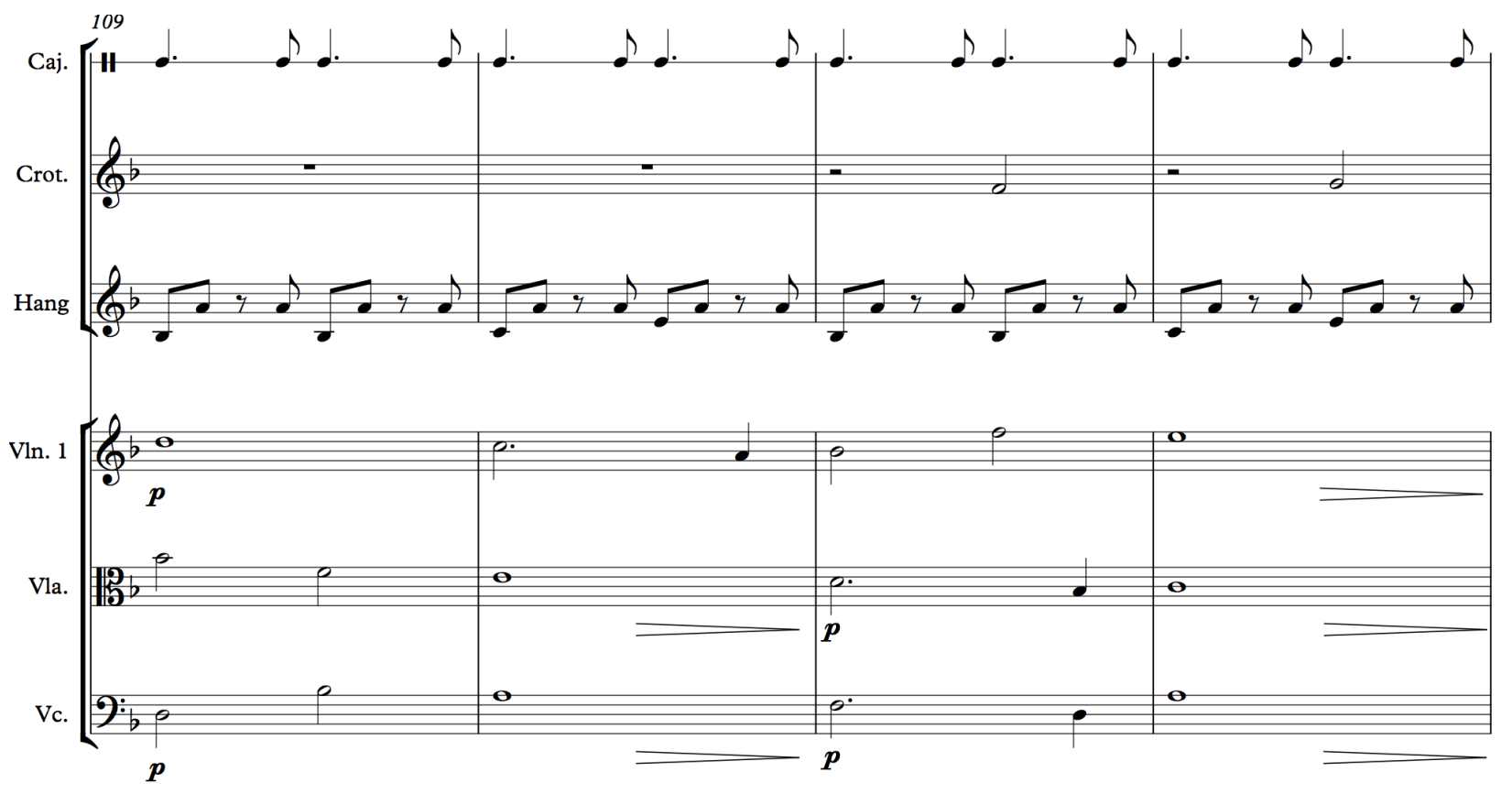

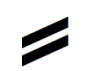

2
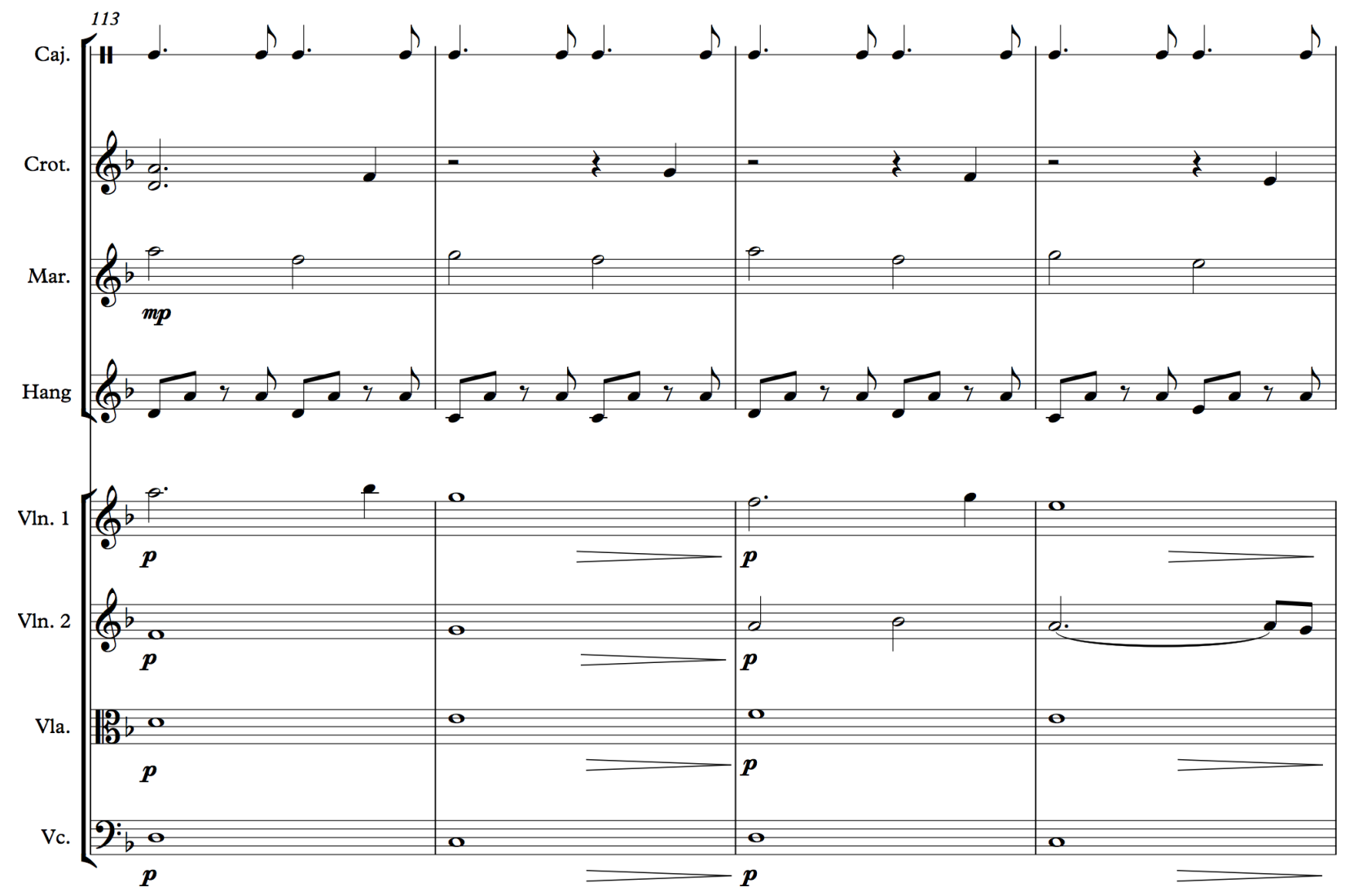

83 


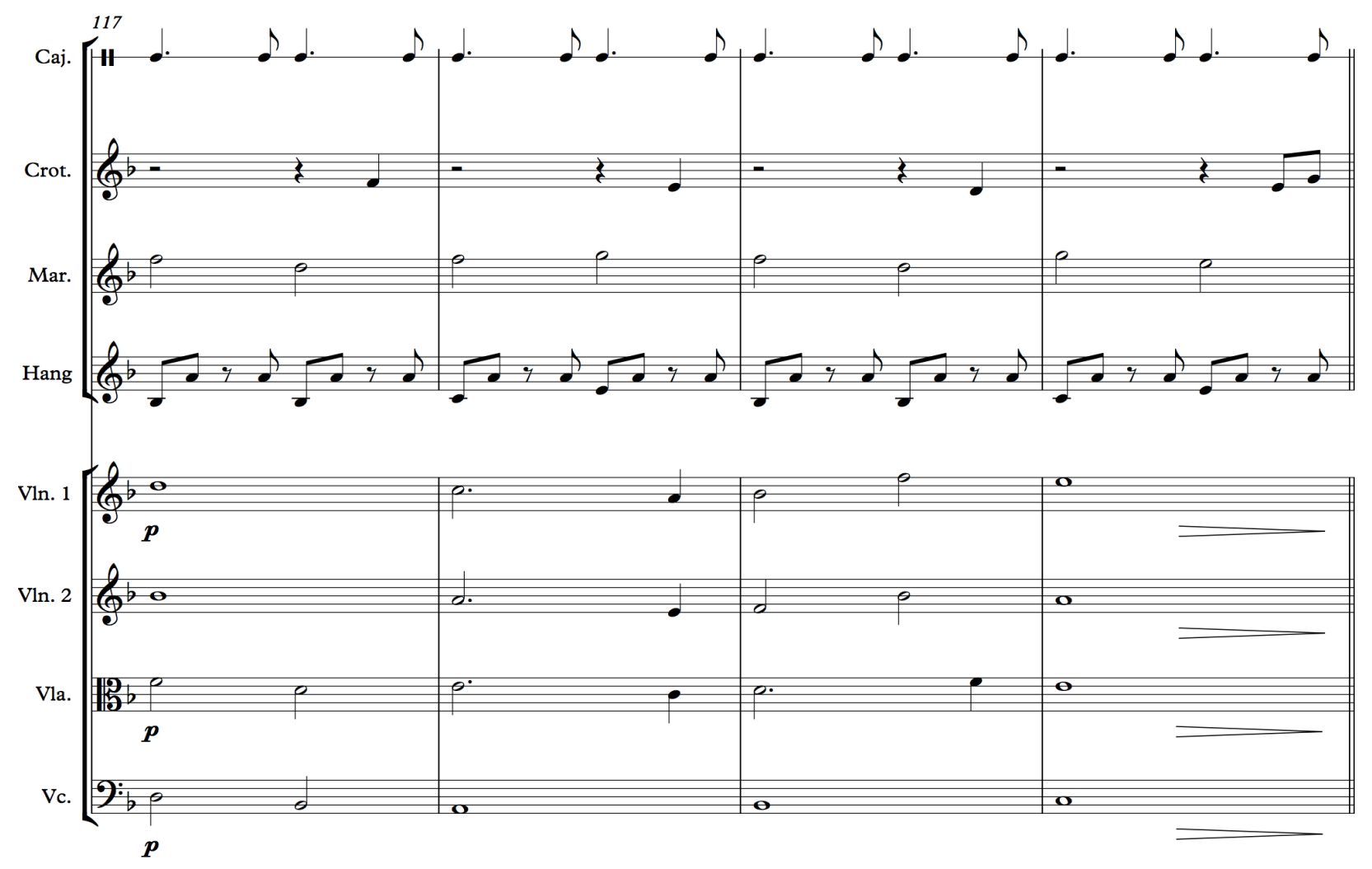

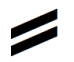

Coda
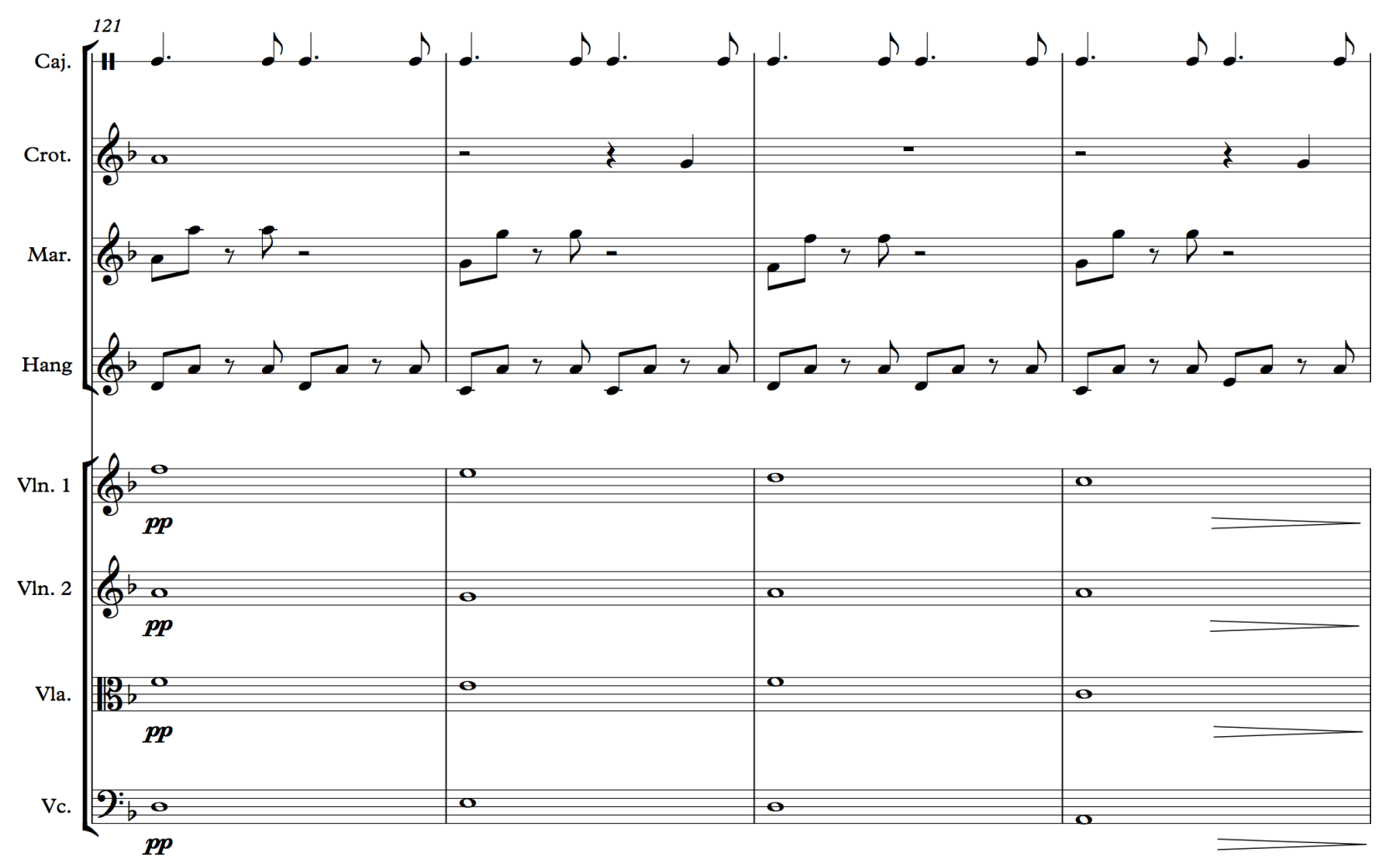

84 


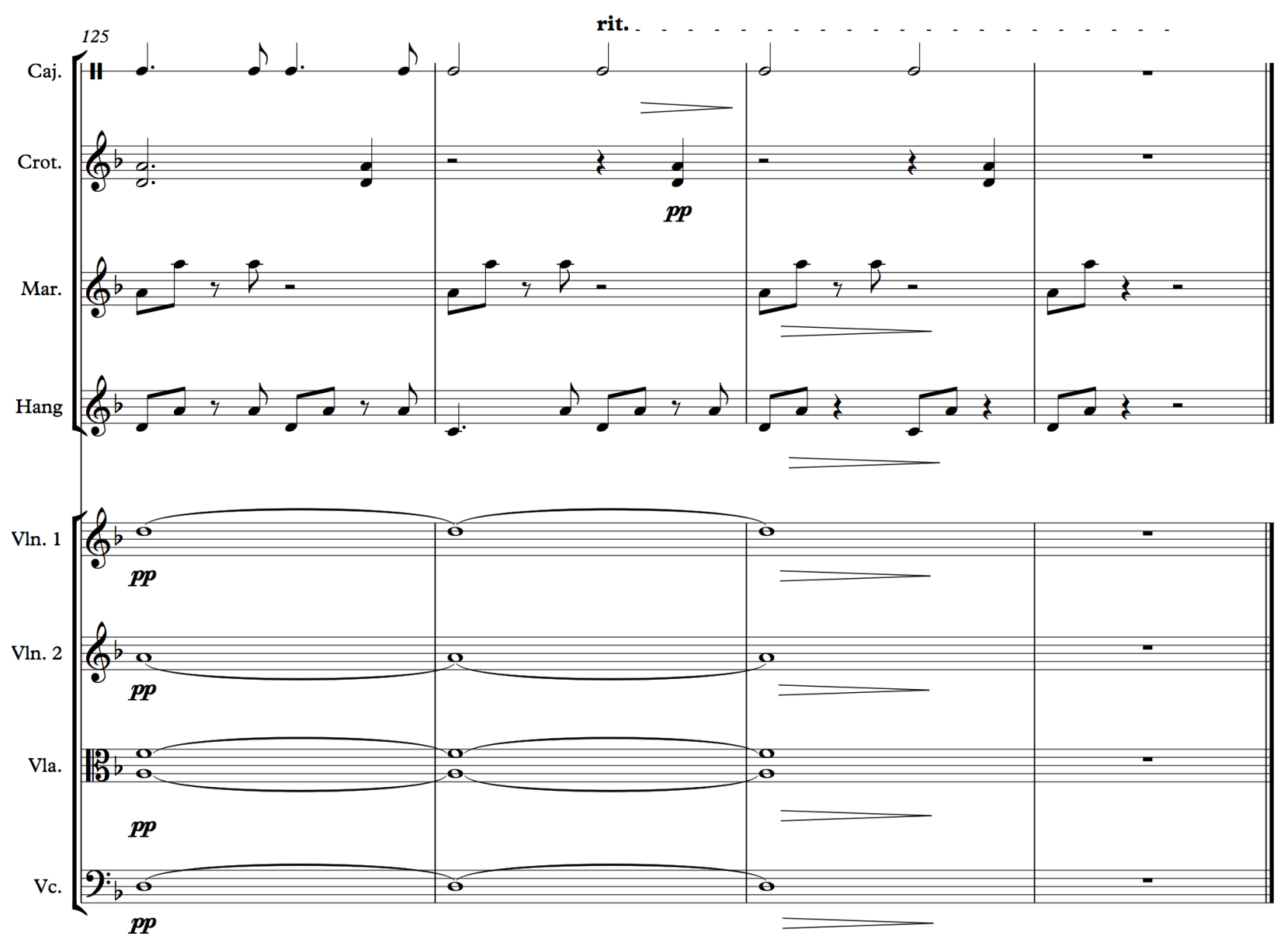

85 